Bundesministerium
für Bildung und Forschung

\title{
Herausforderung Klimawandel
}
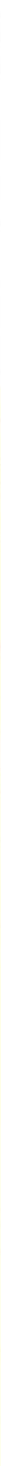


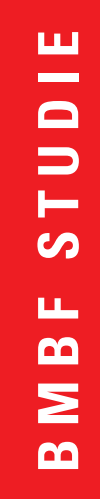

\section{Impressum}

\section{Herausgeber}

Bundesministerium

für Bildung und Forschung (BMBF)

Referat Öffentlichkeitsarbeit

53170 Bonn

\section{Bestellungen}

Schriftlich an den Herausgeber

Postfach 300235

53182 Bonn

oder telefonisch unter der

Rufnummer 01805-BMBF02

bzw. 01805-262302

Fax: 01805-BMBF03

bzw. 01805-262303

0,12 Euro/Min.

E-Mail: books@bmbf.bund.de Internet: http://www.bmbf.de

Berlin, 2003

Gedruckt auf Recyclingpapier

\section{Titelbildmontage}

Michael Böttinger,

Deutsches Klimarechenzentrum

(Klimarechner des DKRZ)

Joachim Biercamp,

Deutsches Klimarechenzentrum

(Simulation der Änderung der

mittleren Temperatur in $2 \mathrm{~m}$ Höhe im Vergleich zum Jahr 1860)

Dr. Annette Münzenberg,

DLR Projektträger,

Umweltforschung und -technik

(Sedimentgestein) 


\section{Herausforderung Klimawandel}


Mitglieder des Sachverständigenkreises „Globale Umweltaspekte“ (SV GUA) des BMBF:

Prof. Dr. R. Zellner, Universität Essen (Vorsitz)

Prof. Dr. G. Brasseur, Max-Planck-Institut für Meteorologie Hamburg

Prof. Dr. M. Claussen, Potsdam-Institut für Klimafolgenforschung

Prof. Dr. N. Jürgens, Universität Hamburg Prof. Dr. J. Negendank, Geoforschungszentrum Potsdam Prof. Dr. U. Platt, Universität Heidelberg

Prof. Dr. W. Seiler, Forschungszentrum Karlsruhe, Garmisch-Partenkirchen

Prof. Dr. G. Stephan, Universität Bern

Prof. Dr. H. von Storch, GKSS Forschungszentrum, Geesthacht

Prof. Dr. J. Thiede, Alfred-Wegener-Institut, Bremerhaven

Prof. Dr. D. Wegener, Universität Dortmund

Prof. Dr. P. Weingart, Universität Bielefeld

Mitglieder des ad hoc Arbeitskreises

„Klimadiskussion“ des Sachverständigenkreises

„Globale Umweltaspekte“ (SV GUA) des BMBF:

Prof. Dr. R. Zellner, Universität Essen (Vorsitz)

Dr. U. Berner, Bundesanstalt für Geowissenschaften und Rohstoffe, Hannover

Prof. Dr. G. Brasseur, Max-Planck-Institut für Meteorologie Hamburg

Prof. Dr. M. Claussen, Potsdam-Institut für Klimafolgenforschung

Prof. Dr. U. Cubasch, Freie Universität Berlin

Prof. Dr. J. Thiede, Alfred-Wegener-Institut, Bremerhaven Prof. Dr. H. von Storch, GKSS Forschungszentrum, Geesthacht

Organisation:

Dr. Annette Münzenberg,

DLR Projektträger Umweltforschung und -technik des BMBF, Bonn 


\section{INHALT}

VORBEMERKUNG

1. WAS IST KLIMA UND WODURCH WIRD ES BESTIMMT? ................. 11

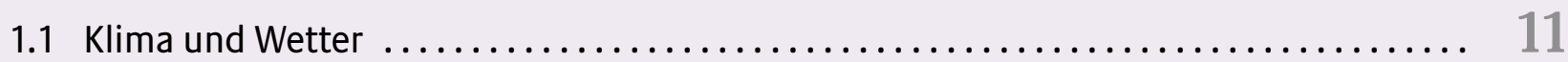

1.2 Das Klimasystem ............................................. 13

1.3 Mechanismen des Klimaantriebs ................................... 14

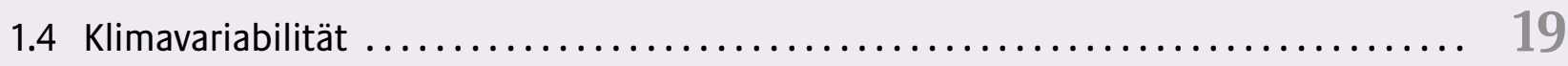

1.5 Wechselwirkungen im Klimasystem ............................... 21

1.6 Klimamodelle ................................................ 25

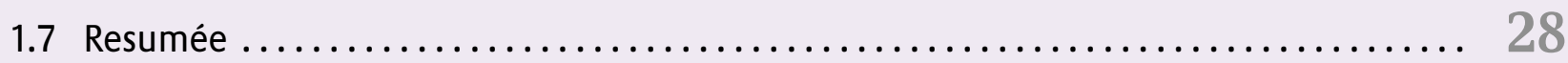

2. WIE SAH DAS KLIMA IN DER ERDGESCHICHTE SOWIE IN DEN LETZTEN 100 Jahren AUS? ........................................... 30

2.1 Informationen aus Klimaarchiven und historischen Klimaaufzeichnungen .......... 30

2.2 Reproduktionen des Klimas durch Modelle ............................ 39

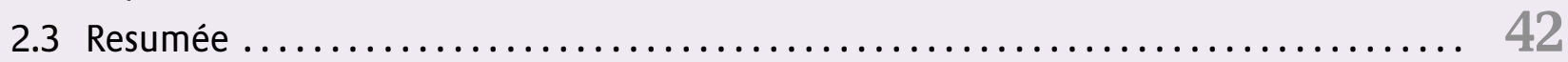

3. WIE WIRD DAS KLIMA IN DER ZUKUNFT AUSSEHEN? ................... 44

3.1 Klimavorhersage .......................................... 44

3.2 Sozioökonomische Szenarien oder: Was bringt Kyoto? .................... 45

3.3 Globales Klima ................................................ 47

3.4 Regionales Klima .............................................. 49

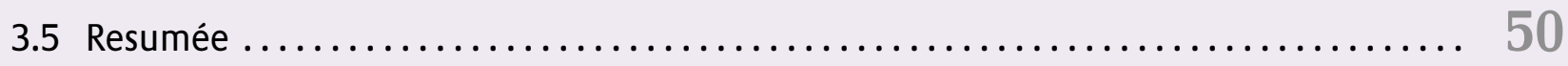

4. WIE GEHEN WIR MIT DEM BEVORSTEHENDEN KLIMAWANDEL UM? .......... 52

4.1 Vermeidung und Anpassung ...................................... 52

4.2 Klimaforschung als sozialer/kultureller Prozess $\ldots \ldots \ldots \ldots \ldots \ldots \ldots \ldots \ldots \ldots . \ldots \ldots$

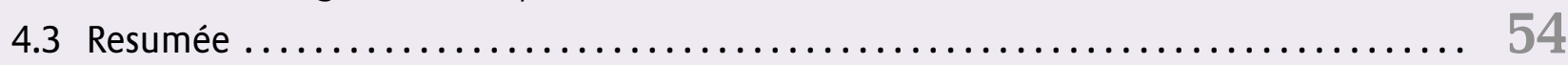




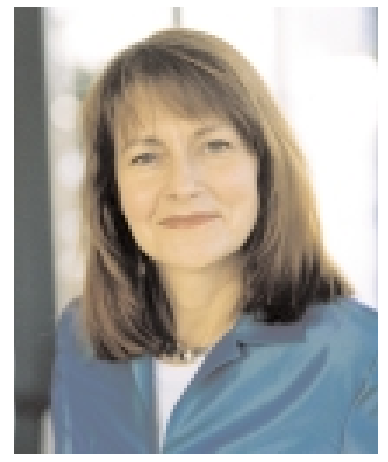

Die Elbeflut 2002, Hitzerekorde, Dürre und Waldbrände in weiten Teilen Europas in diesem Sommer haben die Frage nach einem Klimawandel erneut in den Mittelpunkt öffentlichen Interesses gerückt. Immer wieder wird nach den Ursachen dieser teils mit gravierenden Auswirkungen auf Wirtschaft und Gesellschaft verbundenen extremen Wetterereignisse und nach geeigneten Gegenbzw. Anpassungsmaßnahmen gefragt.

Die Klimaforschung hat sich bereits seit mehr als 10 Jahren mit der Untersuchung des globalen Klimasystems, seiner Beeinflussbarkeit durch den Menschen und möglicher Auswirkungen kommender Klimaänderungen beschäftigt. Viele Antworten auf die Fragen nach grundsätzlichen Mechanismen und Entwicklungstendenzen sind in den letzten Jahren wesentlich klarer geworden. Dies ist auch ein Verdienst intensiver Forschungsförderung des BMBF auf diesem Gebiet im Rahmen der institutionellen BMBFFörderung, vor allem der Einrichtungen der Helmholtz-Cemeinschaft, der Wilhelm-Leibnizund Max-Planck-Gesellschaft, aber auch durch zahlreiche Projektförderprogramme, wie beispielsweise das Deutsche Klimaforschungsprogramm DEKLIM.
Viele Fragen sind aber auch noch heute nicht oder unvollständig beantwortet, und dies eröffnet Ansatzpunkte, inzwischen eingeleitete Maßnahmen zum Klimaschutz immer neu zu bewerten. Welche Schritte zur weiteren Emissionsminderung von Treibhausgasen müssen in Wirtschaft und Gesellschaft, wann und zu welchen Kosten umgesetzt werden? Wie können wir schon heute mit Klimaschwankungen oder den angesprochenen Wetterextremen besser umgehen, um wirtschaftliche Verluste und menschliches Leid zu mindern? Dies sind Fragen, zu deren Beantwortung Forschung, technologische Entwicklung und Innovation erhebliche Beiträge liefern können.

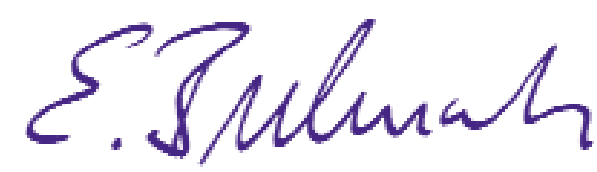

\section{Edelgard Bulmahn}

Bundesministerin für Bildung und Forschung 


\section{VORBEMERKUNG}

Das Klima der Erde hat einen wesentlichen Einfluss auf die Lebensbedingungen von Menschheit und belebter Natur. Die Diskussion über mögliche künftige Klimaänderungen, die zu einer beträchtlichen Veränderung des täglichen Wetters führen könnten, hat alle Schichten unserer Gesellschaft erreicht und beeinflusst in vielen Bereichen politisches und wirtschaftliches Handeln, national wie global. Der Wissensstand der internationalen Klimaforschung ist in den Sachstandsberichten des Intergovernmental Panel on Climate Change (IPCC) zusammengefasst (www.ipcc.ch).

Danach besteht unter den Klimaforschern Konsens darüber, dass neben jener Klimaentwicklung, die durch natürliche Ursachen bedingt und daher grundsätzlich nicht zu vermeiden ist, auch anthropogen bedingte Klimaänderungen in zunehmendem Maße möglich sind. Die im 20. Jahrhundert beobachtete Temperaturerhöhung wird bereits zum größeren Teil auf anthropogene Ursachen zurückgeführt. Aufgrund des Bevölkerungswachstums, des zunehmenden Verbrauchs an fossilen Brennstoffen sowie der fortschreitenden Landnutzungsänderung wird sich diese Tendenz mit hoher Wahrscheinlichkeit in Zukunft verstärkt fortsetzen. Temperatur und Meeresspiegel werden wahrscheinlich weiter ansteigen, Vegetationszonen und Niederschlagsmuster könnten sich verschieben bzw. ändern. Es ist auch wahrscheinlich, dass sich der Wasserkreislauf in mittleren Breiten intensiviert und zu einer Zunahme von einigen Wetterextrema führt. Kontrovers diskutiert wird unter Klimaforschern allerdings, welches Ausmaß die zu erwartenden Veränderungen annehmen werden und welche Auswirkungen dies in verschiedenen Regionen der Erde haben wird. Aussagekräftig sind dabei nicht Einzelereignisse, sondern Trends in den statistischen Größen, z.B. den Mittel- und Extremwerten.
Daraus folgt zum Beispiel: Ein kausaler Zusammenhang eines einzelnen Extremereignisses (wie etwa der Flutkatastrophen des Sommers 2002 in weiten Teilen Deutschlands und Europas) mit einer beginnenden Veränderung des Globalklimas ist wissenschaftlich nicht belegbar.

Der Klimawandel wird die menschlichen Lebensverhältnisse und die Ökosysteme deutlich verändern. Das Ausmaß dieser Veränderung hängt aber davon ab, wie stark und wie schnell dieser Wandel eintritt und welche Fähigkeiten die Gesellschaft und die Ökosysteme entwickeln, um sich anzupassen. Eine realistische Voraussage von Ausmaß und Wirkung von Klimaveränderungen - global und regional - ist deshalb eine große Herausforderung für die Wissenschaft, die hohe gesellschaftliche Relevanz besitzt.

Zu den seit langem bekannten, aber immer noch weiter bestehenden Herausforderungen der Wissenschaft gehören bestimmte Prozesse im Strahlungshaushalt der Atmosphäre sowie die Frage, wie empfindlich diese gegenüber sich ändernden Konzentrationen von Treibhausgasen und Aerosolen sind. Nicht abschließend geklärt ist darüber hinaus, wie groß die Variabilität einerseits von natürlichen Antriebsfaktoren des Klimas ist, zum Beispiel der Leuchtkraft der Sonne oder der Vulkanaktivität, sowie andererseits von verschiedenen internen Rückkopplungsmechanismen des Klimasystems einschließlich der biogeochemischen Stoffkreisläufe. Die Frage nach dem Ausmaß der regionalen oder gar lokalen Ausprägung von Klimawandel und die Zuordnung seiner Ursachen ist eine bekannte, aber längst nicht abschließend beantwortete Frage.

Neue Herausforderungen für Wissenschaft und Gesellschaft liegen auch darin, einerseits die Vermeidbarkeit von anthropogen induziertem Klimawandel sowie andererseits die Folgen von Klimawandel und der begleitenden Verletzlichkeit der Natur und der menschlichen Gesellschaft abzuschätzen. Es erscheint ausgeschlossen, dass ein anthropogener Klimawandel in 
den nächsten Jahrzehnten vollständig oder auch nur überwiegend vermieden werden kann. Darüber hinaus tritt Klimawandel ohnehin auch natürlich auf, wenngleich vermutlich in geringerem Maße als der anthropogene Klimawandel. Daher muss erhebliches Augenmerk auf den Anpassungsbedarf und die Anpassungsmöglichkeiten gerichtet werden. Die Balance zwischen Vermeidung und Anpassung ist Gegenstand aktueller Forschung. Dabei ist besonders zu beachten, dass die Folgen der Klimaänderung erst durch den sozialen und ökonomischen Zustand der jeweils betroffenen Gesellschaft zum Problem, d.h. zu Risiken und schließlich Schäden werden und deshalb z.B. in den Entwicklungs- und Schwellenländern anders ausfallen als in den Industrienationen.

Moderne Klimaforschung ist damit nicht mehr nur eine wissenschaftliche, sondern zunehmend eine gesellschaftspolitische Herausforderung. Da Unsicherheiten der klimatologischen Forschung verbleiben werden und teilweise auch unvermeidlich sind, ist längst deutlich geworden, dass die notwendigen Maßnahmen - Vermeidung von oder Anpassung an Klimawandel eine gesellschaftliche Aufgabe darstellen, die gemeinsam mit Gesellschafts- und Wirtschaftswissenschaftlern und im politischen Konsens gelöst werden muss. Themen wie die Definition von Umweltschutzzielen und deren Umsetzung, Nachfrageänderungen bei den fossilen Primärenergieträgern, Energieeinsparung oder Förderung erneuerbarer Energien, aber auch Änderungen von individuellen Gewohnheiten und Verhaltensmustern können nur im gesellschaftlichen Dialog unter der Beteiligung vieler Disziplinen bearbeitet werden.

Obwohl der Sachverständigenkreis Globale Umweltaspekte des BMBF in Gänze die Notwendigkeit erkannt hat, dass naturwissenschaftliche Klimaforschung durch Wirtschafts- und Sozialwissenschaften ergänzt werden muss, ist die nachfolgende Darstellung im Wesentlichen auf naturwissenschaftliche Aspekte beschränkt. Der
Grund ist, dass die bisherige Klimaforschung hauptsächlich naturwissenschaftlich geprägt war und die Ergebnisse dieser Forschung unverzichtbar für alle anderen Disziplinen sind. Hinzu kommt, dass zum Beispiel sozialwissenschaftliche Ansätze wegen der geringeren Rationalität der verfügbaren Daten nicht mit denselben Kriterien gemessen werden können.

Anlass für den vorliegenden Bericht war u.a. ein national und international wahrzunehmendes Unbehagen an bestimmten Ergebnissen der naturwissenschaftlichen Klimaforschung, die von der Öffentlichkeit und Politik bereits als sicher aufgefasst werden. In Deutschland wurde die Klimadiskussion erneut durch eine Kleine Parlamentarische Anfrage der Abgeordneten A.E. Fischer u.a. an die Bundesregierung zu Stand, Ergebnissen und Perspektiven der Paläoklimaforschung (Bundestagsdrucksache 14/6529) angefacht, die auf das Buch „Klimafakten" (Herausgeber: Berner und Streif, 2001) Bezug nahm. Hintergrund dieser Anfrage ist die Vermutung, dass in den heutigen Computermodellen, die für Szenarien zukünftiger Klimaentwicklungen verwendet werden, einige Einflussgrößen des Klimasystems bislang nicht mit hinreichender Genauigkeit abgebildet sind. Insbesondere wird - im Gegensatz zu einem Teil der Ergebnisse der international durchgeführten Klimamodellierung - der Einfluss des anthropogenen $\mathrm{CO}_{2}$-Zuwachses auf die Temperaturentwicklung der letzten 100 Jahre schwächer eingeschätzt.

Die vorliegende Dokumentation gibt zunächst eine knappe Darstellung des gegenwärtigen Wissensstandes über das Klimasystem, seiner historischen Variabilität und seiner Beeinflussbarkeit durch den Menschen sowie Szenarien der Klimazukunft. Diese soll und kann umfangreiche Darstellungen wie zum Beispiel den dritten Sachstandsbericht des IPCC aus dem Jahre 2001 nicht ersetzen, soll aber gesicherte Erkenntnisse einerseits und offene Fragen andererseits besonders hervorheben. Eine weitere 
Absicht dieser Dokumentation besteht darin, unterschiedliche Interpretationen von Ergebnissen der Klimaforschung zu akzentuieren.

Schließlich soll dargestellt werden, welche Konsequenzen die derzeitigen Ergebnisse der Klimaforschung für Gesellschaft und Politik nach sich ziehen.

Der vorliegende Bericht hat deshalb auch zum Ziel, die von der Öffentlichkeit wahrgenommenen und in den Medien oft übertrieben und falsch dargestellten vermeintlichen Widersprüche in den Aussagen der Klimaforschung aufzulösen. Er soll orientierende Hilfestellung für die Entscheidungsträger in Politik und Gesellschaft sein, aber auch dazu beitragen, den unterschiedlichen Wissenschaftsdisziplinen der Klimaforschung Mut und Unterstützung zu geben, sich den gesellschaftlichen Herausforderungen des Klimaschutzes durch neuartige interdisziplinäre Forschungsansätze anzunehmen.

\section{ZUSAMMEN- FASSUNG \\ DER WICHTIGSTEN AUSSAGEN}

\section{Klima ist nichts Konstantes}

Das Klima der Erde verändert sich ständig auch ohne den Einfluss des Menschen. Die Ursache hierfür sind die verschiedenen Antriebsmechanismen: Geologische Prozesse auf erdgeschichtlicher Zeitskala ebenso wie die Stellung der Erde zur Sonne sind für lang- bis mittelfristige Klimawechsel verantwortlich. Sie haben auch die heutige Warmzeit verursacht, in der wir seit ca. 11.600 Jahren leben. Andererseits schwankt das Klima aber auch allein aufgrund seiner inneren Dynamik: Die Subsysteme des Klimas wie Atmosphäre, Ozeane, Biosphäre und Eismassen sind so genannte nicht-lineare dynamische Systeme, die als Folge kleinster Störungen große Veränderungen zeigen können. Trotz dieser natürlichen Variabilität des Klimas besteht Konsens in der Wissenschaft, dass das Klima auch durch den Menschen, also anthropogen, verändert wird.

\section{Anthropogener Klimawandel findet statt}

Die globale Jahresmitteltemperatur der bodennahen Luft ist seit 1860 um $0,6 \pm 0,2^{\circ} \mathrm{C}$ angestiegen. Dieser Anstieg hatte sowohl natürliche als auch anthropogene Ursachen. Nach dem gegenwärtigen Stand der Forschung kann man davon ausgehen, dass die Erwärmung in den letzten drei Dekaden wesentlich durch die Zunahme der anthropogenen Treibhausgase, insbesondere Kohlendioxid $\left(\mathrm{CO}_{2}\right)$, verursacht worden ist. In der ersten Hälfte des 20. Jahrhunderts dagegen haben vor allem natürliche Fak- 
toren wie die Zunahme des solaren Energieflusses und der Rückgang der Vulkanaktivität zur Erwärmung beigetragen. Welchen genaueren Anteil allerdings natürliche und anthropogene Ursachen am Klimawandel im 20. Jahrhundert haben, darüber besteht in der Wissenschaft noch keine einheitliche Meinung.

\section{Klima ist nicht Wetter: Starkniederschläge sind allein kein Anzeichen einer Klimaänderung}

Der momentane Zustand der Atmosphäre an einem bestimmten Ort wird als Wetter bezeichnet. Unter Klima hingegen wird der langjährige - im Allgemeinen 30-jährige - Mittelwert sowie die Variabilität des Wetters verstanden. Klima ist die Statistik des Wetters; Klimaänderungen sind demzufolge Änderungen der Wetterstatistik. Daher kann auch von einem einzelnen Wetterereignis nicht auf eine Klimaänderung geschlossen werden. Das Auftreten z.B. eines einzelnen Starkniederschlages kann also grundsätzlich nicht als Signal für eine Änderung des Klimas interpretiert werden.

\section{Schnelle Klimaänderungen sind erdgeschichtlich nichts Neues}

Das Klima der letzten 100.000 Jahre vor dem Einsetzen der jetzigen Warmzeit war durch relativ schnelle Temperaturwechsel geprägt. Untersuchungen von Eiskernen in Grönland z.B. zeigen, dass es regional zahlreiche Temperatursprünge von mehreren Grad innerhalb weniger Jahre gegeben hat. Welche Prozesse diese starken sprunghaften Klimaänderungen ausgelöst haben, ist bis heute nicht geklärt, doch deutet Vieles auf sprunghafte Änderungen der Meeresströmungen hin. Auch in der jetzigen Warmzeit, die vor ca. 11.600 Jahren begann, gab es abwechselnd Erwärmungen und Abkühlungen; die Klimaveränderungen waren aber bei weitem nicht so dramatisch und so schnell wie in der vorangegangenen Kaltzeit. Ob der derzeit beobachtete anthropogen beeinflusste Klimawandel stärker ausfallen könnte als die natürlichen Temperatursprünge innerhalb der derzeitigen Warmzeit, wird in der Wissenschaft kontrovers diskutiert.

\section{$\mathrm{CO}_{2}$ und Temperatur beeinflussen sich gegenseitig}

Obgleich die Erforschung der Klimageschichte im Laufe der letzten Jahrzehnte deutliche Fortschritte gemacht hat, ist es bis heute nicht möglich, Änderungen der atmosphärischen $\mathrm{CO}_{2}$-Konzentration im Verlauf der weit zurückliegenden Erdgeschichte mit hinreichender Sicherheit zu rekonstruieren. Für die letzten 400.000 Jahre wurde ein bemerkenswerter Gleichlauf von $\mathrm{CO}_{2}$ und Temperaturänderungen im Wechsel von Kalt- und Warmzeiten gefunden. Aus dieser Ähnlichkeit im Verlauf kann aber nicht geschlossen werden, dass $\mathrm{CO}_{2}$ die Temperaturänderungen angetrieben hat oder umgekehrt. Die atmosphärische $\mathrm{CO}_{2}$-Konzentration ergibt sich aus der Wechselwirkung zwischen den Kohlenstoffreservoirs der verschiedenen Komponenten im Klimasystem. Diese Wechselwirkung hängt unter anderem von der Temperatur ab, die wiederum - neben zahlreichen anderen Prozessen im Klimasystem - auch über den Treibhauseffekt von der $\mathrm{CO}_{2}$-Konzentration bestimmt wird. Als sehr wahrscheinlich gilt, dass die heutige $\mathrm{CO}_{2}$-Konzentration erheblich höher ist als jemals zuvor in den vergangenen 400.000 Jahren. Zu dem heutigen Anstieg der atmosphärischen $\mathrm{CO}_{2}$-Konzentration hat der Mensch durch die Verbrennung fossiler Energieträger deutlich beigetragen und damit den Treibhauseffekt erhöht.

\section{Vertieftes Klimaverständnis durch Klimamodellierung}

Um die Wechselwirkungen der verschiedenen Mechanismen des Klimaantriebs und ihrer Rückkopplungen zu verstehen und um Aussagen 
über die zukünftige Klimaentwicklung zu machen, werden Klimamodelle entwickelt. Klimamodellierung ist der Versuch, das reale Klima in mathematischen Modellen abzubilden und dabei alle bekannten klimarelevanten physikalischen Prozesse zu berücksichtigen. Einige Prozesse im Klimasystem, wie z.B. die Wirkung von Wolken und Aerosolen oder der veränderlichen solaren Leuchtkraft, sind in gegenwärtigen Klimamodellen bisher noch nicht zufriedenstellend dargestellt. Daher müssen Klimamodelle ständig weiter entwickelt und verbessert werden. Hierbei sollte die begonnene fruchtbare Zusammenarbeit zwischen der Klimamodellierung und jenen Disziplinen, die sich der Rekonstruktion des Klimas widmen, fortgesetzt und intensiviert werden.

\section{Klimaszenarien und die Auswirkung des Kyoto-Protokolls}

Klimamodelle sind die wichtigsten wissenschaftlichen Instrumente, um die Reaktion des Klimasystems auf Änderungen verschiedener Antriebe, wie z.B. der $\mathrm{CO}_{2}$-Konzentration, zu untersuchen. Wie sich die Emissionen künftig entwickeln könnten, ist in Szenarien formuliert, die jeweils unterschiedliche Annahmen über die Entwicklung der Weltbevölkerung, ihres Lebensstandards und Energieverbrauchs machen. Alle diese so genannten SRES-Szenarien zeigen bis 2030 etwa die gleiche Entwicklung der globalen Mitteltemperatur; erst danach laufen sie auseinander. Die Spannbreite des projizierten Temperaturanstiegs bis 2100 liegt zwischen 1,4 und 5,8 Grad. Zu den im Kyoto-Protokoll vereinbarten Reduktionszielen der Treibhausgasemissionen liegen ebenfalls Modellrechnungen vor, die, extrapoliert bis 2050, nur eine äußerst geringfügige Änderung (weniger als ein Zehntel Grad) gegenüber der sonstigen Temperaturentwicklung errechnen. Daher ist das Protokoll in seiner jetzigen Form kaum dazu geeignet, das Klima zu stabilisieren. Seine Wirkung ist eher im politischen Bereich zu finden, da es die einzige völkerrechtliche Basis für weitergehende Maßnahmen darstellt.

\section{Die regionale Ausprägung von Klimawandel ist noch unsicher}

Klima wird von den Menschen nicht global, sondern regional bzw. lokal erfahren. Für die Wahrnehmung von Klimawandel spielt deshalb nicht die Änderung von globalen Mittelwerten, sondern die regionale bzw. lokale Ausprägung solcher Mittelwerte die entscheidende Rolle. Dies gilt insbesondere für die Zunahme von Extremereignissen, wie z.B. Dürren, Stürmen oder Starkniederschlägen. Einer Klimamodellierung mit regionaler Auflösung, also mit Aussagen für möglichst kleine Regionen, kommt deshalb eine zunehmende Bedeutung zu. Die bislang vorliegenden Ergebnisse der regionalisierten Modellierung zeigen für die Regionen Mittel- und Nordeuropa übereinstimmend, dass sich die Temperatur in Zukunft im Winter erhöhen wird. Weniger übereinstimmend dagegen sind die Ergebnisse noch im Hinblick auf die Änderungen der Niederschläge in diesen Regionen.

\section{Anpassung an den Klimawandel ist unumgånglich}

In Anbetracht der Entwicklung der letzten Jahre ist es sehr wahrscheinlich, dass die Emission von Treibhausgasen in den nächsten Jahrzehnten weiter anwächst. Dass sich die Emissionen auf gegenwärtigem Niveau oder gar auf einem Niveau des Jahres 1990 in näherer Zukunft stabilisieren, ist unwahrscheinlich, so dass sich das Klima in den kommenden Jahrzehnten auch als Folge menschlicher Aktivitäten weiter ändern wird. Diese Änderung lässt sich nur in gewissem Umfang und auch eher nur langfristig durch geeignete Strategien vermindern. Daher sehen sich Gesellschaft und Politik vor der wichtigen Aufgabe, die Menschen und auch die Wirtschaft auf Veränderungen im Klima vorzubereiten. Dazu gehört vor allem die Entwicklung von 
Technologien und Methoden, die dabei helfen, mit einer sich verändernden Umwelt umzugehen. Die Diskussion um Anpassung an mögliche Klimaänderungen muss im politischen Diskurs größeres Gewicht erhalten.

\section{Klimaforschung als sozialer Prozess}

Klimaforschung ist von hoher gesellschaftlicher Relevanz, aber mit großer Unsicherheit verknüpft. Die Unsicherheit kann in gewissem Maße durch weitere Forschung vermindert werden. Wenngleich Forschung unser Wissen über die relevanten Fragen vermehrt, tauchen in der Regel gleichzeitig weitere ungeklärte Fragen auf, und weitere mögliche Wirkungsketten werden erkannt. In dieser Situation ist Wissenschaft nicht der einzige und auch nicht der wichtigste gesellschaftliche Ratgeber: Naturwissenschaftliche Argumente sind nicht die einzigen, die in den Köpfen der Menschen wirken. Forschung im Bereich Klima und Klimawirkung bezüglich Umwelt, Mensch und seiner Wirtschaft wird damit zu einem sozialen Prozess. Bislang wurde Klimaforschung weitgehend disziplinär von Naturwissenschaftlern betrieben. Es ist aber an der Zeit, die bereits existierenden Ansätze der Klimaforschung im Verbund von Natur- und Sozialwissenschaften weiter voranzutreiben.

\section{WAS IST KLIMA UND WODURCH WIRD ES BESTIMMT?}

In der öffentlichen Diskussion über Klima, Klimaschutz und Klimafolgen treten Fragen auf, die zum Teil auf Unkenntnis des Diskussionsgegenstandes und des gegenwärtigen Forschungsstandes zurückzuführen sind. Zum Teil spiegeln sie aber auch den tatsächlichen wissenschaftlichen Dissens bzw. Forschungsbedarf wider. Zum ersten Themenbereich gehören die Verwechslung der Begriffe Klima und Wetter, die Interpretation einzelner Wetterextreme als Signal eines Klimawandels, die Behauptung, es gäbe keinen Treibhauseffekt, sowie die Vermutung, $\mathrm{CO}_{2}$ wäre auch in der Vergangenheit durchgehend der Antrieb für Klimaänderungen gewesen. In der Klimaforschung dagegen werden u.a. folgende Punkte immer noch kontrovers diskutiert: Wie stark beeinflussen die natürlichen Klimaantriebe, wie z.B. Änderung der Sonnenaktivität und Vulkanismus, die Klimavariabilität im Vergleich zu anthropogenem Antrieb, wie stark sind die internen Rückkopplungsprozesse wie z.B. der Wasserkreislauf einschließlich Wolken und dem positiven wie auch negativen Effekt des Wasserdampfes im Strahlungshaushalt der Atmosphäre? Wie wirkt sich die Klimaänderung auf den Austausch von Treibhausgasen zwischen der Biosphäre und der Atmosphäre aus? Wie zuverlässig ist das Klima modellierbar, ist es gar vorhersagbar, und wie belastbar sind Vorhersagen der Klimamodelle?

\subsection{Klima und Wetter}

Der momentane Zustand der Atmosphäre an einem Ort wird als Wetter bezeichnet. Unter dem Begriff Klima werden hingegen der langjährige - im Allgemeinen 30-jährige - Mittelwert des Wetters sowie die Variabilität des Wetters im Mittel über einen längeren Zeitraum verstanden. Klima ist somit die Statistik des Wetters. Messbare Größen, die das Klima beschreiben, werden Klimaelemente genannt. Hierzu 
zählen sämtliche meteorologischen Größen wie Temperatur, Windgeschwindigkeit, Niederschlagsmenge, Art des Niederschlags, Sonnenscheindauer usw. Die Klimaelemente werden als statistische Kenngrößen angegeben wie Jahresmittel oder Monatsmittel des Niederschlags oder Eintrittswahrscheinlichkeit und die Häufigkeit von Ereignissen wie z.B. mittlere Dauer von Dürren, d.h. Tagen ohne Niederschlag, oder Auftreten von Extremereignissen, wie z.B. Starkniederschlag, Sturm, etc.

Da von einem einzelnen zufälligen Ereignis nicht auf die statistischen Eigenschaften der Grundgesamtheit, der dieses Ereignis zuzuordnen ist, geschlossen werden kann, ist es unmöglich, die Dynamik des Klimas aus einem einzelnen Wetterereignis abzuleiten. Das Auftreten z.B. eines einzelnen Starkniederschlages kann also prinzipiell nicht als Klimaänderungssignal interpretiert werden. Als Beispiel sei hier die Zeitreihe der Jahresmitteltemperaturen der bodennahen Luftschicht in etwa $2 \mathrm{~m}$ Höhe angeführt (siehe Abb. 1), die an der Säkularstation Potsdam aufgenommen wurde. (Als Säkularstationen werden meteorologische Messstationen bezeichnet, an denen seit mehr als hundert Jah-

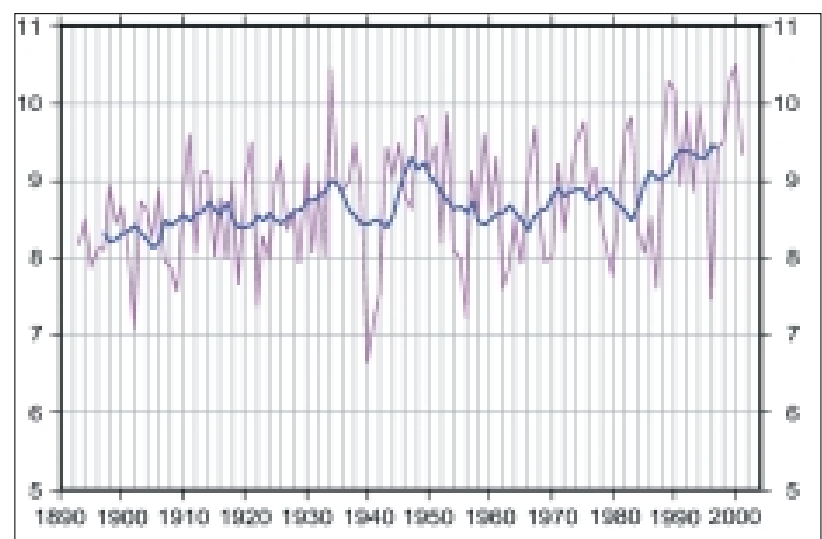

\section{Abbildung 1}

Jahresmitteltemperatur der bodennahen Luftschicht gemessen an der Säkularstation Potsdam von 1893 bis 2001 (siehe auch www.klima-potsdam.de). Die blaue Kurve kennzeichnet die Zeitreihe von Mittelwerten, bei der neben dem aktuellen Jahr auch die vier Jahre davor und danach in die Berechung mit einbezogen wurden.

Quelle: Säkularstation Potsdam (Deutscher Wetterdienst) ren meteorologische und klimatologische Aufzeichnungen durchführt werden. Für weitere Informationen siehe www.klima-potsdam.de).

Die Potsdamer Zeitreihe zeigt ein sehr warmes Jahr 2000 und ein sehr kaltes Jahr 1996 (Der Winter 1995/96 war außergewöhnlich kalt und langandauernd). Die Jahre 2000 und 1996 können bezüglich der Jahresmitteltemperatur als Extremereignisse angesehen werden, doch weder kündigt das Jahr 2000 den Beginn einer besonderen Warmzeit, noch das Jahr 1996 den Beginn einer neuen Eiszeit an. Die Zeitreihe der Jahresmitteltemperaturen von 1893 bis 2002 zeigt eine ansteigende Jahresmitteltemperatur von etwa $1^{\circ} \mathrm{C}$ in 100 Jahren. Daher ist zu erwarten, dass mit fortschreitender Zeit sehr warme Jahre als Extremwert, z.B. als wärmstes Jahr seit Beginn der Messung, erscheinen. Auch das sehr kalte Jahr 1996 erscheint in der hundertjährigen Messreihe wärmer als die Jahre 1893, 1894, 1902, 1922, 1940, 1941 und 1956. Definiert man die Jahresmitteltemperatur des Jahres 1996 als Schwellenwert, unterhalb dessen ein Jahr als extrem kalt bezeichnet werden kann, so stellt sich heraus, dass die Anzahl kalter Jahre in der ersten Hälfte der Jahrhundertreihe dreimal größer ist als in der zweiten Hälfte. Eine statistische Absicherung dieser Aussage ist aufgrund der geringen Anzahl extrem kalter Jahre in diesem 100-Jahres-Abschnitt sehr unsicher. Generell gilt, dass zur statistischen Betrachtung von Extremereignissen wesentlich längere Zeitreihen zur Verfügung stehen müssen als zur Beschreibung einfacher statistischer Kenngrößen wie Mittelwert und Varianz.

Die Aussagen bezüglich der statistischen Behandlung von Extremereignissen in einer Messreihe gelten analog für die Betrachtung von räumlichen Mittelwerten und an verschiedenen Orten gemessenen einzelnen Zeitreihen. Grundsätzlich kann nicht von der Messung an einem Ort auf den globalen Trend geschlossen werden. Während die Messreihe in Potsdam einen Anstieg der Jahresmitteltemperatur von 
etwa $1^{\circ} \mathrm{C}$ in den letzten hundert Jahren zeigt, wird im globalen Mittel ein Anstieg von $0,6 \pm 0,2^{\circ} \mathrm{C}$ berechnet. Es gibt, wie detaillierte Analysen zeigen, Gebiete auf der Erde, in denen die Temperatur der bodennahen Luftschicht in diesem Zeitraum sogar abgenommen hat. Dafür hat die Temperatur in anderen Gebieten stärker zugenommen als im globalen Mittel. Die Angabe $\pm 0,2^{\circ} \mathrm{C}$ ist als Unsicherheit der Abschätzungen des Temperaturanstieges zu interpretieren. Diese Unsicherheit entsteht dadurch, dass nicht an allen Orten auf der Welt die Lufttemperatur registriert wird. Insbesondere über den Ozeanen gibt es immer noch große Messlücken, die durch aufwendige Interpolationsverfahren geschlossen werden. Dies gilt erst recht für einen Referenzzeitraum vor etwa 100 Jahren, in dem nur in Europa, an den Küstenzonen Nordamerikas und Ostasiens sowie entlang der großen Schifffahrtslinien die bodennahen Temperaturen regelmäßig gemessen wurden.

\subsection{Das Klimasystem}

Wenngleich das Klima von den Menschen als atmosphärischer Zustand wahrgenommen wird, so ist die Dynamik des Klimas nicht allein durch die Atmosphäre verursacht. Unter Klimadynamik verstehen wir Mechanismen, die den mittleren Zustand und die Schwankungen in der Atmosphäre verursachen. Die längerfristigen Veränderungen der Atmosphäre werden wesentlich durch die Wechselwirkung der Atmosphäre mit dem Ozean und den Landoberflächen sowie der Vegetation und den Eismassen geprägt.

Das Klimasystem (Abb. 2) besteht aus verschiedenen Untersystemen: der Atmosphäre, der Hydrosphäre (Ozeane, Flüsse, Seen, Regen, Grundwasser), der Kryosphäre (Inlandeismassen, Meereis, Schnee, Permafrost), der marinen und terrestrischen Biosphäre, dem Erdreich, und, wenn Zeitskalen über viele Jahrtausende betrachtet werden, der Erdkruste und dem oberen Erdmantel. Diese Unterteilung erfolgt im Wesentlichen aufgrund der beteiligten Medien (gasförmig, flüssig, fest) und der Zeitskalen, die für typische Änderungen in den Untersystemen beobachtet werden können (siehe Tab. 1). Die Untersysteme sind über Energie-, Massen- und Impulsflüsse miteinander gekoppelt.

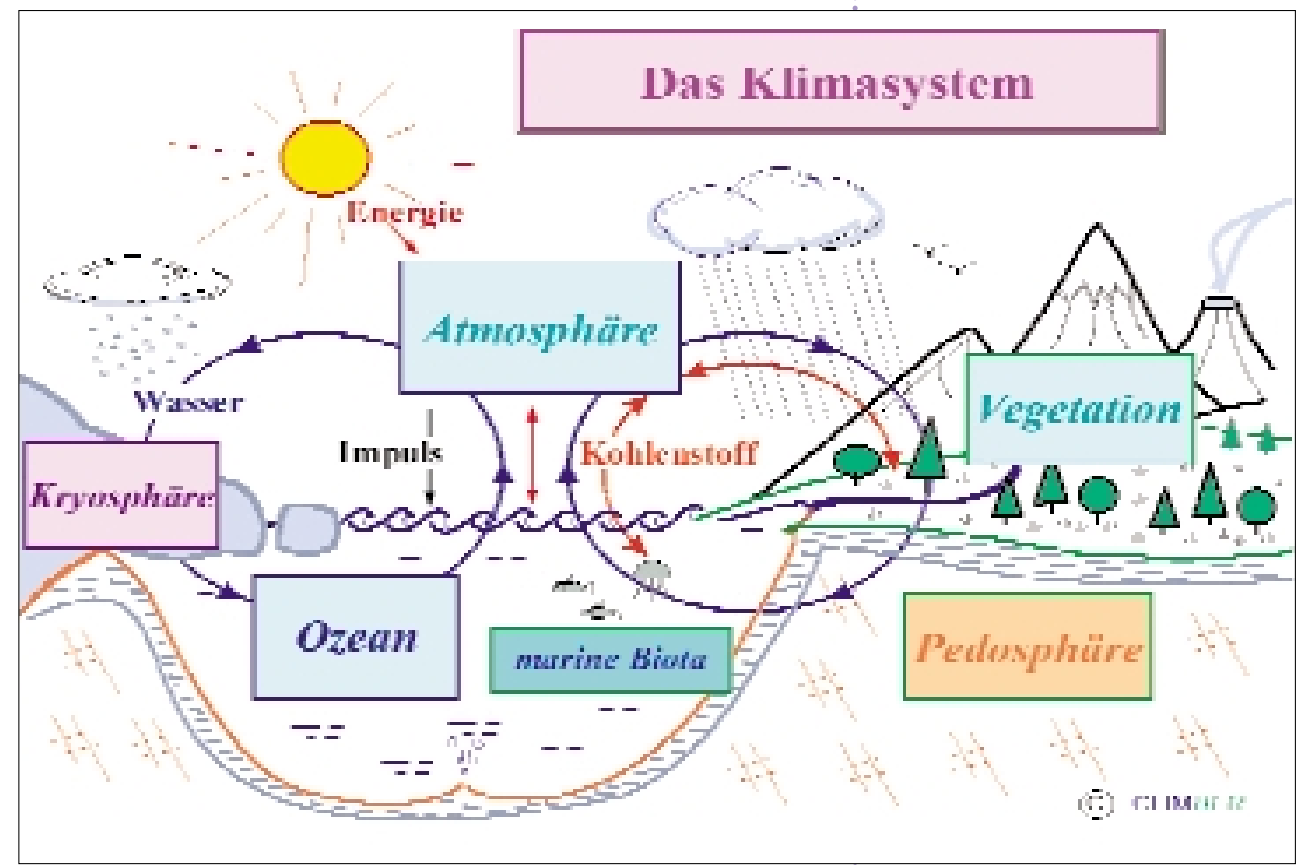

Abbildung 2

Schematische Darstellung der verschiedenen Komponenten des Klimasystems und der sie verbindenden Flüsse. 
Tabelle 1 Klimauntersysteme und typische Zeitskalen ihrer Prozesse

\begin{tabular}{|c|c|c|}
\hline KOMPONENTE & PROZESS & ZEITSKALA \\
\hline Atmosphäre & $\begin{array}{l}\text { Wetterdynamik in der Troposphäre } \\
\text { (etwa } 0-10 \mathrm{~km} \text { ) } \\
\text { Wellenbewegung in der Stratosphäre } \\
\text { (etwa } 10-50 \mathrm{~km} \text { ) }\end{array}$ & $\begin{array}{l}\text { 1-10 Tage } \\
100 \text { Tage bis etwa } 2 \text { Jahre }\end{array}$ \\
\hline $\begin{array}{l}\text { Hydrosphäre } \\
\text { (nur Ozeane) }\end{array}$ & $\begin{array}{l}\text { Wärmeausbreitung im oberen Ozean } \\
(0-100 \mathrm{~m}) \\
\text { Durchmischung des tiefen Ozeans }\end{array}$ & $\begin{array}{l}\text { Monate } \\
\text { Jahrhunderte bis Jahrtausende }\end{array}$ \\
\hline Kryosphäre & $\begin{array}{l}\text { Ausdehnung des Meereises } \\
\text { Aufbau und Schmelzen von Talgletschern } \\
\text { Eisströme im Inlandeis } \\
\text { Aufbau und Zerfall von Permafrost und } \\
\text { Inlandeismassen }\end{array}$ & $\begin{array}{l}\text { Jahre bis Jahrzehnte } \\
\text { Jahrzehnte bis Jahrhunderte } \\
\text { Jahrhunderte } \\
\text { Jahrzehntausende bis } \\
\text { (vermutlich) Jahrmillionen }\end{array}$ \\
\hline Biosphäre & $\begin{array}{l}\text { Aktivität der Photosynthese } \\
\text { Mineralisation von Biomasse } \\
\text { Änderung in der Zusammensetzung } \\
\text { eines Bestandes } \\
\text { Wandern von Vegetationszonen }\end{array}$ & $\begin{array}{l}\text { Minuten } \\
\text { Monate bis Jahrhunderte } \\
\text { Jahrzehnte } \\
\text { Jahrhunderte }\end{array}$ \\
\hline Pedosphäre & $\begin{array}{l}\text { Erwärmung des Bodens } \\
\text { Grundwasserneubildung }\end{array}$ & $\begin{array}{l}\text { Tage bis Jahre } \\
\text { Jahre bis Jahrtausende }\end{array}$ \\
\hline Lithosphäre & $\begin{array}{l}\text { Vertikale Ausgleichsbewegung, } \\
\text { Entgasen von } \mathrm{CO}_{2} \text {, Wasser etc. }\end{array}$ & kontinuierlich \\
\hline
\end{tabular}

Aus der Tabelle ist zu ersehen, dass unterschiedliche Prozesse auf zum Teil deutlich verschiedenen Zeitskalen ablaufen, so dass auch Klimaänderungen auf unterschiedlichen Zeitskalen möglich sind. So ist z.B. das Entstehen und Vergehen von Eiszeiten über Jahrhunderttausende und das Auftreten der so genannten „Kleinen Eiszeit” (siehe Abschnitt 2.1) vor einigen hundert Jahren durch unterschiedliche Prozesse hervorgerufen worden. Diese können daher auch nicht direkt miteinander verglichen werden.

\subsection{Mechanismen des Klimaantriebs}

Die Sonne ist der Motor unseres Klimasystems. Ihr Antrieb ist jedoch nicht immer gleich, sondern ändert sich durch verschiedene Faktoren auf unterschiedlichen Zeitskalen.

- Die Leuchtkraft der Sonne ändert sich auf nahezu allen Zeitskalen. Der Energiefluss von der Sonne zur Erde nimmt im Laufe von Jahrmilliarden Jahren allmählich zu (etwa $10 \%$ pro Milliarde Jahre). Für die Betrachtung der Klimadynamik im Laufe der letzten hunderttausend Jahre sind die solaren Aktivitätsänderungen 
der Sonne im Bereich von etwa 11, 22, 78 und vermutlich auch 208, 1500 und 2500 Jahren interessant. Der Energiefluss von der Sonne einschließlich seiner Schwankungen kann erst in den letzten etwa 20 Jahren von Satelliten aus gemessen werden. Für die Zeit davor werden die solaren Schwankungen aus Beobachtungen der Änderungen der Sonnenflecken oder aus Konzentrationsänderungen kosmogener Isotope abgeschätzt. Während die Tatsache, dass Schwankungen des solaren Energieflusses Klimavariabilität hervorrufen, nicht umstritten ist, wird über die Größe dieses Effektes im Vergleich zu anderen Antrieben weiterhin diskutiert (siehe Kapitel 2).

\section{- Zusammen mit dem Magnetfeld der Erde} schirmt das Magnetfeld der Sonne die Atmosphäre vor kosmischer Partikelstrahlung ab. Wenn die Magnetfelder sich ändern, ändert sich auch der Strom kosmischer Partikel in die Atmosphäre. Diese Partikel führen zur Bildung von Ionenclustern, die als Kondensationskeime heranwachsen und damit die Wolkenbildung verstärken können. Die Klimarelevanz kosmischer Partikelstrahlung und des Erdmagnetfeldes wird zur Zeit kontrovers diskutiert.

- Die Erdbahn um die Sonne ist ständigen Änderungen unterworfen und führt zu nennenswerten Verschiebungen in der regionalen Verteilung der solaren Einstrahlung auf Zeitskalen von 19.000 bis zu 413.000 Jahren. Diese zyklischen, zumeist mit dem Namen Milankovitch verbundenen Schwankungen verursachen signifikante Klimaschwankungen. Während der letzten 1 Millionen Jahre treten die stärksten erstaunlicherweise bei dem 100.000-jährigen Zyklus auf, der mit der veränderlichen Exzentrizität der Erdbahn und damit nur mit marginalen Schwankungen im solaren Energieangebot einhergeht.

Neben den Faktoren, die die Sonnenintensität an jedem Punkt der Erdoberfläche bestimmen, gibt es noch weitere natürliche Einflüsse auf das Klimageschehen:
- Langsame Konvektionsbewegungen im Erdmantel führen zu tektonischen Prozessen, wie Kontinentaldrift, Auffaltung von Gebirgen, Änderung des Ausgasens von $\mathrm{CO}_{2}$ aus dem Erdinneren. Sie spielen für die langfristige Klimadynamik im Rahmen von Millionen Jahren eine prägende Rolle.

- Für kurzfristige klimatische Einflüsse ist die an tektonische Prozesse gekoppelte Vulkantätigkeit mitverantwortlich. Durch Vulkanaktivität gelangen gasförmige und partikelförmige Spurenstoffe in die Atmosphäre, die den Strahlungshaushalt der Atmosphäre ändern (siehe hierzu auch unten, Treibhauseffekt).

- Ein in seiner Variabilität nur unzulänglich abzuschätzender Klimaantrieb sind Einschläge größerer Meteoriten. Für die Diskussion der gegenwärtigen Klimaänderung spielt dieser Faktor allerdings keine Rolle.

Das wohl prominenteste Thema in der Klimadiskussion ist der so genannte Treibhauseffekt. Der Treibhauseffekt ist rein atmosphärischer Natur. Er ist zunächst nicht etwas menschgemachtes, sondern etwas ganz natürliches (siehe Kasten „Der Treibhauseffekt....., Seite 16). Ohne diesen so genannten primären Treibhauseffekt wäre Leben auf der Erde nicht möglich.

Seit Beginn des Industriezeitalters verändert der Mensch die Konzentration der klimarelevanten Spurengase in der Atmosphäre und bewirkt damit einen zusätzlichen, sekundären Treibhauseffekt. Die wichtigsten Treibhausgase sind das Kohlendioxid, Methan, Distickstoffoxid und die FCKWs, die durch unterschiedliche menschliche Aktivitäten in die Atmosphäre emittiert werden (vgl. Tabelle 3). Die Wirksamkeit der anthropogenen Beiträge hängt unter anderem davon ab, wie stark die jeweiligen Absorptionsbanden der natürlichen Treibhausgase bereits gesättigt sind. Bei einigen anthropogenen Treibhausgasen sind die natürlichen Absorptionsbanden nur bis zu einem geringen Grad bzw. gar nicht gesättigt wie bei den FCKWs. Die Folge ist, dass ein zusätzliches Molekül dieser Gase eine 


\section{DER TREIBHAUSEFFEKT, KLIMAWIRKUNG VON GASEN UND AEROSOLEN}

Von entscheidender klimatischer Bedeutung bei den Strahlungsvorgängen in der Atmosphäre ist, dass die langwellige Wärmestrahlung der erwärmten Erdoberfläche die Atmosphäre größtenteils nicht auf direktem Wege verlässt, sondern von atmosphärischen Spurengasen, den natürlichen Treibhausgasen, und von Wolken zunächst teilweise absorbiert wird. Spurengase und Wolken emittieren diese Energie einerseits in den Weltraum und andererseits in Richtung Erdoberfläche zurück, die dadurch zusätzlich aufgeheizt wird. Der auf diese Weise hervorgerufene Wärmestau in der unteren Atmosphäre bewirkt einen Temperatureffekt von $+33^{\circ} \mathrm{C}$ bzw. eine Erwärmung von $-18^{\circ} \mathrm{C}$ (bei Annahme einer Atmosphäre ohne Wolken und Spurengase) auf $+15^{\circ} \mathrm{C}$ und ermöglicht damit überhaupt erst Leben auf der Erde. In Anlehnung an das Garten-Treibhaus bezeichnet man den Wärmestau in der unteren Atmosphäre als „Treibhauseffekt“.

Die eigentlichen Verursacher des Treibhauseffekts sind eine Reihe von Spurengasen wie Wasserdampf $\left(\mathrm{H}_{2} \mathrm{O}\right)$, Kohlendioxid $\left(\mathrm{CO}_{2}\right)$, Methan $\left(\mathrm{CH}_{4}\right)$, Distickstoffoxid $\left(\mathrm{N}_{2} \mathrm{O}\right)$, Ozon $\left(\mathrm{O}_{3}\right)$ u.a., deren Anteil an der Gesamtmasse der Atmosphäre zusammen weniger als $1 \%$ ausmacht. Diese Treibhausgase lassen die kurzwellige Solarstrahlung weitgehend passieren, absorbieren aber die langwellige Wärmestrahlung der Erdoberfläche im Infrarotbereich in

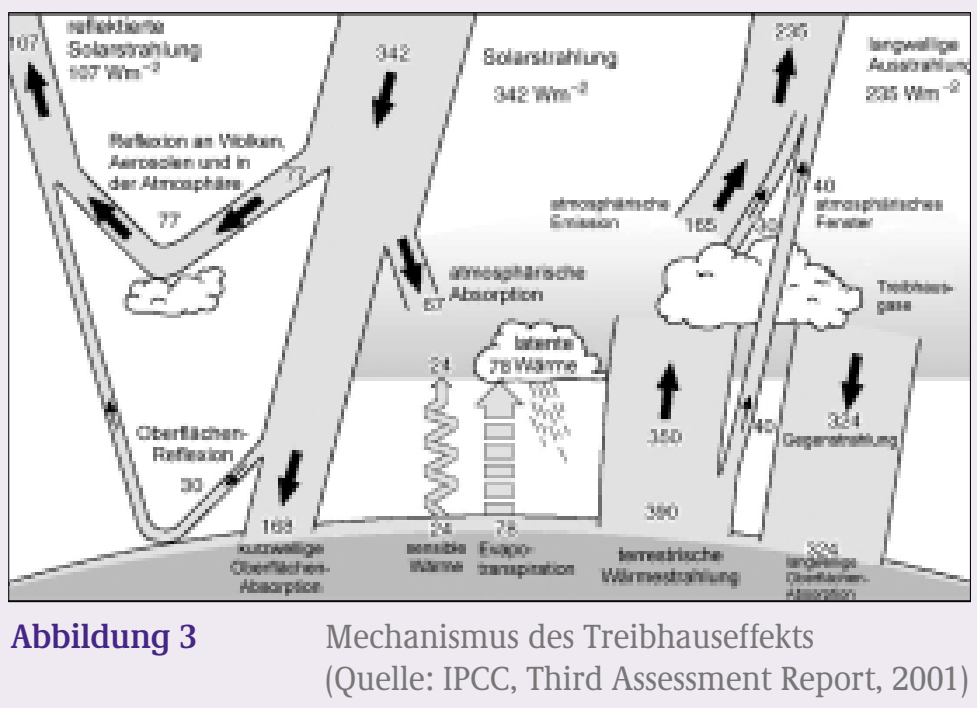

\section{Tabelle 2 Beitrag von natuirlichen} Spurengasen der Atmosphåre zum natürlichen Treibhauseffekt

Treibhausgas

Beitrag zum natürlichen Treibhauseffekt [\%]

Wasserdampf $\left(\mathrm{H}_{2} \mathrm{O}\right) \quad 62$

Kohlendioxid $\left(\mathrm{CO}_{2}\right) \quad 22$

Ozon, bodennah $\left(\mathrm{O}_{3}\right) \quad 7$

Distickstoffoxid $\left(\mathrm{N}_{2} \mathrm{O}\right) \quad 4$

Methan $\left(\mathrm{CH}_{4}\right) \quad 2,5$

andere 2,5

Quelle: Kondratyev und Moskalenko (1984)
Wellenlängenbereichen ab etwa $3 \mu \mathrm{m}$. Dabei absorbieren die einzelnen Spurengase in unterschiedlichen Absorptionsbanden.

Das wichtigste natürliche Treibhausgas ist Wasserdampf, das für fast zwei Drittel des natürlichen Treibhauseffekts verantwortlich ist. Es absorbiert in breiten Spektralbereichen um $3 \mu \mathrm{m}, 5 \mu \mathrm{m}$ und $20 \mu \mathrm{m}$ nahezu vollständig. Es lässt aber in anderen Wellenlängenbereichen wie um $4 \mu \mathrm{m}$ und um $10 \mu \mathrm{m}$ die Infrarotstrahlung nahezu ganz passieren. In diesen Spektren setzen die anderen Treibhausgase an. So absorbiert das zweitwichtigste natürliche Treibhausgas, das Kohlendioxid, gerade 
um $4 \mu \mathrm{m}$ und $15 \mu \mathrm{m}$. Ozon, Distickstoffoxid und Methan füllen weitere Lücken des Wellenlängenspektrums.

Neben den Treibhausgasen sind Aerosole*) für das Klimasystem von Bedeutung. Sie gelangen direkt, beispielsweise durch Sandstürme oder bei Vulkanausbrüchen, in die Atmosphäre. Sie werden auch aus gasförmigen Vorläufersubstanzen in der Atmosphäre gebildet. Aerosole beeinflussen das Klimasystem sowohl direkt aufgrund ihrer Wechselwirkung mit der Strahlung als auch indirekt aufgrund ihrer Rolle als Wolkenkondensationskerne. Optische Eigenschaften und die Fähigkeit einzelner Partikel, als Wolkenkondensationskern aktiviert zu werden, sind durch Partikelgröße, chemische Zusammensetzung und der Menge des am Aerosol gebundenen Wassers bestimmt. Beispielsweise Schwefelaerosol absorbiert kaum im sichtbaren Spektralbereich, so dass Streuvorgänge dominieren. Diese Reflektion von Solarstrahlung bedeutet eine Abkühlung des Systems Erde-Atmosphäre. Dahingegen führt die Absorption von Solarstrahlung durch Rußaerosol zu einer Erwärmung der Atmosphäre.

*) Das atmosphärische Aerosol ist definiert als die Gesamtheit aller in einem Luftvolumen befindlichen Partikel unterschiedlichster Form, Textur, chemischer Zusammensetzung und Größe.

wesentlich höhere Treibhauswirkung hat als ein zusätzliches $\mathrm{CO}_{2}$-Molekül. So besitzt etwa ein Methan-Molekül das 23-fache und ein FCKW11Molekül das 4600-fache Treibhauspotential eines $\mathrm{CO}_{2}$-Moleküls.

Neben den Strahlungseigenschaften hängt die Wirkung der Treibhausgase im Klimasystem auch von der Verweilzeit der Treibhausgase in der Atmosphäre ab. Das durch menschliche Aktivitäten in die Atmosphäre emittierte Kohlendioxid wird durch die Bildung von Biomasse und die Lösung von $\mathrm{CO}_{2}$ im Ozean wieder aus der Atmosphäre entfernt. Aufgrund der Dynamik der genannten Prozesse kann die Verweildauer des anthropogenen Kohlendioxids nur näherungsweise angegeben werden. Nach gegenwärtigen Abschätzungen liegt sie im Bereich von 50 bis 200 Jahren. Demgegenüber wird etwa die atmosphärische Lebensdauer von Methan fast ausschließlich durch die Oxidation mit $\mathrm{OH}$ in der Atmosphäre kontrolliert, woraus ein mittlerer Verbleib in der Atmosphäre von 12 Jahren resultiert. Die lange Verweilzeit von Distickstoffoxid von 114 Jahren erklärt sich daraus, dass dieses Treibhausgas hauptsächlich durch Photolyse in der Stratosphäre entfernt wird.
Dem anthropogenen Treibhauseffekt entgegen wirkt die vom Menschen verursachte Erhöhung der Aerosolkonzentration in der Atmosphäre. Diese hat ihre Ursache hauptsächlich in der Nutzung fossiler Energierohstoffe, in der Verbrennung von Biomasse und in Emissionen der Landwirtschaft. Bei diesen werden Schwebstoffe wie Ruß, Verbrennungsaerosole oder auch Gase gebildet (Schwefeldioxid, Stickoxide, Ammoniak), deren Oxidation in der Atmosphäre selbst ebenfalls zu Aerosolen führt. Bedeutende Mengen von Aerosolen stammen aber auch aus der natürlichen Aufwirbelung von Böden (Mineralaerosole) und der Meeresoberfläche (Seesalzaerosole) sowie aus der Oxidation von biogen produzierten Kohlenwasserstoffen (Terpene). Aufgrund der räumlichen und zeitlichen Veränderung der Quellstärken von Aerosolen sowie ihrer begrenzten Lebensdauer ist die Beladung der Atmosphäre mit Aerosolen räumlich und zeitlich ebenfalls sehr variabel. Bezüglich ihrer Klimawirkung haben Aerosole zwei unterschiedliche Eigenschaften: Sie sind erstens direkt strahlungsaktiv, indem sie Sonnenlicht reflektieren, und zweitens indirekt, da sie einen Einfluss auf die Wolkenbildung besitzen (vgl. Kasten). 


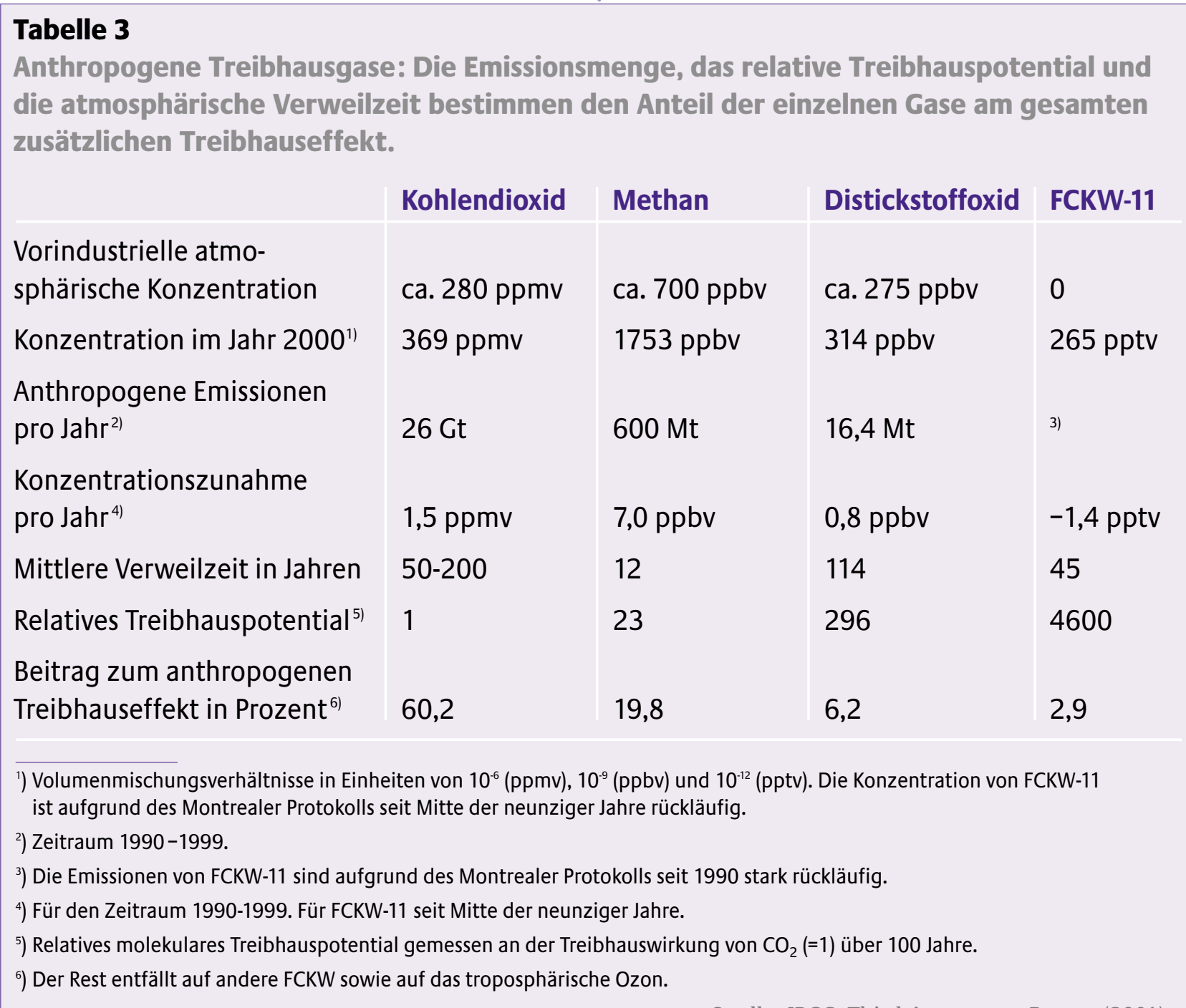

Quelle: IPCC, Third Assessment Report (2001)

Eine detaillierte Darstellung der verschiedenen durch den Menschen seit Beginn der Industrialisierung hervorgerufenen Antriebe im Klimasystem findet man in Abb. 4. Aus dieser Abbildung ist zu erkennen, dass die langlebigen und gleichmäßig verteilten Treibhausgase zusammen zu einem Strahlungsantrieb von $2,45 \mathrm{Wm}^{-2}$ seit Anfang des Industriezeitalters geführt haben, wovon mehr als die Hälfte auf das Kohlendioxid entfällt. Die Beträge zum Strahlungsantrieb der anderen Faktoren (stratosphärisches Ozon, troposphärisches Ozon, Aerosole, Flugverkehr, Landnutzungsänderung und Sonneneinstrahlung) sind jeweils vergleichsweise klein und haben sowohl positive als auch negative Vorzeichen. Es ist aber zu beachten, dass der wissen- schaftliche Kenntnisstand bezüglich der Strahlungsantriebe sehr unterschiedlich ist. Er ist allein hoch bei den Treibhausgasen und wird niedrig bzw. sehr niedrig beim Effekt der Aerosole und anderer. Insbesondere ist beim indirekten Effekt der Aerosole nur das Vorzeichen klar, nicht aber die Größe; bei dem Effekt des mineralischen Aerosols nicht einmal das Vorzeichen. Es ist deshalb denkbar, dass die gesamten unbekannten Effekte zusammen genommen den anthropogenen Effekt durch die Treibhausgase mehr als kompensieren.

Klimarelevant sind darüber hinaus Änderungen in der Landnutzung. Insbesondere die Überführung großer Flächen in landwirtschaftliche Nut- 


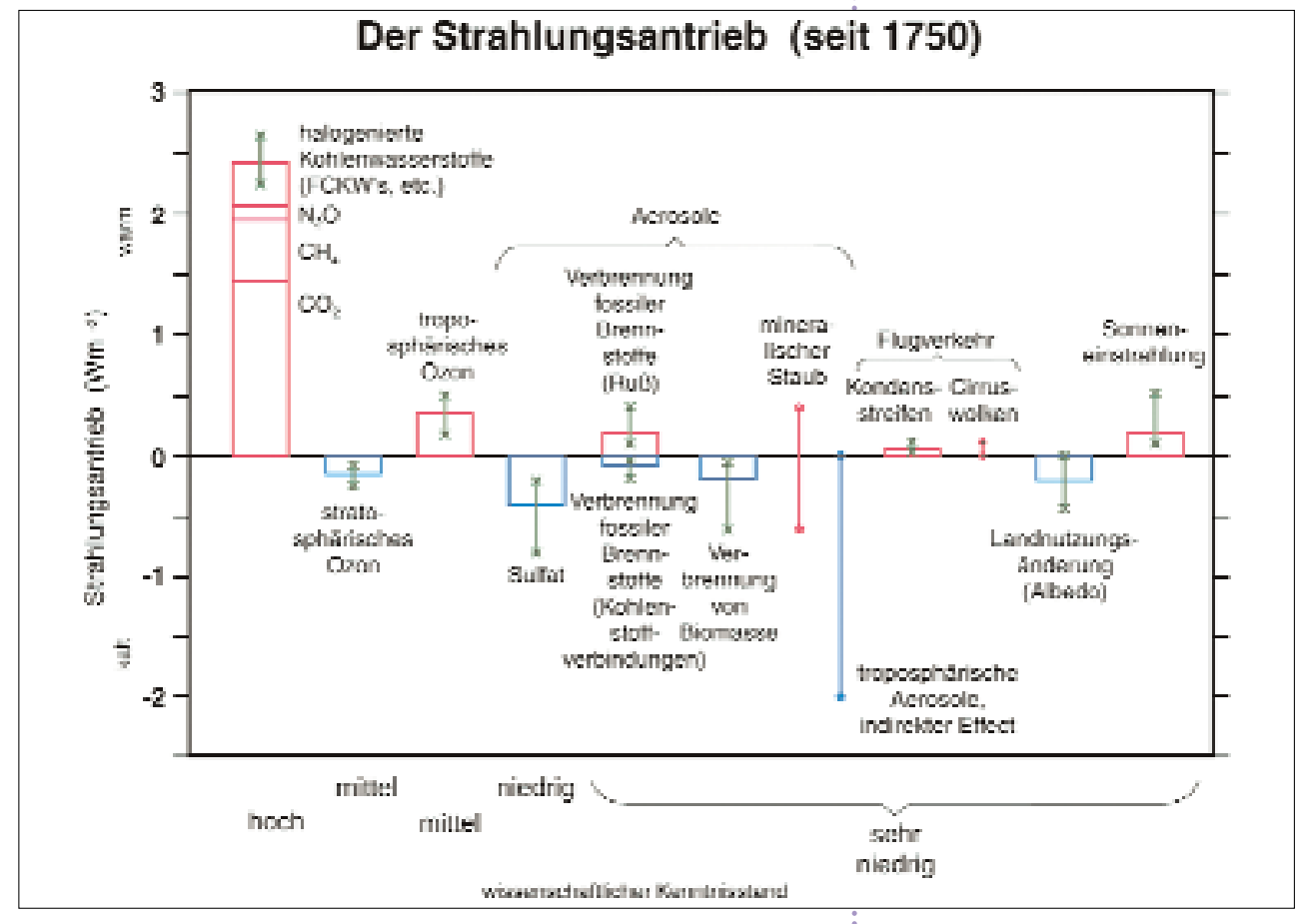

Abbildung 4

Der Strahlungsantrieb

des Klimasystems im

Jahr 2000 relativ zum

Jahr 1750. Änderungen

in den Strahlungsantrie-

ben rühren von Ände-

rungen in der Zusam-

mensetzung der Atmo-

sphäre, von Veränderungen in der Landnutzung und von der Veränderung der Sonneneinstrahlung her. Menschliche Aktivitäten beeinflussen jeden Faktor mit Ausnahme der Sonnenaktivität.

Quelle:

IPCC, Third Assessment Report (2001)

zung sowie die Entwaldung hat zweifelsfrei Auswirkungen auf das lokale Klima. Der Mechanismus hinter dieser Veränderung ist die Modifikation der Bodenreibung und des Energie- und Wasseraustausches zwischen atmosphärischer Grenzschicht und Boden sowie die Veränderung der Albedo. Durch Landnutzungsänderungen werden ebenfalls Treibhausgase emittiert. Inwieweit Landnutzungsänderungen auf einer großen Skala etwa kontinentale Klimaänderungen verursachen können, ist nicht einwandfrei geklärt.

Eine extreme und lokalisierte Form der Landnutzung stellt die Verstädterung dar, die zu lokalen „Wärmeinseln” und veränderten Niederschlags- und Windverhältnissen führt. Gemeinsam mit zum Teil dramatischen Erhöhungen der lokalen Emissionen von Schadgasen kommt es in den Städten in verstärktem Maße zu Veränderungen der lokalen Umweltbedingungen. Probleme der Verstädterung einschließlich der möglichen Versorgungsdefizite mit Frischwasser sind besonders ausgeprägt in den so genannten „Megacities” der Schwellen- und Entwicklungsländer.

\subsection{Klimavariabilitåt}

Klima ist nichts Konstantes, es variiert ständig. Ursache hierfür sind zum einen die in Kapitel 1.3 besprochenen Antriebsmechanismen, die ihrerseits ebenfalls Schwankungen unterworfen sind. Andererseits schwankt das Klimasystem auch bei konstanten externen Antrieben. Hintergrund dieses Phänomens ist die innere Dynamik des Klimasystems. So kann zwar ein besonders feuchter Sommer durch eine Häufung einer charakteristischen Wetterlage gedeutet, die Häufung dieser Wetterlage selbst jedoch kann in der Regel nicht erklärt werden.

Über lange Zeit galt die Argumentation über veränderliche externe Faktoren als einzig Akzeptable. Dies erklärt die ungeheure Popularität der Sonnenfleckenzyklen, die seit Jahrhunderten die Menschen fasziniert haben und immer wieder in Relation zu Klimaschwankungen gestellt wurden. Generell ist auch immer wieder versucht worden, Klimaschwankungen als periodische Phänomene zu verstehen. Die Erfindung der harmonischen Analyse, mit der alle Zeitserien in periodische Komponenten zerlegt werden können, ergab eine Flut von angeblichen Periodizitäten, die selbst in einschlägigen Lehr- 
büchern der 1930er Jahre mehrere Seiten füllten. Diese Vorstellungen leben in der Öffentlichkeit weiter und mischen sich immer wieder in die gegenwärtige wissenschaftliche Debatte, so dass man noch in den 1990er Jahren erleben konnte, wie mit Hilfe der harmonischen Analyse Prognosen für mehrere Jahre versucht worden sind.

Inzwischen ist das mathematische Verständnis über das Verhalten komplexer Systeme mit sehr vielen Freiheitsgraden erheblich angewachsen. In den 1960er Jahren wurde klar, dass nichtlineare Systeme wie Atmosphäre, Ozean und damit auch das Klima auf kleinste Störungen hin ein deutlich verändertes Verhalten zeigen können, so dass die Entwicklung dieser Systeme nur für kurze Zeit vorhersagbar ist. Nur wenn ein System wenige Freiheitsgrade hat, ergeben sich zwar komplexe, aber doch regelmäßige Strukturen. Die Klimakomponenten sind aber nicht aus wenigen Komponenten aufgebaut, sondern aus unendlich vielen, in mannigfaltiger Größe und verschiedenster Dynamik, vom Wirbel in der Grenzschicht, dem Kondensationsverhalten in Wolken bis hin zur Möglichkeit, bei gleichem großskaligen Zustand verschiedene Intensitäten z.B. des Golfstroms zu haben. Die Wirkung dieser unendlich vielen Komponenten ist, dass das System in mancher Hinsicht nicht vom mathematischen Konstrukt eines trägen Zufallsprozesses zu unterscheiden ist. Solche Prozesse zeigen nicht nur schnell fluktuierende Schwankungen wie das Wetter, sondern auch teilweise sehr langsame, unregelmäßige Fluktuationen von Jahrzehnt zu Jahrzehnt und länger. Über endliche Zeitintervalle können sich Wetterfluktuationen zufälligerweise zu signifikanten langlebigen Anomalien, z.B. im Ozean, aufaddieren, die erheblich länger andauern als die Wetterfluktuationen selbst. Das Zusammentreffen von schnell und langsam veränderlichen Klimasystemkomponenten bildet die wesentliche Voraussetzung für dieses Verhalten.

Einzelne Zustände in näherer Zukunft - wie das Wetter eines Tages - sind daher nicht vorhersag- bar - wohl aber die langsame Entwicklung statistischer Parameter wie Mittelwert und Standardabweichung wichtiger Klimagrößen (Klima = Statistik des Wetters!), die durch Größen wie Erdbahnparameter, Konzentration von Treibhausgasen etc. beeinflusst werden. Je kürzer die Zeitskala, desto wichtiger die Wirkung der stochastischen Vorgänge, die Schwankungen „ohne Ursache” generieren. In welchem Maße bei längeren Zeitskalen die Bedeutung der Stochastik abnimmt und die der externen Faktoren zunimmt, ist nicht abschließend geklärt.

Die Abbildung 5 zeigt eine Skizze der Variabilität der bodennahen Lufttemperatur in Form eines Spektrums. Ein Spektrum zeigt die Varianz der Schwankungen in Abhängigkeit von einer Zeitskala. Spektren wie in Abbildung 5 sind in vielen Klimaarchiven zu finden. Eine Anzahl von herausragenden Maxima („,peaks”) sind in der Skizze zu erkennen, die als direkte Antwort des Klimasystems auf äußere Klimaantriebe interpretiert werden können, wie z.B. der Tagesgang und der Jahresgang als direkte Reaktion auf den periodischen Antrieb des solaren Energieflusses. Andere Maxima liegen zwischen 100.000 und 20.000 Jahren. Diese werden auf Änderungen in der geographischen Verteilung des solaren Energieflusses aufgrund von Änderungen der Erdbahn um die Sonne zurückgeführt. In realen Klimaarchiven treten neben den hier skizzierten Maxima noch andere auf, die zum Teil mit externen Antrieben, wie z.B. Intensitätsschwankungen des solaren Energieflusses, oder interner Variabilität, sozusagen den Eigenschwingungen des Klimasystems, in Verbindung gebracht werden.

In der Debatte über die Klimavariabilität beobachtet man immer wieder, dass überholte bzw. zu simple Konzepte zur Interpretation herangezogen werden. Hier ist vor allem die schon erwähnte harmonische Analyse zu nennen, aber auch die Theorie nichtlinearer Systeme mit wenigen Freiheitsgraden, die zu Konfusion in der Frage der Vorhersagbarkeit von Klima führt. Ein weiteres Missverständnis ist die leider weit 


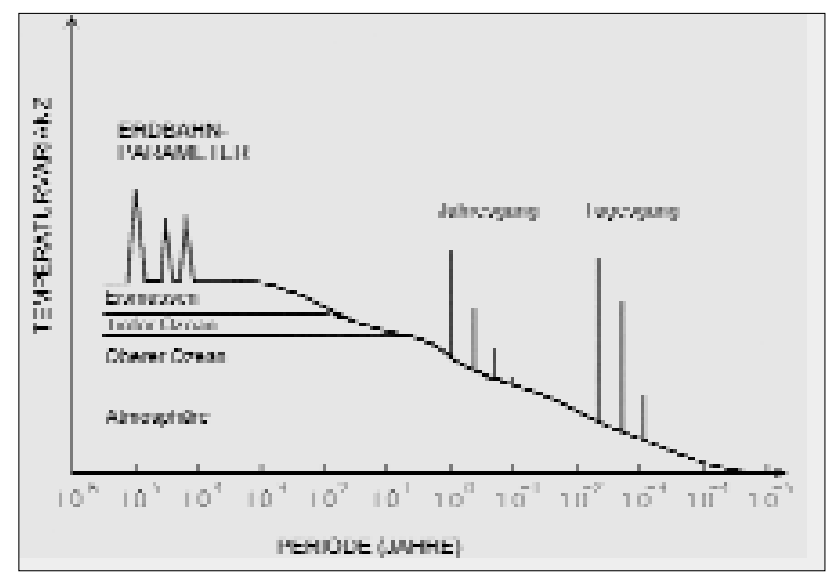

Abbildung 5

Schematische Darstellung des Spektrums atmosphärischer Temperaturvarianz. Quelle: Crowley und North (1992), mit Ergänzungen (Claussen, 2003)

verbreitete Vorstellung, dass es für Wetterextreme, also einzelne Wind- oder Regenstürme oder besonders warme Sommer oder verregnete Winter, eine „Ursache” geben müsse, für die dann allzu oft diverse menschliche Aktivitäten herhalten müssen.

\subsection{Wechselwirkungen im Klimasystem}

Wie in den vorangegangenen Kapiteln ausgeführt, bestimmen verschiedene Prozesse im Klimasystem seine Variabilität und seine Reaktion auf externe Anregungen. Wechselwirkungen können die ursprüngliche Anregung verstärken (positive Rückkopplung) oder dämpfen (negative Rückkopplung). Ihre Darstellung ist deshalb wichtig für die realistische Interpretation der Klimaentwicklung.

Eine wichtige Diskussion in der Klimaforschung ist, inwieweit alle wesentlichen Prozesse berücksichtigt und ob die wesentlichen Wechselwirkungen zwischen diesen Prozessen realistisch beschrieben sind. Man geht heute davon aus, dass die meisten wichtigen Prozesse und Rückkopplungen im Klimasystem bekannt sind und in den Modellen zumindest im Ansatz richtig dargestellt werden. Allerdings gibt es signifikante Kenntnislücken auch bei diesen grundlegenden Prozessen und Wechselwirkungen, wie etwa der Aerosol-Wolken-Wechselwirkung, die zwar qualitativ, aber nicht quantitativ verstanden ist. Trotz dieser positiven Einschätzung kann nicht ausgeschlossen werden, dass einige relevante Prozesse und Wechselwirkungen bisher übersehen worden sind.

Einer der wichtigsten Rückkopplungsmechanismen, der verantwortlich für einen Großteil der Erwärmung ist und den man als Reaktion auf einen Anstieg der atmosphärischen $\mathrm{CO}_{2}$-Konzentration verzeichnet, ist die Zunahme des atmosphärischen Wasserdampfes. Mit dem Anstieg der Temperatur in der Atmosphäre erhöht sich auch ihre Fähigkeit, Wasserdampf aufzunehmen. Da Wasserdampf ebenfalls ein Treibhausgas ist, könnte es damit, unabhängig von der Wolkenbildung, zu einer positiven Rückkopplung kommen.

Klima wird auch in erheblichem Maße durch Wolken beeinflusst. Die Wolkenbildung und die Strahlungseigenschaften der Wolken hängen von der Verteilung des Wasserdampfes, der Wassertröpfchen, der Eispartikel und der Aerosole ab.

Eine Erwärmung der Atmosphäre hat einen Einfluss auf den Grad der Wolkenbedeckung und die Höhe der Wolken. Bei höheren Temperaturen können Wolken austrocknen und sich auch teilweise auflösen. Damit ist aber der Weg für eine effizientere Emission von Infrarotstrahlung in den Weltraum frei, es findet also eine Abkühlung statt - somit hätte man eine negative Rückkopplung. Gleichzeitig nimmt jedoch die Sonneneinstrahlung zu, die vom Klimasystem der Erde aufgenommen wird, da weniger Wolken sie reflektieren. Es gibt keine einfache Methode, zu bestimmen, welche Rückkopplung überwiegt. Durch eine generelle Erwärmung ist darüber hinaus die Verschiebung einer Wolkenschicht in höhere und damit auch kältere Regionen möglich. Kältere Wolken emittieren andererseits weniger langwellige Strahlung (= Wärme) als wärmere, das heißt, es bleibt durch diesen Effekt mehr Wärme im System. Hier käme es also zu einer positiven Rückkopplung. 
Es wird vermutet, dass durch die globale Erwärmung auch der so genannte Thermostateffekt ausgelöst werden könnte. Durch die zunehmende Konvektion in den Tropen bei einer globalen Erwärmung kommt es zu der Ausbreitung eines Cirrusschirmes, an dem die eingehende Solarstrahlung reflektiert wird. Dieses führt zu einer Abkühlung und damit zu einer negativen Rückkopplung. Auch die Wechselwirkung zwischen Aerosolen und Wolken ist wichtig: Mehr Aerosole können zu kleineren Wolkentröpfchen und damit zu einer Erhöhung der Albedo führen.

Wolken sorgen über Konvektion außerdem für eine Umverteilung des Wasserdampfes in der Erdatmosphäre und beeinflussen in großem Maße die vertikale Temperaturverteilung. Hiermit spielen die Wolken in die Wasserdampfrückkopplung mit hinein.

Insgesamt sind die Rückkopplungen bei Wolken sehr komplex, da sie positive und negative Vorzeichen annehmen können. Summiert man über alle Effekte, so kommt man nach dem derzeitigen Erkenntnisstand auf eine leicht positive Rückkopplung.

Auch Änderungen in der Stratosphäre und die in ihr ablaufenden dynamischen, chemischen und strahlungsbedingten Vorgänge beeinflussen das Klimasystem. Umgekehrt haben auch Veränderungen im Klimasystem einen Einfluss auf die Stratosphäre und insbesondere auf den Ozongehalt. Seit nunmehr zwei Jahrzehnten nimmt der Ozongehalt der Stratosphäre systematisch ab mit den größten Veränderungen in den Polarregionen. Diese Ozonveränderungen haben auch zu einer Kühlung der Stratosphäre geführt, die wiederum zu einer veränderten Dynamik des Austausches zwischen Stratosphäre und Troposphäre führen kann. Umgekehrt wandern dynamische Wellen, die in der Troposphäre erzeugt werden, in die Stratosphäre. Das Ausmaß dieser Wellenanregung ist auch von der Temperaturstruktur der Troposphäre abhängig und damit kann eine Klimaänderung auf die
Struktur und Dynamik der Stratosphäre zurückwirken.

Wegen seiner großen thermischen Trägheit, seiner Speicherfähigkeit und seiner Effizienz im meridionalen Transport ist der Ozean ein wesentlicher Faktor im Klimageschehen. Das El Niño-Phänomen, das mit signifikanten Wetteranomalien in den Tropen auf der Skala von wenigen Jahren einhergeht und so direkt vom Menschen erfahren wird, beruht auf Veränderungen in der Zirkulation des tropischen Pazifik, die über eine positive Rückkopplung mit der Atmosphäre verbunden sind. Die thermohaline Zirkulation im Atlantik (THC $\left.{ }^{*}\right)$ ist verantwortlich für den größten Teil des meridionalen ozeanischen Wärmetransportes. Dieses kann Auswirkungen auf das regionale und globale Klima haben, auch auf dekadischen und JahrhundertZeitskalen. Auch ist der Ozean ein ganz wesentlicher Speicher für anthropogenes $\mathrm{CO}_{2}$. Generell gibt es wenig Kontroversen innerhalb der Wissenschaft über die Rolle des Ozeans im Klimasystem, wohl aber viele offene Fragen. Solche Fragen betreffen etwa die Konvektion, die Anbindung von Randmeeren (z.B. Mittelmeer) an die großen Becken und auch den Einfluss der Temperatur auf die Speicherfähigkeit für anthropogenes $\mathrm{CO}_{2}$. Ein kritischer Aspekt ist aber die Rolle der Wirbel im Ozean auf längeren Zeitskalen, die bisher nur über kürzere Zeiten und für regionale Meere untersucht wurden. Von der Beantwortung wird aber keine wesentliche Veränderung der bisherigen Einschätzung der Klimarelevanz des Ozeans erwartet.

\footnotetext{
*) Die THC wird durch Dichteunterschiede, die durch Temperatur- und Salzgehaltseffekte hervorgerufen werden, angetrieben. Im Nord-Atlantik fließt warmes Wasser an der Oberfläche nach Norden und kaltes Wasser in der Tiefe gen Süden. Die THC wird durch Veränderungen in ihrer Dichtestruktur, die durch Niederschlagsänderungen, Verdunstungsänderungen, durch geänderten Süßwasserzustrom aus Flüssen, durch Meereisveränderung und veränderten Wärmeaustausch hervorgerufen werden, beeinflusst.
} 
Die Gegenden der Erde, die jahreszeitlich oder ganzjährig von Schnee und Eis bedeckt sind, werden unter dem Begriff der Kryosphäre zusammengefasst. Meereis ist wichtig, weil es die einfallende Solarstrahlung stärker reflektiert als die Meeresoberfläche, und es isoliert den Ozean gegen den Wärmeverlust an die Atmosphäre während des Winters. Eine Verringerung der Meereisbedeckung führt also zu einer positiven Rückkopplung. Da das Meereis auch weniger Salz enthält als das Meerwasser, nimmt in den obersten Schichten der Salzgehalt bei der Bildung von Meereis zu. Dieses führt zu einem vermehrten Austausch des Oberflächenwassers mit den Wassermassen des tiefen Ozeans und beeinflusst damit die gesamte ozeanische Zirkulation. Das Abbrechen von Eisbergen und Abschmelzen des Schelfeises bringen Süßwasser zurück in den Ozean. Eine Änderung in diesen Prozessen verändert den Salzgehalt im Ozean und kann die Ozeanzirkulation modifizieren.

Etwa 25\% der Landoberfläche wird von bis zu $1,5 \mathrm{~km}$ mächtigem und vermutlich weiträumig gashydrathaltigem Permafrost unterlagert. Die größten Permafrostgebiete finden sich im nördlichen Eurasien und Nordamerika. Über die Geschichte seiner Bildung ist nur wenig bekannt. In weiten Gebieten Nordeurasiens und -amerikas scheint er derzeit langsam zu zerfallen, was zu schneller Erosion entlang der Küsten und einer Aufweichung der Landoberflächen mit entsprechender Zerstörung der technischen Infrastruktur in menschlich genutzten Gebieten führt. In welchem Umfang das Treibhausgas Methan aus pedogenen Stoffumsätzen oder aus dem Zerfall von Gashydraten freigesetzt werden kann, ist zur Zeit Gegenstand umfangreicher Forschungsprojekte.

Die Wechselwirkung der Atmosphäre mit Landoberflächen und Böden erfolgt auf zwei unterschiedlichen Wegen: Prozesse, die die bodennahen Energie-, Massen- und Impulsflüsse direkt beeinflussen, also etwa Änderungen der Vegetationsbedeckung und Vegetationsstruktur, werden als biogeophysikalische Wechselwirkungen bezeichnet. Diese wirken sich über die Änderung des Reflexionsvermögens solarer Strahlung (Albedo) auf die Strahlungsbilanz oder über die Änderung der Rauhigkeit der Landoberfläche auf die Verdunstung und den vertikalen Fluss fühlbarer Wärme aus.

Austauschprozesse zwischen Atmosphäre und Oberfläche, die die chemische Zusammensetzung der Atmosphäre ändern, sind biogeochemische Wechselwirkungsprozesse. Dazu zählen insbesondere der Austausch von Treibhausgasen wie $\mathrm{CO}_{2}$ und $\mathrm{CH}_{4}$. Biogeophysikalische und biogeochemische Prozesse wirken in der Natur zusammen. So ändert sich z.B. mit der Photosynthese nicht nur der $\mathrm{CO}_{2}$-Austausch, sondern auch die Transpiration, also der Wasserdampffluss aus der Biosphäre in die Atmosphäre. Beide Prozesse werden von der Vegetation über die Blattöffnungen (die Stomata) gesteuert, wobei diese Steuerung auch als Rückkopplungsprozess anzusehen ist, da die Blattöffnungen auf das Lichtangebot, also Sonnenstand und Bewölkung, und den momentanen Zustand der bodennahen Luftschicht, im Wesentlichen die Trockenheit oder Wasserdampfaufnahmefähigkeit der Luft, und das Wasserangebot der oberflächennahen Bodenschicht reagiert.

Im letzten Sachstandsbericht des IPCC wurde den biogeophysikalischen und biogeochemischen Wechselwirkungsprozessen im Klimasystem sowie dem Einfluss von Landnutzungsänderungen auf die Klimadynamik im Vergleich zu anderen Klimaprozessen relativ wenig Beachtung geschenkt. Neuere Berichte, insbesondere der sich in Veröffentlichung befindliche Synthesebericht des IGBP-Kernprojektes BAHC, zeigen jedoch, dass Änderungen der Landoberflächen erhebliche Auswirkungen zumindest auf das regionale, aber vermutlich auch das globale Klima haben, die der Größenordnung nach denen durch Emission von Treibhausgasen angeregten gleich kommen können.

Von großer Bedeutung für das Klimasystem ist der Kohlenstoffkreislauf. An diesem sind als 
klimawirksame Gase das $\mathrm{CO}_{2}$ und das Methan beteiligt. Beide sind über ihre biogeochemischen Zyklen an die marinen und terrestrischen Quellen gekoppelt.

Die Anreicherung von $\mathrm{CO}_{2}$ in der Atmosphäre hängt davon $\mathrm{ab}$, wie viel $\mathrm{CO}_{2}$ in die Atmosphäre emittiert und wie viel von der Landoberfläche und der Ozeanfläche aufgenommen wird.

Die anthropogene Kohlendioxidemission, die aus der Verbrennung von fossilen Energieträgern, der Zementproduktion und der sich ändernden Landnutzung resultiert, beträgt derzeit ca. 30 Mrd. Tonnen Kohlendioxid oder ca. 8 Mrd. Tonnen Kohlenstoff pro Jahr. Von diesem zusätzlichen Kohlendioxid verbleiben heute ca. $40 \%$ in der Atmosphäre, ca. $60 \%$ werden durch Senken wie die Ozeane und die Landvegetation aufgenommen.

Es existieren allerdings große Unsicherheiten über die jährlichen Mengen, die z.B. von den Ozeanen aufgenommen werden. Ozeanographische und atmosphärische Messungen sowie ergänzende Modellierungen legen nahe, dass die jährliche Aufnahme von anthropogenem $\mathrm{CO}_{2}$ hoch variabel ist und im Zeitraum 1990 bis 1999 zwischen jährlich 2 und 9 Mrd. Tonnen geschwankt hat. $\mathrm{CO}_{2}$ wird auch durch Landökosysteme aufgenommen, wobei die borealen Wälder der Nordhemisphäre eine herausragende Rolle einnehmen. Wie groß die Menge des aufgenommenen anthropogenen Kohlendioxids tatsächlich ist, lässt sich zur Zeit nur ungenügend abschätzen. Derzeit deuten forstwirtschaftliche Befunde auf eine Zunahme des jährlichen Holzwachstums hin und Satellitenbeobachtungen zeigen eine stärkere Begrünung der nordhemisphärischen Wälder seit 1980, beides möglicherweise Auswirkungen des vermehrten Stickstoffeintrages, aber auch der so genannten Kohlendioxiddüngung und der Temperaturzunahme. Im Verlauf der letzten 150 Jahre ist generell eine Zunahme der Senkenstärke zu verzeichnen. Es ist derzeit aber noch unklar, ob dieser Trend auch in der Zukunft anhalten wird.
Die im Boden vorhandene Biomasse (Humus und anderes organisches Material) wird auf mindestens das Vierfache der oberirdischen Vegetation geschätzt. Anthropogene Einflüsse, z.B. durch Bewirtschaftung von Böden und vermehrten Eintrag von Stickstoff, führen zu einer Änderung der terrestrischen Senkenstärke. Mit der landwirtschaftlichen Bodenbearbeitung (wie dem Pflügen) setzt z.B. eine Zersetzung der organischen Bodensubstanz ein, die zu einer Reduzierung der ursprünglichen Menge des organischen Materials von bis zu $40 \%$ führen kann. Hierdurch gelangen entsprechende Mengen Kohlendioxid in die Atmosphäre. Ein entscheidender Unsicherheitsfaktor bei der Abschätzung von Senken in der Landbiosphäre ist die Reaktion der Abbauprozesse im Boden auf Klimaänderung, Kohlendioxidanstieg und Stickstoffeintrag.

Aufgrund dieser in den obigen Abschnitten aufgeführten Unsicherheiten bei der Berechnung der Kohlendioxidflüsse kann die Verweildauer von $\mathrm{CO}_{2}$ in der Atmosphäre, wie im Kapitel 1.3 erwähnt, nur auf 50-200 Jahre grob abgeschätzt werden.

Die Klimarelevanz der erst kürzlich entdeckten „tiefen Biosphäre” in den oberen Schichten der Erdkruste ist bisher nicht Gegenstand der Forschung gewesen. Die jüngsten Ergebnisse aus Tiefseebohrungen deuten darauf hin, dass die Menge lebender organischer Materie innerhalb der tiefen Biosphäre derjenigen der terrestrischen und ozeanischen Biomasse nahe kommt. Über ihre Energie- und Stoffumsätze ist jedoch kaum etwas bekannt, obwohl vermutet wird, dass sie relativ langsam sind. Ebenso unbekannt und unverstanden sind Phänomene wie das Austreten von Methan aus dem Erdmantel.

Eine weitere Komponente des Kohlenstoffkreislaufs bildet das Methan. Es kann bei einem schnellen Klimaübergang einen Risikofaktor darstellen, weil Methanhydrate, die gefroren im Kontinentalschelf und in der Tundra gebunden sind, bei einer hinreichend großen globalen 
Erwärmung freigesetzt werden können. Dies betrifft besonders die Methanreserven der Tundra. Ein Teil des Methans wird in einem solchen Fall zwar im Tundraboden durch bakterielle Umsetzung in Kohlendioxid umgewandelt, jedoch könnte das restliche Methan als Spurengas in die Atmosphäre gelangen. Letzteres könnte zu einer weiteren Temperaturerhöhung führen, da Methan ein starkes Treibhausgas ist.

Der bei weitem größte Anteil der Hydratvorkommen liegt im Bereich der marinen Kontinentalränder, wo schnelle Sedimentationsraten und ein hoher Gehalt an organischem Material für die erforderliche (überwiegend bakterielle) Methanbildung hinreichende Bedingungen schaffen. Tektonische Bewegungen wie auch Änderungen des Meeresspiegels führen zu Verschiebungen des Stabilitätsfeldes der marinen Methanhydrate, so dass auf diese Weise große Mengen an Methan freigesetzt werden können. Es ist derzeit aber noch nicht abschätzbar, ob die aus marinen Sedimenten freigesetzten Methanmengen in ihrer Gesamtheit atmosphärenwirksam werden oder ob oxidierende bakterielle Prozesse im Sediment oder in der Wassersäule den Methanfluss in die Atmosphäre dämpfen oder gar unterbinden. Auch lassen sich die Geschwindigkeiten dieser Prozesse nach dem bisherigen Kenntnisstand nur ungenau einschätzen.

Die Wechselwirkungsprozesse zwischen den Klimasystemkomponenten sind im Allgemeinen nicht-lineare Ereignisse, d.h. das Klimasystem reagiert disproportional auf eine Antriebsänderung. Insbesondere sind plötzliche schnelle Klimaänderungen möglich, ebenso wie verschiedene Gleichgewichtszustände, die mit ein und derselben gegebenen Konfiguration von Antrieben vereinbar sind.

In den Klimaarchiven finden sich zahlreiche Hinweise auf rasche Klimaänderungen, die als nicht-lineare Ereignisse oder nicht-lineare Reaktionen auf Antriebsänderungen interpretiert werden können. Dazu zählen die so genannten
Dansgaard-Oeschger-Zyklen und Heinrich-Ereignisse während des letzten Glazials, die mit Änderungen der Jahresmitteltemperatur von mehreren Grad innerhalb weniger Jahre oder Jahrzehnte einhergehen. Dansgaard-OeschgerZyklen werden als rasche Übergänge in der thermohalinen Zirkulation und damit des meridionalen Wärmetransports im Atlantik interpretiert. Die Heinrich-Ereignisse werden auf das Kalben größerer Inlandeismassen des nordamerikanischen (laurentidischen) Eisschilds zurückgeführt. Während das Inlandeis sich über mehrere Jahrtausende aufbaut, geschieht das Kalben größerer Eismengen wesentlich schneller, innerhalb weniger Jahrhunderte oder gar Jahrzehnte, sobald das Inlandeis eine kritische vertikale Mächtigkeit erreicht hat.

Auch die Verschiebung von Vegetationszonen kann im Vergleich zu den das Klima antreibenden Prozessen rasch verlaufen. So deuten Rekonstruktionen der Vegetationsbedeckung Westafrikas auf eine schnelle Ausdehnung der Sahara (auf ihren heutigen Umfang) vor etwa 5.500 Jahren hin. Dagegen hat sich der externe Antrieb, im Wesentlichen die durch die Erdbahn um die Sonne bestimmte solare Strahlung und damit der Temperaturkontrast zwischen Kontinent und Ozean, der den Sommermonsun steuert, während der letzten Jahrtausende stetig und allmählich geändert.

\subsection{Klimamodelle}

Um die sehr komplexen Wechselwirkungen des Klimasystems zu verstehen und um quantifizierbare Aussagen über das zukünftige Klima zu machen, werden Klimamodelle entwickelt. Solche Klimamodelle sind mit der Zunahme der Leistungsfähigkeit der Computer immer komplexer geworden (siehe Kasten „Klimamodelle“).

Die Reaktion der Öffentlichkeit auf Klimamodelle ist sehr unterschiedlich. Sie reicht von blindem Vertrauen - ob des Einsatzes effizienter Rechenmethoden - bis zu großem Misstrauen ob des Verlustes an Durchschaubarkeit und die 
ständig erfahrene Wahrnehmung, dass meteorologische Ereignisse, wie z.B. das Wetter, grundsätzlich nur innerhalb gewisser Erwartungswerte und innerhalb gewisser Zeitskalen vorausgesagt werden können. Dieses wird dadurch verständlich, dass in der Laien- und Wissenschaftssprache der Begriff „Modell” vielseitig verwendet wird. Jede Disziplin hat einen anderen Begriff; so nennen Physiker Vorformen von Theorie ein „Modell”; für einen Ceologen ist auch eine kartographische Darstellung ein „Modell”, für einen Statistiker die Annahme einer Verteilung, und für viele ist es im Wesentlichen ein an empirisch erhobene Daten angepasstes Regressionsmodell. In der Klimaforschung ist ein Klimamodell eine mehr oder weniger gute mathematische Beschreibung des Klimasystems. Es darf dabei aber nicht mit der Realität verwechselt werden.

In der Klimaforschung werden zwei verschiedene Arten von Modellen verwendet. Zum einen stark vereinfachende konzeptionelle Modelle, die komplexe Vorgänge auf einige wenige dominierende Sachverhalte reduzieren. Zu diesen Modellen gehört das so genannte Energiebilanzmodell. Mit ihm kann die Temperatur in Bodennähe berechnet werden, wenn z.B. die einfallende Sonnenstrahlung und die Wärmeabstrahlung der Erde sowie eine absorbierende und abstrahlende Atmosphäre mit seinen Treibhausgasen die einzigen bestimmenden Prozesse wären. Um ein realitätsnäheres Bild zu bekommen, werden daher in einer zweiten Art von Modellen möglichst viele Prozesse gleichzeitig berücksichtigt (siehe Kasten). Diese Modelle basieren auf Wettervorhersagemodellen, deren horizontale Auflösung reduziert worden ist, um mit der verfügbaren Rechnerkapazität auszukommen, und in die zusätzliche Komponenten wie Ozean und Biosphäre eingebaut worden sind, um Klimafragen behandeln zu können. Derartige Modelle repräsentieren eine Art „Ersatzrealität”, ein „virtuelles Labor”, in dem die anderweitig unmöglichen Experimente mit dem Klimasystem durchgeführt werden können.
Simulationen mit solchen Modellen werden „numerische Experimente” genannt. Die Vorbereitung, Durchführung und Bewertung solcher Experimente erfordert ähnliches Geschick wie die Durchführung „richtiger” Laborexperimente, in denen ja auch anhand idealisierter „Modelle” das Verhalten realer Systeme nachempfunden wird. In den letzten Jahrzehnten sind Modelle der Hauptkomponenten des Klimasystems (Atmosphäre, Ozean, Meereis, Landoberflächen) individuell entwickelt und zusammen geführt worden. Die weitere Entwicklung und die Kopplung der Modellsysteme ist aber immer noch Gegenstand der Forschung.

Wie in Kapitel 1.5 bereits angesprochen, haben viele Aspekte des Klimasystems eine chaotische Natur. Seine Entwicklung hängt stark von kleinen Störungen in den Anfangsbedingungen des Systems ab. Diese Sensitivität begrenzt die Simulation der detaillierten Entwicklung des Wetters auf etwa zwei Wochen. Die Vorhersagbarkeit des Klimageschehens ist nicht so begrenzt, da hier die langsam veränderlichen Anteile des Klimasystems dominieren. Um die Modellunsicherheiten und die Anfangswertproblematik festzustellen, ist es notwendig, mehrere Klimasimulationen von verschiedenen Anfangsbedingungen und mit verschiedenen Modellen durchzuführen. Ein derartiges Ensemble ergibt die Grundlage für eine Wahrscheinlichkeitsabschätzung einer Klimaänderung.

Vollständige Klimamodelle sind sehr komplex und stellen große Anforderungen an die Rechenleistung. Um verschiedene Szenarien und die Sensitivität auf verschiedene Parameter auszutesten, werden vereinfachte Modelle eingesetzt. Diese Vereinfachungen können in größeren Gitterabständen und Vereinfachungen in den physikalischen und dynamischen Prozessen bestehen. Diese vereinfachten Modelle, Modelle mittlerer Komplexität und komplexe Modelle formen eine Hierarchie, die notwendig ist, die Klimamodelle vollständig auszutesten. 


\section{KLIMAMODELLE}

Die komplexen Klimamodelle basieren auf wohlbekannten physikalischen Gesetzen (Bewegungsgleichungen nach Newton, 1. und 2. Hauptsatz der Thermodynamik, Gasgleichung, Kontinuitätsgleichung), die auf einem drei-dimensionalen Gitter, das den Globus umspannt (wie z.B. in Abb. 6), gelöst werden. Für Klimasimulationen müssen die einzelnen Klimasystemkomponenten (Atmosphäre, Ozean, Landoberflächen, Kryosphäre und Biosphäre) sowie die gegenseitigen Wechselwirkungen berechnet werden. Für die Berechnung der Atmosphäre benutzt man in der Praxis häufig Wettervorhersagemodelle, die für Fragestellungen der Klimaforschung angepasst wurden. Diese Modelle haben den Vorteil, dass sie tagtäglich eingesetzt werden, die Programme also gut ausgetestet sind. Im Gegensatz zu der Wettervorhersage berechnet man bei Klimaprojektionen nicht das vom Anfangszustand abhängige Wetter der nächsten 3 bis 7 Tage, sondern die Änderung des Klimas, d.h. das statistische Mittel über viele Wetterereignisse, als Reaktion auf Veränderungen der Randbedingungen.

Die meisten Modelle enthalten zwar eine Darstellung aller Klimasubsysteme und der wichtigen Prozesse, aber teilweise nur in vereinfachter Form. In globalen Klimamodellen sind Atmosphären- und Ozeanmodelle gekoppelt worden. In dem Atmosphärenmodell werden z.B. Gleichungen gelöst, die die großskalige Entwicklung und den Transport von Impuls (Wind), Wärme und Feuchtigkeit beschreiben. Ähnliche Gleichungen werden im Ozean berechnet. Zur Zeit liegt die Auflösung der atmosphärischen Komponente der Modelle bei $250 \mathrm{~km}$ in der Horizontalen und $1 \mathrm{~km}$ in der Vertikalen (oberhalb der bodennahen Grenzschicht, die höher aufgelöst wird). Die typische Auflösung eines Ozeanmodells liegt bei 200 bis $400 \mathrm{~m}$ in der Vertikalen und bei 125 bis $250 \mathrm{~km}$ in der Horizontalen. Die Gleichungen werden etwa in halbstündigen Zeitschritten gelöst. Viele Prozesse, wie z.B. Wolkenbildung oder Ozeankonvektion, finden auf kleineren Skalen als die Modellgitterabstände statt und können deshalb nicht explizit berechnet werden. Ihr mittlerer Effekt wird durch eine auf physikalischen Prinzipien beruhende Beziehung zwischen der großräumigen Strömung und diesen Vorgängen dargestellt, man spricht hier von Parametrisierung.

Klimasimulationen werden nach folgender Strategie durchgeführt:

Zuerst wird eine Kontrollsimulation mit dem Modell berechnet, die das heutige Klima widerspiegelt. Hier wird das Modell mit den derzeit herrschenden Bedingungen verglichen. Dann wird ein Klimaänderungsexperiment durchgeführt, z.B. mit einem Anstieg der Kohlendioxidkonzentra-
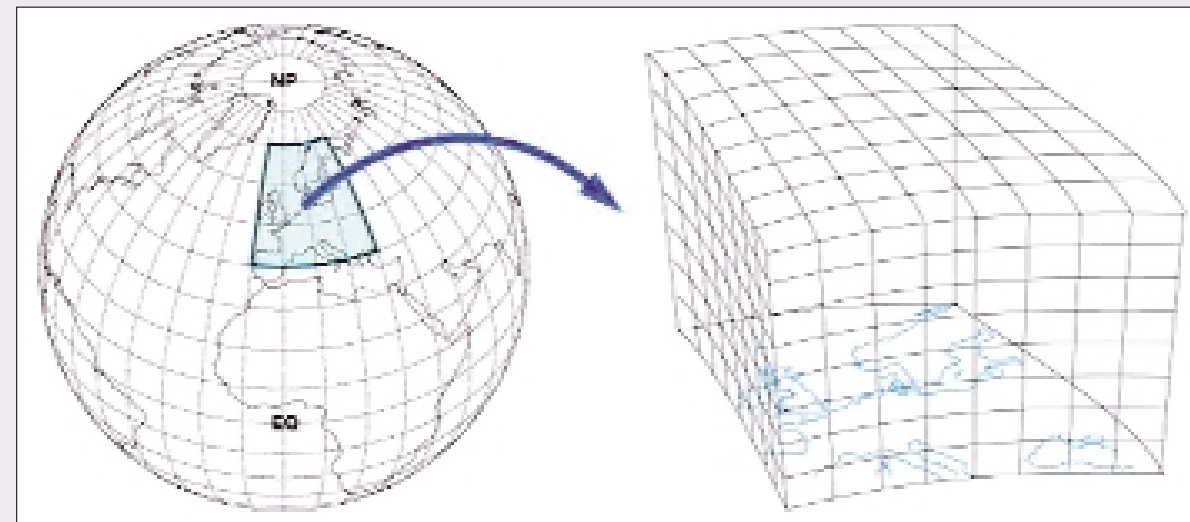

Abbildung 6

Das Gitter in einem

Atmosphärenmodell 
tion in der Atmosphäre. Beide Simulationen werden zueinander in Beziehung gesetzt, um die Klimaänderung zu bestimmen. Dieses Verfahren führt man nicht nur einmal durch, da es sich nicht um eine Vorhersage im klassischen Sinne handelt, sondern mit möglichst vielen Hochrechnungen, um ein statistisches Ensemble und damit auch eine Aussage über die Unsicherheit zu erhalten.

Dieses Verfahren liegt z.B. der Abb. 12 zugrunde, in der die Modellunsicherheit, die durch viele Modellexperimente abgeschätzt wurde, durch ein graues Band dargestellt wird. Es ist grundsätzlich unmöglich, eine genauere Aussage zu treffen, da die Modelle keine deterministische Aussage machen können. Man kann nur eine Wahrscheinlichkeitsdichtefunktion berechnen, die mit zunehmender Anzahl der Simulationen aussagekräftiger wird.

Derzeit arbeitet man an der Ankopplung des Kohlenstoffkreislaufs über Land und in den Ozeanen. Die chemischen Wechselwirkungen werden gerade in die Klimamodelle eingebracht, aber es liegen noch keine gekoppelten Klimahochrechnungen mit einem derartigen Modell vor. Letztendlich möchte man so viele Aspekte des Klimasystems wie möglich einbauen, so dass alle Komponenten miteinander in Wechselwirkung treten können.

Klimamodelle bilden das Klimasystem in mathematischen Gleichungen ab, die zum großen Teil auf physikalischen Gesetzen beruhen, aber auch semi-empirische Komponenten enthalten. Sie bilden die einzige Möglichkeit, zukünftige Entwicklungen des Klimas abzuschätzen. Dass sie das heutige und historische Klimageschehen realistisch wiedergeben, gibt Vertrauen in ihre Fähigkeit, zukünftige Klimaentwicklungen zu simulieren. Allerdings hängt die Güte der Modellergebnisse auch entscheidend von den Eingabegrößen ab. So ist z.B. die Prognose der Entwicklung der anthropogenen $\mathrm{CO}_{2}$-Emissionen unsicher.

\subsection{Resumée}

\section{- Was ist Klima und warum verändert es sich ständig?}

Klima wird allgemein als Statistik des Wetters definiert. In der Klimaphysik wird der Begriff jedoch weiter gefasst und das Klima als Statistik des gesamten Klimasystems (Atmosphäre, Biosphäre, Eismassen, Ozean) aufgefasst. Klima wird durch eine Vielzahl von internen und externen Prozessen „angetrieben”. Änderungen sol- cher Antriebe, wie z.B. in der Stärke des solaren Energieflusses oder in der geographischen Verteilung des solaren Energieflusses, die durch die Änderung der Erdbahn um die Sonne bedingt sind, machen sich proportional (linear) oder disproportional (nicht-linear) in Klimaänderungen bemerkbar. Die verschiedenen Komponenten des Klimasystems haben ihre eigenen charakteristischen Zeitskalen. Sie sind durch Energie-, Impuls- und Stoffkreisläufe miteinander gekoppelt. Dies führt auch bei konstanter Änderung des Antriebs, wie zum Beispiel dem Jahresgang des solaren Energieflusses, zu interner, vom Klimaantrieb scheinbar entkoppelter Klimavariabilität.

\section{- Was bedeutet die globale Mitteltemperatur?}

Die globale Mitteltemperatur wird durch die Interpolation von Temperaturmessungen an einzelnen Klimastationen auf großräumige Temperaturmuster berechnet, aus denen schließlich durch Flächenmittelung die Mitteltemperatur gewonnen wird. Aufgrund der zeitlichen und räumlichen Zunahme von Temperaturmessun- 
gen im letzten Jahrhundert ist die globale Mitteltemperatur heute eine gut zu bestimmende Größe. Für viele Klimaprozesse, wie zum Beispiel für den Treibhauseffekt, ist die Änderung der globalen Mitteltemperatur der vielleicht wichtigste Indikator.

\section{- Sind Extremereignisse wie z.B. Hochwasser Anzeichen für einen Klimawandel?}

Einzelne Wetterereignisse, also auch einzelne extreme Ereignisse, sind für sich genommen keine Anzeichen für einen Klimawandel. Erst, wenn sich die Statistik der Extremereignisse ändert, spricht man von einem Klimawandel. Eine globale Zunahme extremer Niederschläge als Folge der Zunahme der bodennahen, global gemittelten Lufttemperatur ist physikalisch zwar plausibel; eine allgemein anerkannte Theorie steht wegen der Unsicherheit der Klimamodelle bezüglich der Beschreibung von extremen Niederschlägen jedoch noch aus. Tatsächlich zeigen statistische Untersuchungen von Niederschlagsintensitäten in einigen Regionen der Welt, wie z.B. in den USA oder an der Station Hohenpeißenberg (Bayern) des Deutschen Wetterdienstes, dass die Häufigkeiten von Extremniederschlägen kaum oder nicht mit der bodennahen Temperatur korreliert sind. Dies widerspricht aber nicht der physikalisch plausiblen Erwartung solcher Korrelationen, da sich diese nicht notwendigerweise auch regional einheitlich ausprägen.

\section{- Gibt es einen Treibhauseffekt?}

Der natürliche Treibhauseffekt ist das natürliche Lebenselixier auf der Erde. Ohne die natürlichen Treibhausgase (Wasserdampf, $\mathrm{CO}_{2}, \mathrm{CH}_{4}$, Ozon, $\mathrm{N}_{2} \mathrm{O}$ ) läge die bodennahe globale DurchschnittsTemperatur der Luft nur bei $-18^{\circ} \mathrm{C}$ anstelle der tatsächlichen $+15^{\circ} \mathrm{C}$. Dem natürlichen Treibhauseffekt überlagert ist der anthropogene Treibhauseffekt. Dieser entsteht dadurch, dass zusätzlich Treibhausgase wie $\mathrm{CO}_{2}, \mathrm{CH}_{4}$ oder FCKW in die Atmosphäre eingebracht werden.
Allein die $\mathrm{CO}_{2}$-Konzentration ist seit Beginn der Industrialisierung von ca. 280 ppm auf 370 ppm angestiegen.

\section{- Wie wirken sich Wasserdampf, $\mathrm{CO}_{2}$, Wolken und Aerosole aus?}

Der Gehalt an Wasserdampf in der Atmosphäre nimmt zu, wenn es wärmer wird. Da Wasserdampf ein Treibhausgas ist, wird also der Treibhauseffekt verstärkt. Zur Zeit wird dagegen noch kontrovers diskutiert, ob und in welchem Ausmaß Wolken den anthropogenen Treibhauseffekt verstärken. Es hängt davon ab, in welcher Höhe sie auftreten, welche Fläche sie überdekken und wie stark die Aerosole auf die Wolkenbildung Einfluss nehmen. Aerosole, wie z.B. die Sulfatteilchen, dämpfen den Treibhauseffekt aufgrund der verstärkten Rückstreuung der Sonnenstrahlung. Bei Rußaerosolen geht man von einer erwärmenden Wirkung aus - aber auch hier sind die Unsicherheiten groß.

\section{- Wie groß ist der Anteil natürlicher Faktoren (Z.B. Sonne) am Klimawandel?}

Nach allem, was man über die beteiligten Strahlungsprozesse heute weiß, und aufgrund der physikalischen Interpretation vergangener Klimaänderungen (siehe Kapitel 2) waren Schwankungen des solaren Energieflusses und der Vulkanaktivität die wichtigsten Antriebsfaktoren für Klimaänderungen der letzten Jahrhunderte. Über längere Zeiträume von Hunderttausenden von Jahren spielt die Änderung der Erdbahn um die Sonne und die damit verbundene Änderung in der geographischen Verteilung des solaren Energieflusses eine dominierende Rolle.

\section{- Wie groß ist der Anteil des Menschen am Klimawandel?}

Nach dem gegenwärtigen Kenntnisstand müssen wir davon ausgehen, dass die Klimaänderung des letzten Jahrhunderts sowohl durch natürliche Faktoren als auch durch den Menschen verursacht worden ist. Während der letz- 
ten drei Jahrzehnte wird vermutlich der Beitrag des Menschen sogar dominant gewesen sein. Die wesentlichen Ursachen sind die Emissionen von Treibhausgasen und Aerosolen sowie die veränderte Landnutzung.

\section{- Was sind Klimamodelle?}

Die im Klimasystem ablaufenden Prozesse werden in Klimamodellen mittels mathematischer Gleichungen dargestellt. Sie sind die einzige Möglichkeit, auch zukünftige Klimabedingungen vorauszusagen. Klimamodelle sind modifizierte, auf Klimabedingungen angepasste Wettervorhersagemodelle. Fehler entstehen einerseits dadurch, dass bestimmte Prozesse, die im Klimasystem ablaufen, noch unzureichend verstanden sind, und andererseits, weil wegen der beschränkten Rechnerkapazitäten die Lösung der Gleichungen mathematisch nicht exakt ist. Zusätzliche Einschränkungen in der Abbildung des Klimas kommen aus der chaotischen Natur des Klimasystems selbst.

\section{WIE SAH DAS KLIMA IN DER ERDGESCHICHTE SOWIE IN DEN LETZTEN 100 JAHREN AUS?}

Klima und Klimaänderungen hat es während der gesamten geologischen Geschichte des Planeten Erde gegeben. Sie haben ihren Niederschlag in den Fossilien und Gesteinen aller Perioden der Erdgeschichte gefunden. Während der letzten Millionen Jahre sind globale Klimaeigenschaften zusätzlich in den großen Eisschilden der Antarktis und Arktis dokumentiert worden. Die Untersuchung des Klimas in der geologischen Vorzeit ist von großem Interesse, weil damals - im Gegensatz zu den letzten 150 Jahren - Klimaänderungen ausschließlich auf natürliche Ursachen zurückzuführen waren.

\subsection{Informationen aus Klimaarchiven und historischen Klimaaufzeichnungen}

Viele Eigenschaften des Klimas lassen sich aus seiner Geschichte ableiten, die in so genannten geologischen Archiven bewahrt werden. In den Geowissenschaften werden Ablagerungen aus dem Meer und aus Seen, das Eis von Gebirgsgletschern, der Antarktis und Grönland sowie Baumringe untersucht. Aus diesen Befunden wird das Klima der Vergangenheit rekonstruiert (siehe Kasten „Klimaarchive und Methoden“). Nur durch die Untersuchung dieser Klimaarchive sowie der modelltheoretischen Interpretation kann es gelingen, die Grundzüge der natürlichen Klimaeigenschaften zu bestimmen und vom modernen, anthropogenen Einfluss auf Klimaänderungen in der heutigen Zeit zu trennen.

\section{Die letzten 570 Millionen Jahre und die Entwicklung des Lebens}

Die Vielfalt des heutigen pflanzlichen und tierischen Lebens hat sich nach bescheidenen Anfängen während der letzten 570 Millionen Jahre entwickelt, wobei zwischen den Klimaeigenschaften und Klimaänderungen sowie der Entwicklung des Lebens (dabei auch des Menschen) engste Wechselbeziehungen bestehen. 


\section{Klimaarchive und Methoden}

Unterschiedlichste Methoden stehen bereit, um Aufschluss über Klimabedingungen früherer Zeiten zu gewinnen. So ist es heute z.B. möglich, die Wassertemperaturen ehemaliger Ozeane, die Luftfeuchtigkeit bzw. Trockenheit untergegangener Kontinente oder die Gaszusammensetzung einer früheren Atmosphäre zu rekonstruieren.

Neben langen Messreihen (etwa für die letzten 150 Jahre) und einzelnen schriftlichen Dokumenten (etwa für die letzten 3000 Jahre) gibt es natürliche terrestrische und marine Klimaarchive, aus denen mit Hilfe von Proxies Klimaeigenschaften abgeleitet werden können. Im Zuge der fortlaufenden Weiterentwicklung verfeinerter Datierungstechnik kann heute das globale Paläoklima und seine Veränderungen über lange geologische Zeiträume für eng definierte Zeitscheiben und für Zeitserien dargestellt werden, wobei deren zeitliche Auflösung von der Natur des bewahrten „Klimasignals” abhängig ist und sich von täglichen Wachstumsrhythmen in biogenen Materialien über saisonale zu jährlichen und mehrjährigen Klimaänderungen erstrecken kann.

Komplexe isotopische (z.B. von Sauerstoffisotopenverhältnissen in Eiskernen) und biogeochemische (z.B. von temperaturabhängigen Alkenonen in marinen Sedimenten) Analysen ermöglichen gerade für die jüngsten geologischen Zeiträume die Rekonstruktion klimabedingter Umweltbedingungen in höchstem Detail. Es hat sich gezeigt, dass z.B. die Vergesellschaftung verschiedener Kleinstlebewesen der Meere von den Temperaturen des Oberflächenwassers abhängt, so dass man in der Lage ist, über statistische Bewertungen mathematische Funktionen zu ermitteln, die es erlauben, aus der beobachteten Populationsökologie auf Temperaturverhältnisse zu schließen.

Ein Beispiel für eine solche Detailtreue sind Ablagerungen in Seen. Hier sammeln sich Bodenpartikel, Pollen, Blätter und Staub. In den oft meterdicken Seeablagerungen ist die Klima- und Vegetationsgeschichte einer Region über Jahrtausende Schicht für Schicht aufgezeichnet. Unter besonders günstigen Ablagerungsbedingungen bildet sich sogar eine Jahresschichtung aus. Diese Klimachroniken enthalten Jahresaufzeichnungen, die noch exaktere Zeitmarken sind als der Historiker sie für die Rekonstruktion der Menschheitsgeschichte bis zur Zeit der Pharaonen zur Verfügung hat.

Von besonderer Bedeutung sind neben dem Klimaarchiv der Meeres- und Seenablagerungen die Informationen aus den Kernen von Eisbohrungen. Untersuchungen an Eiskernen zeigen die natürliche Variabilität des atmosphärischen Kohlendioxids über die vergangenen 400.000 Jahre mit höherer Verlässlichkeit als Sedimentkerne, da die Zusammensetzung der im Eis eingeschlossenen Luft direkt gemessen werden kann.

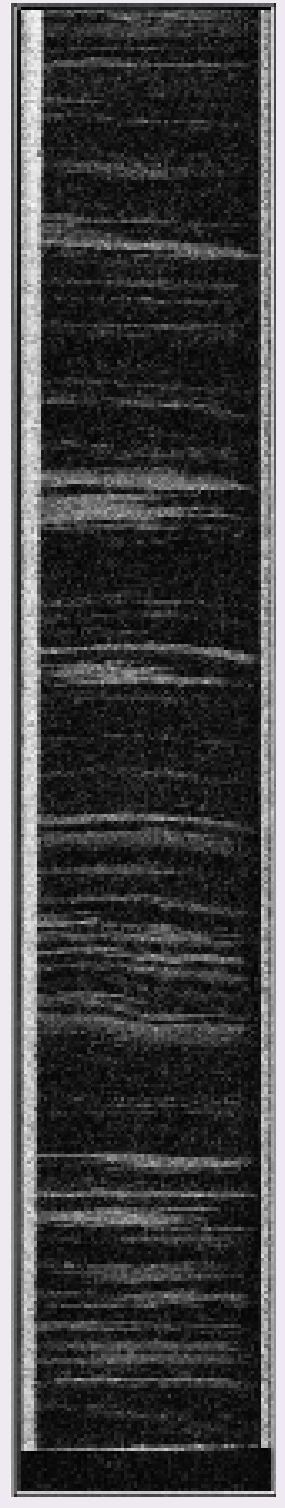


Die Rekonstruktionen der früheren Umweltbedingungen und damit der früheren Klimawandel unterscheiden sich in den Skalen ihrer zeitlichen und räumlichen Auflösung, je nachdem, ob z.B. Baumringe oder jährlich geschichtete Seesedimente, Anwachsstreifen von Korallen/Mollusken, Eiskerne, Tiefseesedimentkerne oder Meeresspiegelstände als Klimaarchive untersucht werden.

Abbildung 7 zeigt ein $50 \mathrm{~cm}$ langes Eissegment des NGRIP-Eisbohrkerns*) aus $2700 \mathrm{~m}$ Tiefe des grönländischen Eisschilds im Durchlicht. Das Eissegment ist auf 84.870 Jahre vor heute datiert und umfasst eine Zeitspanne von ca. 50 Jahren. Die Grauwerte sind invertiert, d.h. vollständig transparentes Eis erscheint schwarz. Das Eis offenbart eine regelmäßige Abfolge von weißen Schichten, den sogenannten „cloudy bands”, an denen das Licht stark gestreut wird. Ursache dafür ist ein erhöhter Staubanteil im sommerlichen Schneefall im Glazial.

*) NGRIP: North Greeland Ice Core Projekt 1996-2000, Bohrlokation: 75 N, 45 W, absolute Eismächtigkeit am Bohrpunkt ca. $3100 \mathrm{~m}$.

Es zeichnet die Erde vor allen anderen Himmelskörpern aus, dass das Klima innerhalb von Grenzen schwankte und dass Leben auf der Erde dadurch zwar beeinflusst, aber nie vollständig zerstört wurde.

Unser Verständnis von Klimaeigenschaften und ihren Veränderungen hängt auf vielfache Weise von den über die Erdgeschichte bewahrten Klimaarchiven ab. Weil sich grundlegende Eigenschaften der globalen Umwelt radikal verändert haben, ist es außerordentlich schwierig, die Klimate der frühen Erdgeschichte zu verstehen und mit dem heutigen Klima zu vergleichen.

Die Rekonstruktionen des Klimas sind außerordentlich unsicher. Es bestehen erhebliche Probleme bei der zeitlichen Zuordnung in den Klimaarchiven. Über die Funktion des Kohlenstoffkreislaufes gibt es unterschiedliche Hypothesen. Gesichert ist, dass die Plattentektonik, u.a. die Veränderung des Ausgasens von $\mathrm{CO}_{2}$ aus dem Erdinneren, die sich im Laufe der Jahrmillionen ändernde Verwitterung und die Evolution der Biosphäre den $\mathrm{CO}_{2}$-Haushalt nachhaltig beeinflusst haben. Da diese verschiedenen Prozesse teilweise gegenläufig wirken, ist ein direkter Zusammenhang zwischen Temperatur und atmosphärischer $\mathrm{CO}_{2}$-Konzentration nicht zwingend notwendig. In der Tat zeigen paläoklimatologische Befunde in manchen Zeitabschnitten keinen und in anderen einen deutlichen Gleichlauf. Auch bezüglich des Klimaantriebs bestehen noch große Unsicherheiten, denn in diesem Zeitraum können auch beispielsweise Einschläge von größeren Meteoriten und Änderungen in der kosmischen Partikelstrahlung eine Rolle gespielt haben. Daher ist ein Vergleich von langfristigen Klimaänderungen mit den Klimaänderungen der letzten Jahrtausende nur bedingt möglich.

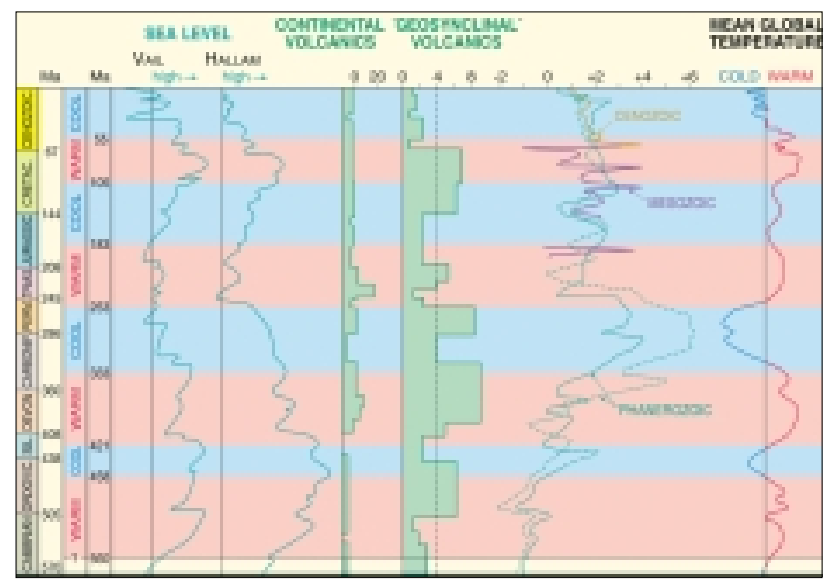

Abbildung 8

Rekonstruktion des globalen Meeresspiegels, der Vulkanaktivität und der über mehrere Jahrtausende geglätteten globalen Mitteltemperatur der letzten 570 Millionen Jahre (nach Frakes et al., 1992). 


\section{Die letzten 2 Millionen Jahre und die}

\section{Milankovitch-Klimazyklen}

In der jüngsten geologischen Vergangenheit hat sich wieder eine kalte Phase des Klimas entwickelt, die aufgrund der Verteilung von Land und Meer zur Bildung von eisbedeckten Gebieten in beiden Polarregionen geführt hat. Kontinentaldrift (Plattentektonik und Ozeanbodenspaltung) und die sich ergebende Wanderung von Kontinenten in Polarregionen hat die Pole vom „ozeanisch-atmosphärischen Wärmeaustauscher" isoliert und somit Orte möglicher Abkühlung durch Strahlungsprozesse geschaffen. Dabei liegt ein kleiner Kontinent, der von einem ringförmigen Ozean umgeben wird, über dem Südpol, während sich der Nordpol in einem kleinen von Kontinenten umgebenden Ozeanbecken mit einem sehr eingeschränkten Wasseraustausch mit den Weltmeeren befindet. Im Ergebnis hat sich deshalb ein Klimasystem mit großen Temperaturunterschieden zwischen den Tropen und den Polargebieten entwickelt.

Innerhalb der letzten wenigen Millionen Jahre pendelte das Klima zwischen kälteren und wärmeren Phasen. Dabei leben wir heute unter dem Einfluss eines bereits ca. 10.000 Jahre andauernden warmen Klimas. Die Wechsel zwischen warmen und kalten Klimaphasen (im so genannten „Quartär”) vollzogen sich im Rhythmus der Änderungen der Erdbahn um die Sonne, den so genannten Milankovitch-Zyklen. In Abhängigkeit der Geometrie der Erdbahn um die Sonne wechselten warme und kalte Klimaphasen in Abständen von 40.000 bis 100.000 Jahren. Während der letzten 800.000 Jahre sind die Extreme der warmen und kalten Klimaphasen im Rhythmus von ca. 100.000 Jahren aufeinander gefolgt, etwa gleichzeitig mit den Schwankungen der Exzentrizität der Erdbahn um die Sonne (vgl. Kapitel 1). Die zwischen den Extremen liegenden Zeitintervalle waren meist durch ein relativ kühles Klima geprägt, so dass das Klima der jüngsten geologischen Vergangenheit wesentlich länger kühl als warm war. Ähnliche „rhythmische" Änderungen sind für viele der früheren Zeitalter in Sedimentbecken beobachtbar und werden als Milankovitch-Zyklen interpretiert.

Untersuchungen an Eiskernen aus der Antarktis, in denen die Atmosphäre früherer Zeiten in Form von Luftbläschen erhalten ist, haben gezeigt, dass sich nicht nur die Temperatur in regelmäßigen Abständen, sondern auch gleichzeitig die Konzentrationen der Treibhausgase in der Atmosphäre änderten. Hohe Konzentrationen von z.B. Methan und $\mathrm{CO}_{2}$ sind an warme Klimaphasen gebunden, während sie in kalten Klimaphasen immer wieder auf niedrige Werte zurückfielen (vgl. Abb. 9). Die Bestimmung der Prozesse, die den globalen Kohlenstoffumsatz kontrollieren und die bisher nur unvollständig verstanden sind, haben daher eine hohe wissenschaftliche Priorität.

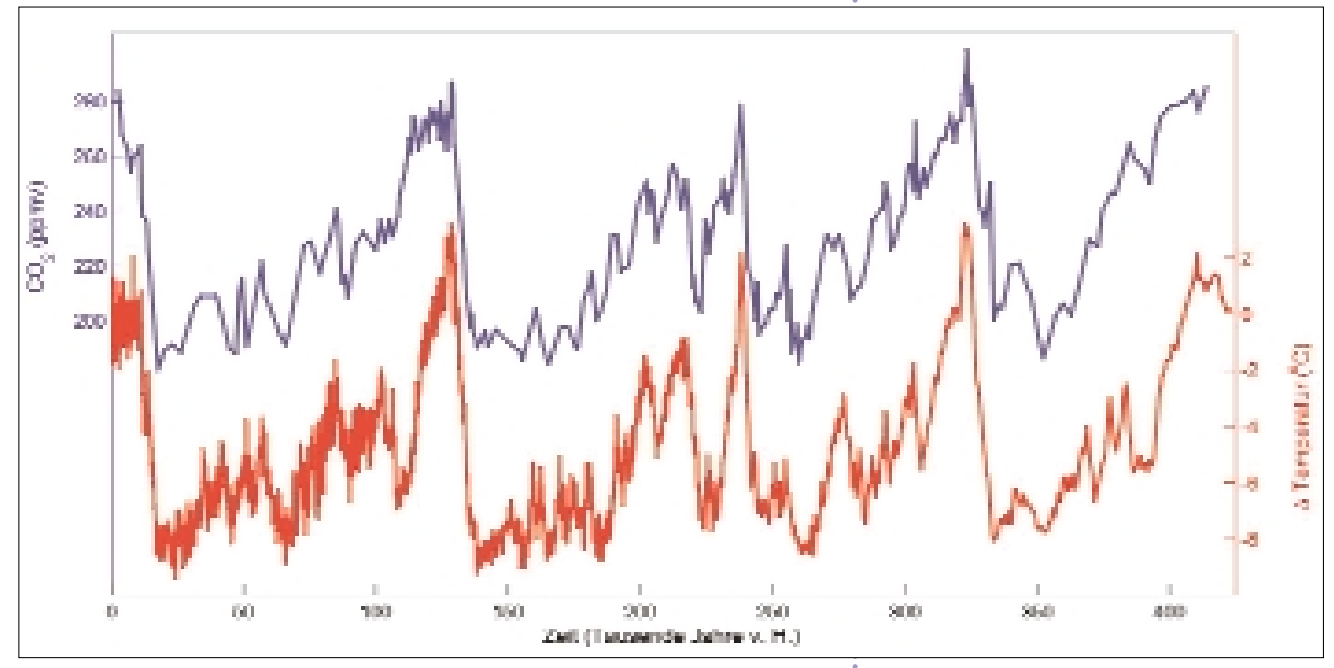

Abbildung 9

Atmosphärische $\mathrm{CO}_{2}$ Konzentration und lokale Temperaturänderungen an der Forschungsstation Vostok (Antarktis) über die letzten 400.000 Jahre, gewonnen aus Eisbohrkernanalysen.

Quelle: Petit et al., 1999, mit Ergänzungen (Claussen, 2003) 


\section{Die letzten 100.000 Jahre und sprunghafte Klimaänderungen}

Das Klima vor dem Einsetzen der jetzigen warmen Klimaphase, in der Zeit von etwa 80.000 bis 11.500 Jahren vor heute, war durch den im geologischen Maßstab schnellen Wechsel von Temperaturen geprägt. Die besten Beispiele dafür sind in den Eiskernen von Grönland gefunden worden, die mit ihrer jährlichen Schichtung die Dauer der Wechsel bestimmen lassen. Während der gesamten letzten kalten Klimaphase, der so genannten Weichsel-Eiszeit, hat es in Grönland zahlreiche Sprünge zwischen dramatischer Erwärmung und Abkühlung von mehr als $10^{\circ} \mathrm{C}$ innerhalb von wenigen Jahrzehnten gegeben. Ähnliche Wechsel haben sich in zeitlich hoch auflösenden Meeresablagerungen beobachten lassen, die schnelle Veränderungen der Eigenschaften der Wassermassen des Weltmeeres belegen. Der Verlauf dieser Veränderungen scheint ebenfalls einer zyklischen Entwicklung zu folgen (Dansgaard-Oeschger-Zyklen, vgl. Abb. 10), nur erfolgen die Wechsel von kalt zu warm fast sprunghaft, innerhalb von einigen Jahrzehnten. Welche Prozesse diese sprunghaften globalen Klimaänderungen ausgelöst haben, ist bis heute nicht eindeutig geklärt.

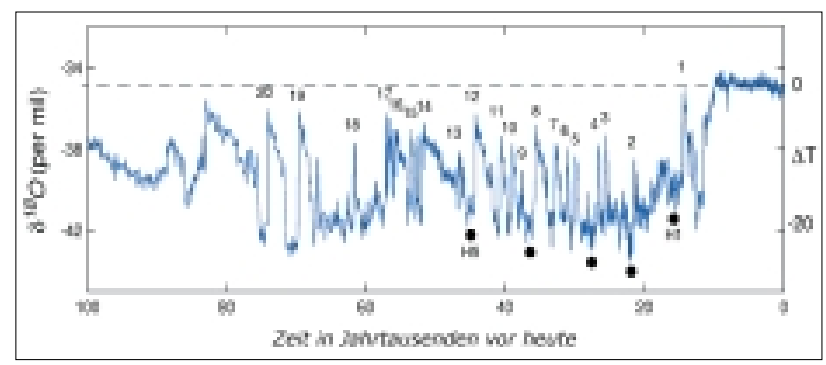

Abbildung 10

Temperaturschwankungen über Grönland aus Messungen in dem GISP (Greenland Ice Sheet Project, Grootes et al., 1993) Eisbohrkern. Die Zahlen kennzeichnen die Warmphasen während der letzten Eiszeit und die schwarzen Punkte (H1, ..., H5) die so genannten Heinrich-Ereignisse, während der große Mengen des Eisschildes über Nordamerika abgebrochen und in den Nordatlantik verdriftet worden sind.

Quelle: nach Ganopolski und Rahmstorf (2001) mit Veränderungen (Claussen, 2003)
Während der letzten Eiszeit erreichten die Inlandeismassen ihre größte flächenhafte Ausdehnung vor etwa 21.000 Jahren. Die Gletscher reichten damals bis ins mittlere Schleswig-Holstein, Mecklenburg-Vorpommern und Berlin/Brandenburg. Auch der Rückgang der Eismassen am Ende der Eiszeit war von sprunghaften Klimaänderungen begleitet. Die Durchschnittstemperaturen über dem Nordatlantik und Nordeuropa stiegen vermutlich innerhalb weniger Jahre um 10 bis 15 Grad.

\section{Die letzten 10.000 Jahre und das relativ stabile Klima des Holozäns}

Die jüngste warme Klimaphase war zwar nicht frei von Abkühlungen und Erwärmungen, aber ihre Klimaumschwünge waren bei weitem nicht so dramatisch wie in der vorangegangenen Kaltzeit. Dennoch waren sie markant genug, um in historischen Zeiten die soziale und ökonomische Entwicklung der menschlichen Kulturen zu beeinflussen. Ein Beispiel für das Ausmaß der damaligen Klimafluktuationen in Europa zeigt die Rekonstruktion der Gletscherstände in den Alpen. Es gibt deutliche Belege anhand der Vegetationsverbreitung, dass die Alpen wiederholt nahezu frei von Gletschern waren, und dies nicht nur zur Zeit des holozänen Klimaoptimums.

Die wärmste Phase der letzten 10.000 Jahre findet sich im so genannten holozänen Optimum, dem so genannten Atlantikum, 9200 bis 5600 Jahre vor heute. Temperaturrekonstruktionen an Sedimenten aus den Subtropen und die Variation der Schmelzereignisse auf Grönland zeigen die globale Ausprägung dieser wärmsten Phase des Holozäns.

Neuere Klima-Rekonstruktionen an Höhlensintern des Oman legen eine Verbindung zwischen Niederschlagsgeschehen/Monsun und den solaren Aktivitätsänderungen während des holozänen Klimaoptimums nahe. Die Rekonstruktion der Eisbergdrift im Atlantik zeigt ebenfalls eine auffällige Korrelation mit solaren Aktivitätsänderungen im gesamten Verlauf der letzten 11.000 Jahre (vgl. Abb. 11). 


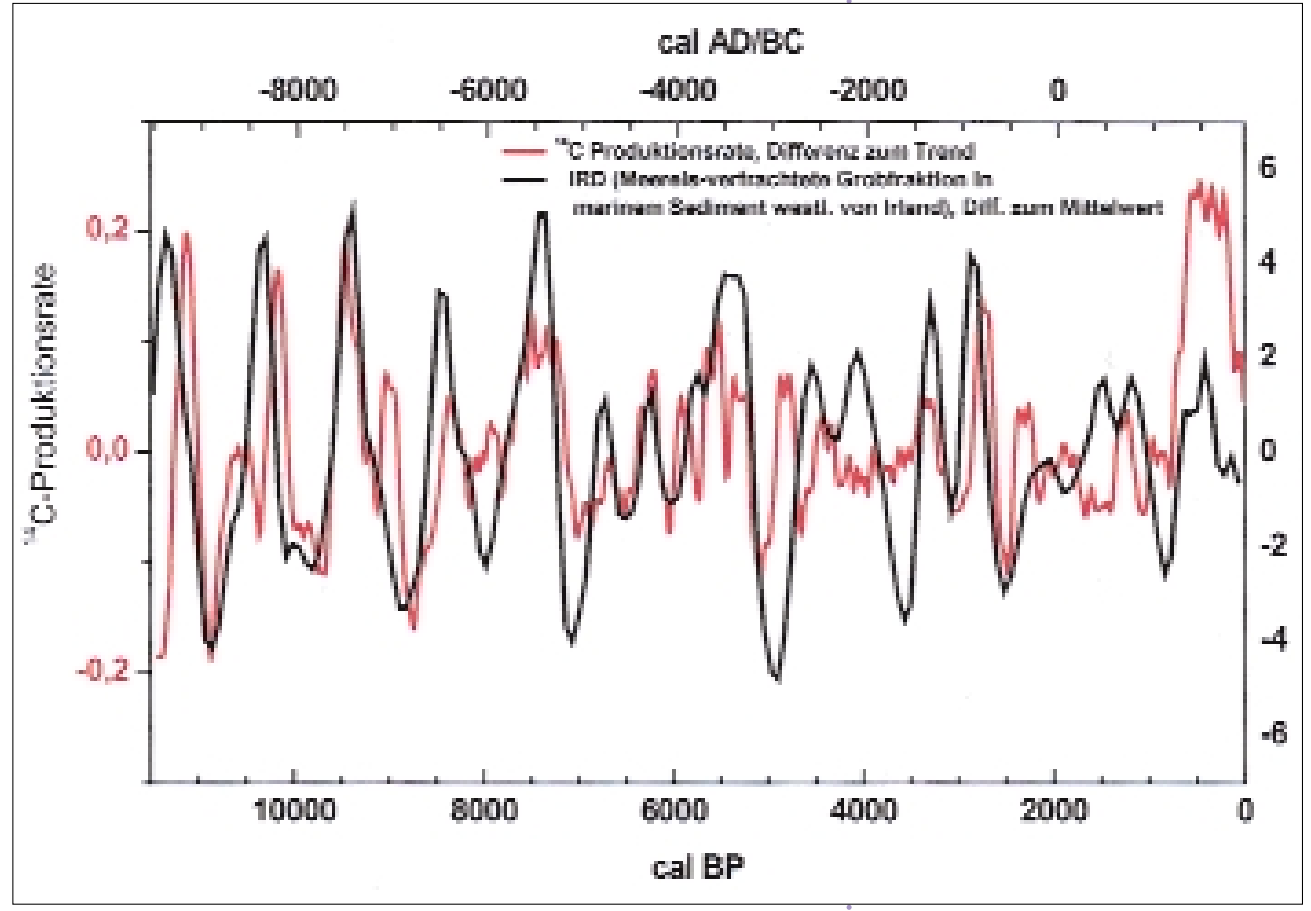

Abbildung 11

${ }^{14} \mathrm{C}$ Produktionsrate (rote Kurve), ein Maß für die Intensität der Höhenstrahlung und damit für die Aktivität der Sonne, und Menge - in relativen Einheiten - des durch Eisberge verdrifteten Gesteinsmaterials westlich von Irland (schwarze Kurve) als Funktion der Zeit, einmal als Kalenderjahre vor heute und einmal als Jahre vor und nach Christus dargestellt. Diese Kurve wurde in vereinfachter Form von Bond et al. (2001) übernommen.

Die letzten 1000 Jahre, das mittelalterliche Klima-Optimum und die Kleine Eiszeit Eisbohrkerne und eine Vielzahl von weiteren Rekonstruktionen, aber auch schriftliche historische Aufzeichnungen belegen weltweit, welche Dynamik in der Temperatur- und Klimaentwicklung der letzten 1000 Jahre stecken. Vom Klima- optimum des Hochmittelalters erfolgt der Abstieg des Klimas zur so genannten „Kleinen Eiszeit" im 14. Jahrhundert, die, immer wieder unterbrochen durch wärmere Phasen, bis Mitte des 19. Jahrhunderts andauerte und dann in der Neuzeit in die nächste warme Phase des Klimas überging (siehe Abb. 12).

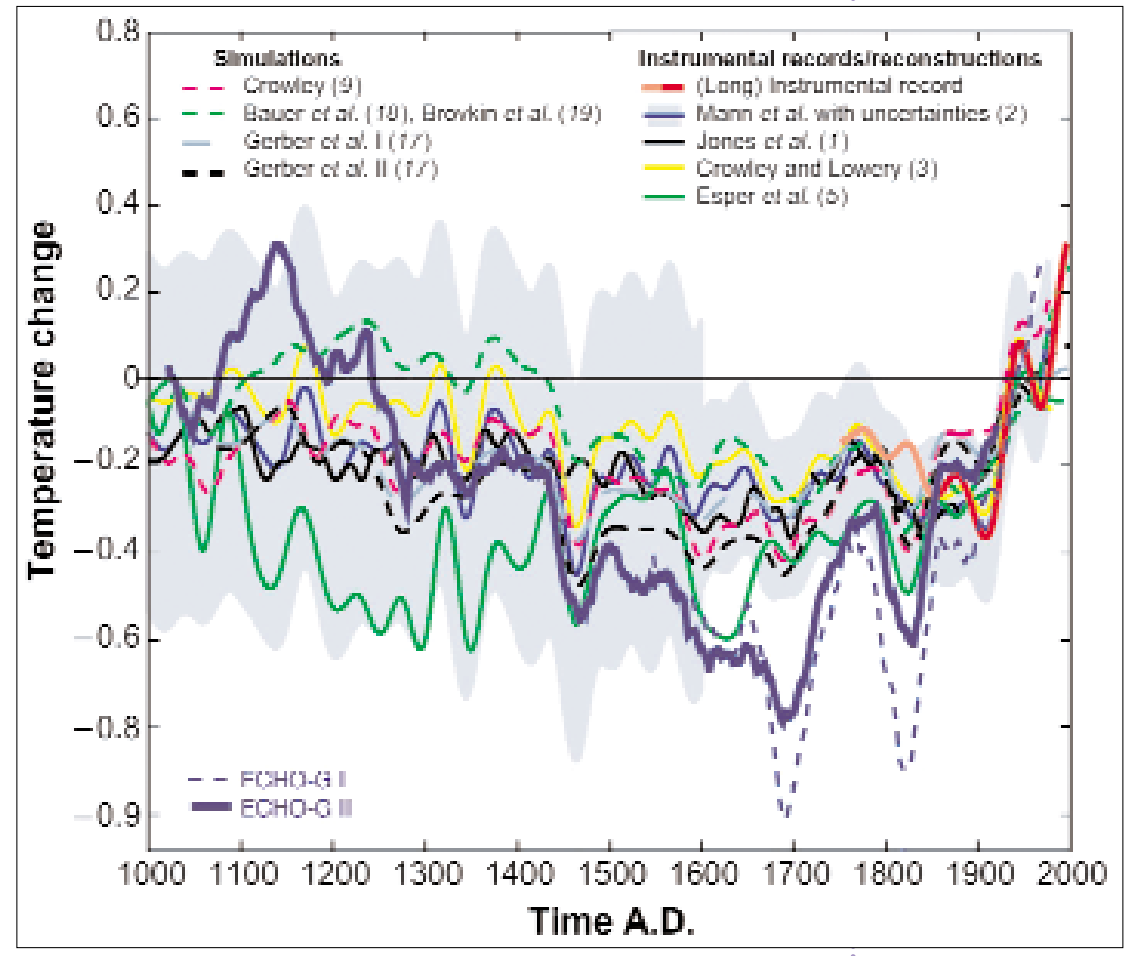

Abbildung 12

Vergleich von rekonstruiertem und modelliertem Verlauf der Jahresmitteltemperatur der bodennahen Luftschicht gemittelt über die Nordhemisphäre. Die grau schattierte Fläche gibt die Unsicherheit der Rekonstruktionen wieder. Grüne Kurve: Rekonstruktion der Sommertemperatur über den außertropischen Kontinenten. Sämtliche Kurven sind mit einem zeitlichen Mittel über 40 Jahre geglättet. Nach Mann (2002). 
Eisbohrkerne zeigen uns, wie sich das atmosphärische Kohlendioxid im Verlauf der letzten 1000 Jahre entwickelt hat: Nahezu gleich bleibende Konzentrationen bis zum Beginn des 18. Jahrhunderts, gefolgt von einem rapiden Anstieg, der durch die menschlichen Emissionen verursacht wurde. Auch wenn der Mensch seit den frühen Stadien seiner Entwicklung begon- nen hat, auch die Eigenschaften der Landoberflächen stark zu verändern und somit Einfluss auf das Klimasystem zu nehmen, nimmt man doch an, dass die Klimaschwankungen der letzten tausend Jahre bis zum Einsetzen der intensiven Industrialisierung im Wesentlichen auf natürliche Klimaänderungen zurückzuführen sind.

\section{Historische Klimaaufzeichnungen}

Direkte Messungen von klimatischen Parametern existieren etwa für die letzten 150 Jahre. Möchte man Informationen über den Klimaverlauf vor dieser Zeit, so ist man auf die Auswertung von historischen Dokumenten angewiesen. Sie enthalten eine Vielzahl von klimarelevanten Hinweisen, die sich auf Naturkatastrophen, Witterungsverläufe und das tägliche Wetter beziehen. So wurden Wasserstände und Vereisungen von Flüssen und Seen protokolliert, teilweise brachte man sogar Wasserstandsmarken an. Man beschrieb zudem in Mitteleuropa den Schneefall und die Schneebedeckung. Belege sind hierfür auch die Bilder der holländischen Meister aus dem 17. Jahrhundert (vgl. Abb. 13). Historische Dokumente vermitteln auch einen recht guten Überblick über Ernteerträge (z.B. Getreide und Wein) inklusive der Reifezeit verschiedener Pflanzen. Kirchliche Quellen geben Hinweise auf klimatische Sondersituationen, wenn z.B. Bittprozessionen gegen eine Dürre beschrieben werden.

Die Hochwasserflutwelle der Elbe und seiner Nebenflüsse des Jahres 2002 hatte die Größenordnung eines Jahrhunderthochwassers erreicht. Wie historische Quellen zeigen, war dieses Hochwasser aber nur eines von mehreren solchen Ereignissen während der letzten eintausend Jahre. Eine extreme Hochwasserkatastrophe ereignete sich z.B. 1784, die unter anderem die „Alte Brücke” in Heidelberg zerstörte. Das Superereignis allerdings war die Überschwemmungskatastrophe von 1342, die in allen mitteleuropäischen Flussgebieten ungeheuere Schäden hinterließ und als das eigentliche Jahrtausendereignis bezeichnet werden kann.

Die historischen Daten lassen sich oft in quantitative „Klimaindizes”, z.B. saisonale Niederschlagssummen oder saisonal gemittelte Temperaturen, überführen. Dazu werden die gleichen Verfahren benutzt wie im Falle der natürlichen Klimaarchive (wie Baumringe oder Eiskerne). Mit der Hilfe historischer Informationen ist es z.B. gelungen, die Variation des mittelalterlichen Klimas und den Übergang in die Neuzeit für Mitteleuropa zu rekonstruieren.

Abbildung 14 zeigt die Rekonstruktion der Klimaanomalien der Winterhalbjahre in der Schweiz seit 1496 nach einer Klimaklassifikation von Pfister.

Die historische Klimarekonstruktion hat gegenüber den natürlichen Klimaarchiven den Vorteil, dass die Datierung meist unproblematisch ist. Andererseits stehen die historischen Daten unter dem Vorbehalt der gesellschaftlichen Wahrnehmung und Praxis, die sich ebenfalls innerhalb weniger Jahre ändern kann und sicher oft geändert hat. 


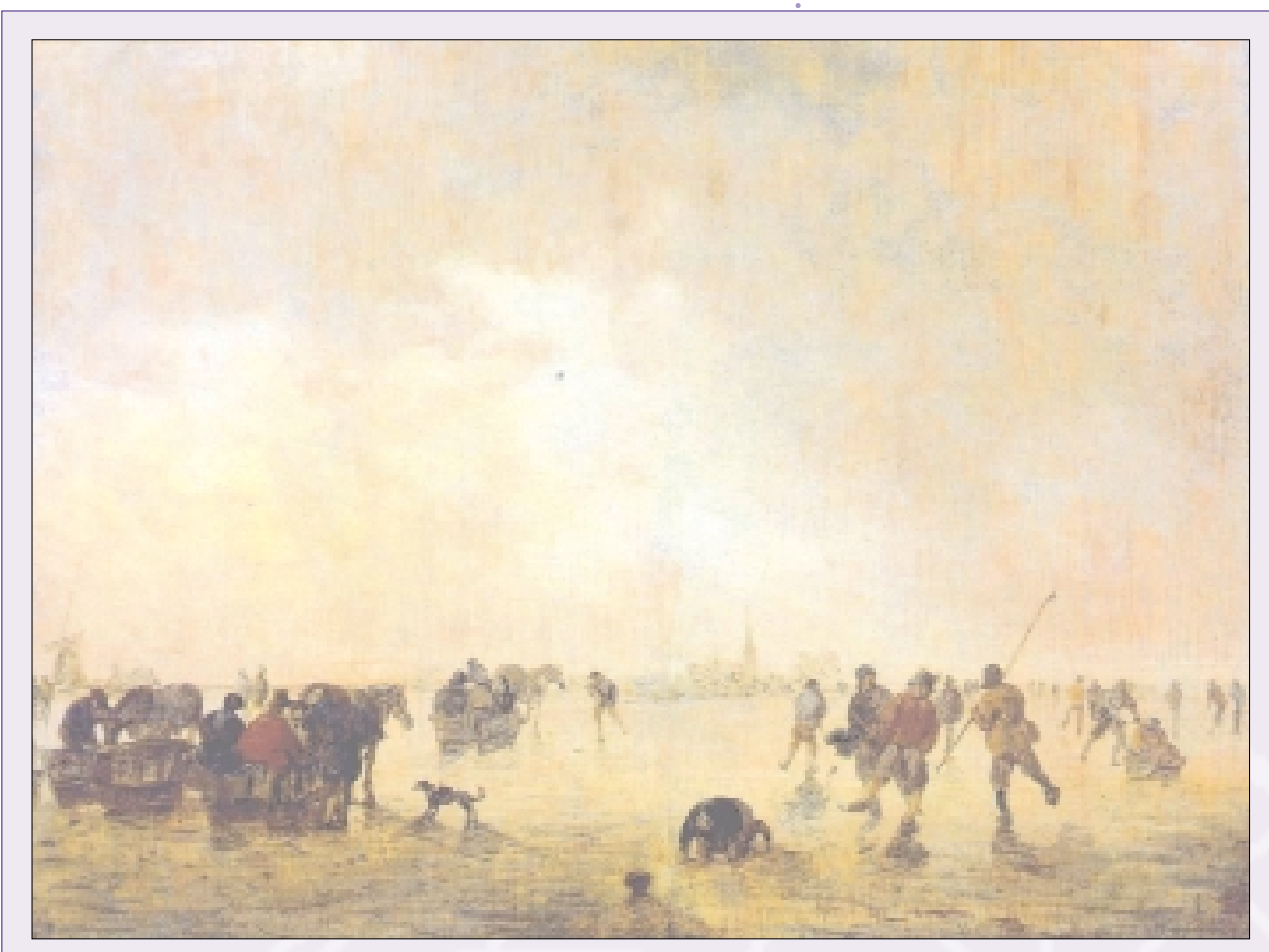

Abbildung 13

Die „Kleine Eis-

zeit" in der Male-

rei: Eislandschaft

mit Schlittschuh-

läufern (1643),

gemalt von

Jan van Goyen

(1596-1656).

Abbildung 14

Temperatur-

bedingungen in

der Schweiz, nach

der Klassifikation

von Pfister

(Pfister, 1999). 


\section{Die letzten 100 Jahre und die \\ Industrialisierung}

Die globale bodennahe Lufttemperatur ist seit dem späten 19. Jahrhundert um $0,6^{\circ} \mathrm{C} \pm 0,2^{\circ} \mathrm{C}$ angestiegen. Die 1990er Jahre waren die wärmste Dekade und 1998 das wärmste Jahr seit Beginn der instrumentellen Aufzeichnungen im Jahre 1861. Wie man Abb. 15 entnehmen kann, trat das Anwachsen der globalen Temperatur in zwei Phasen auf: 1910 bis 1945 und seit 1976. Die Temperaturanstiegsrate betrug in beiden Perioden ungefähr $0,15 \mathrm{~K}$ pro Dekade. In der jüngsten Zeit erwärmen sich Landgebiete schneller als die Ozeane. Zwischen 1950 bis 1990 nahm die Ozeanoberflächentemperatur nur halb so stark zu wie die mittlere Landtemperatur. Die bisher absolut höchste Globaltemperatur 1997 bis 1998 wurde durch ein El NiñoEreignis hervorgerufen.

Die Erwärmungsmuster haben sich im Laufe des 20. Jahrhunderts verändert. Am Ende des 20. Jahrhunderts fand das stärkste Anwachsen der Temperatur auf den Kontinenten der mittleren und hohen Breiten der Nordhalbkugel statt; in der Südhemisphäre dagegen war die Erwärmung schwächer. Eine Abkühlung findet man im Nordatlantik und Nordpazifik. Allerdings hat sich dieser Effekt im Nordatlantik in den letzten Jahren nicht fortgesetzt, sondern eine Erwärmung hat wieder eingesetzt. Die neueren Änderungsmuster hängen wahrscheinlich von der Nordatlantik-Oszillation und der dekadischen Pazifik-Oszillation ab. Regionale Temperaturänderungen von wenigen Dekaden Länge hängen daher sehr von der regionalen Variabilität im Klimasystem ab und können sich deshalb deutlich vom globalen Mittelwert unterscheiden.

Neue Analysen zeigen, dass sich der globale Wärmeinhalt der Ozeane in der Tiefsee seit 1950 deutlich erhöht hat. Die Hälfte dieses Anstieges ist in den obersten 300 m der Ozeane zu sehen, was einem Temperaturanstieg von $0,04^{\circ} \mathrm{C}$ pro Dekade entspricht. Die Tag-NachtUnterschiede der Temperatur in der bodennahen Luftschicht über Land nehmen seit $1950 \mathrm{ab}$. Die Minimaltemperaturen nehmen ungefähr doppelt so schnell zu $\left(0,2^{\circ} \mathrm{C} /\right.$ Dekade $)$ wie die Maximaltemperaturen $\left(0,1^{\circ} \mathrm{C}\right)$.

Nach dem gegenwärtigen Stand der Forschung, d.h. nach dem gegenwärtigen Stand unseres Prozessverständnisses, müssen wir davon ausgehen, dass die globale Erwärmung der bodennahen Luftschicht in den letzten Dekaden durch die Zunahme der anthropogenen Treibhausgas-

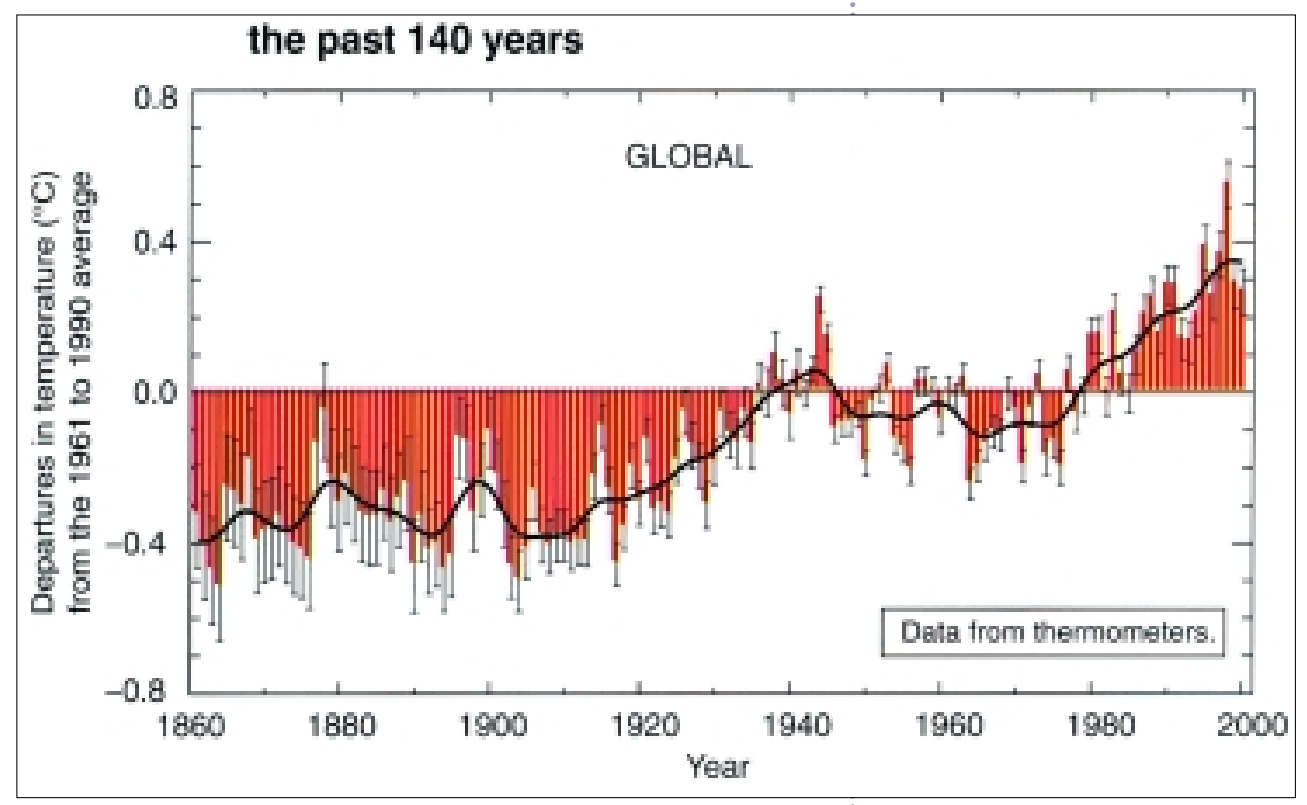

Abbildung 15

Die bodennahe Lufttemperatur im Jahresmittel (rote Balken) und über 10 Jahre gemittelt (schwarze Linie). Die Intervallstriche an den roten Balken repräsentieren das 95\% Vertrauensniveau. Es gibt die Unsicherheiten an, die durch Datenlücken, Instrumentenfehler, sowie Fehler durch das Korrekturverfahren bei den Ozeandaten und für die Verstädterung entstehen. Quelle: IPCC, Third Assessment Report (2001) 
emissionen angestoßen worden ist. Insbesondere in der ersten Hälfte des 20. Jahrhunderts haben dagegen auch natürliche Klimaantriebe wie eine Zunahme des solaren Energieflusses und Rückgang der Vulkanaktivität zur Erwärmung beigetragen. Aufgrund der zufälligen internen Klimavariabilität und der Wechselwirkungen zwischen den Klimasystemkomponenten (vgl. Kapitel 1) ist eine eindeutige quantitative Zuordnung der beobachteten Erwärmung zu den verschiedenen Klimaantrieben, einschließlich des Beitrags der anthropogenen Treibhausgase, allerdings nur bedingt möglich.

\subsection{Reproduktionen des Klimas durch Modelle}

Um die aus paläoklimatologischen Archiven gewonnenen Daten physikalisch interpretieren zu können, werden ebenfalls Klimamodelle benötigt. Umgekehrt dienen paläoklimatologische Daten aber auch der Validierung der Klimamodelle. Validierung und Interpretation werden mit jeweils verschiedenen Datensätzen durchgeführt.

Im Rahmen der Paläoklimamodellierung gibt es zwei verschiedene Modellierungsstrategien: Modelle können im so genannten Zeitscheibenmodus oder im transienten Modus benutzt werden. Im Zeitscheibenmodus werden die Randbedingungen, mit Ausnahme des Tages- und Jahresgangs der solaren Einstrahlung, konstant gelassen. Im transienten Modus werden zeitlich sich ändernde Randwerte (z.B. die Änderung der Erdbahn um die Sonne) aus Rekonstruktionen vorgegeben. Simulationen mit komplexen Klimasystemmodellen wurden bisher lediglich über den Zeitraum der letzten maximal 10.000 Jahre beschrieben.

\section{Die letzten 10000 Jahre}

Als wesentliches Ergebnis der Klimasimulationen kann hervorgehoben werden, dass Klimamodelle, die lediglich die Atmosphäre und den Ozean als dynamische Klimasystemkomponenten enthalten, die wesentlichen Strukturen der holozänen Klimaentwicklung nur unzureichend wiedergeben. Z.B. fällt die Änderung des nordafrikanischen Sommermonsuns in diesen Modellen zu schwach aus, ebenso die Temperatur- und Meereisänderung der arktischen Klimazone. Nur die Modelle, in denen die Vegetation als interaktive Systemkomponente eingebunden ist, vermögen die drastischen Klimaänderungen in den Subtropen und der Arktis nachzuvollziehen. Insbesondere können die vollständig gekoppelten Modelle den Rückgang der Sahara im frühen Holozän vor gut 10.000 Jahren und die Verschiebung der arktischen Baumgrenze qualitativ richtig darstellen. Als weiteres Ergebnis zeigen transiente Modellexperimente, dass bezüglich der Klimaänderungen im globalen und hemisphärischen Mittel die Änderung der Erdbahn wesentlich wichtiger ist als die Änderung der Solarkonstante.

\section{Die letzten 1000 Jahre}

In einer kürzlich durchgeführten Klimasimulation wurden die letzten 450 Jahre nachgerechnet. Man geht dabei davon aus, dass zu Beginn dieses Zeitraums der Einfluss des Menschen, jedenfalls global gesehen, gering war; als äußere Antriebe werden Sonnenaktivität, Vulkanismus sowie die Treibhausgase vorgeschrieben, die bis zum Beginn der Industrialisierung überwiegend natürlichen Ursprungs waren. Wert und Verlauf dieser Antriebe leitet man aus so genannten „Stellvertreter”-Daten („Proxies”) her, da sie, ebenso wie die Temperaturen und andere Klimaelemente, damals nicht direkt gemessen wurden. Aus solchen Proxy-Daten wie Baumringen und Sedimentbohrkernen und einer Vielfalt von Aufzeichnungen (Ernteerträge, Deichreparaturkosten, Segelzeiten von Schiffen) kann man aber auch den Verlauf des historischen Klimas rekonstruieren. Das numerische Experiment zeigt, dass das Klimamodell die so rekonstruierte globale Klimaentwicklung (Abb. 16) und insbesondere das Phänomen der sogenannten „Kleinen Eiszeit” in Europa recht realistisch zu simulieren vermag. 


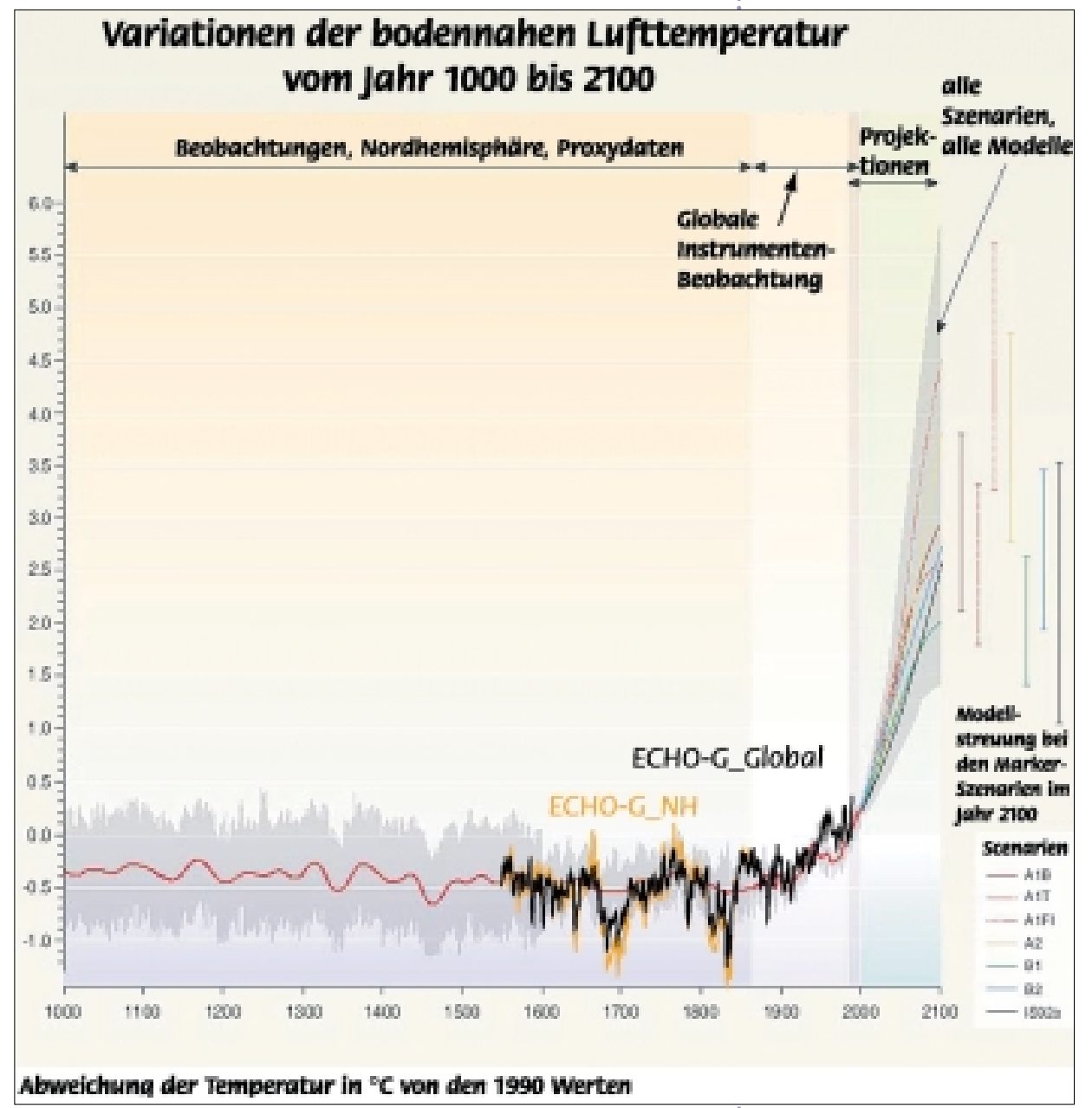

Abbildung 16

Änderung der global gemittelten bodennahen Lufttemperatur bezogen auf das Jahr 1990. Für den Zeitraum 1000 bis 1860 wurden nur Werte aus der Nordhemisphäre, ermittelt aus Baumringen, Korallen, Eisbohrkernen und historischen Überlieferungen hergeleitete Daten, verwendet. Der Zeitraum von 1860 bis 2000 basiert auf direkten atmosphärischen Messungen. Ebenfalls gezeigt ist das Ergebnis einer Klimasimulation für die letzten 450 Jahre (für die Nordhalbkugel: beige Kurve; globales Mittel: schwarze Kurve:). Die Temperaturhochrechnung bis zum Jahr 2100 erfolgte anhand verschiedener Szenarien (siehe Kap. 3).

Quelle:

IPCC, Synthesebericht des Third Assessment Reports (2001)

Die Klimaberechnung zeigt auch, dass besonders während des „Späten Maunder Minimums” (1675-1715), einer Zeit verringerter Sonnenaktivität und nahezu verschwindender Sonnenflekkenaktivität, das Klima global kälter war als heute. Diese Kältephase - ein Höhepunkt der Kleinen Eiszeit - ist durch historische Aufzeichnungen für Europa dokumentiert; wir kennen sie z.B. aus den berühmten Winterlandschaften zeitgenössischer holländischer Meister. Ein Vergleich der Klimarekonstruktion mit der Modellsimulation zeigt für Mitteleuropa eine gute Übereinstimmung (Abb. 17), während man in Nordeuropa deutliche Unterschiede sieht; diese könnten aber auch auf die schlechte Datenlage in diesen Gebieten zurückzuführen sein.

\section{Das Klima im Zeitalter der Industrialisierung} Eine häufig in der Öffentlichkeit gestellte Frage ist, inwieweit die Sonne und die Vulkane an den in den letzten 150 Jahren beobachteten Klimaveränderungen beteiligt sind, oder ob diese primär durch den Menschen bzw. die Industrialisierung hervorgerufen wurden. Klimamodelle können helfen, die vielfach umstrittenen Ursachen für diese Klimaveränderungen zu identifizieren.

Hierzu hat man mehrere Klimamodellexperimente durchgeführt: In einem ersten Experiment berücksichtigte man im Modell nur natürliche Klimaantriebe bzw. deren Schwankungen, in einem zweiten nur die anthropogenen und in einem dritten die natürlichen und die anthropogenen. Die Ergebnisse solcher Klimaexperimente sind in Abb. 18 wiedergegeben. Wie man aus dieser Abbildung erkennen kann, muss man beide ursächlichen Anteile berücksichtigen, um eine Übereinstimmung von Simulation und Beobachtung zu erhalten. 

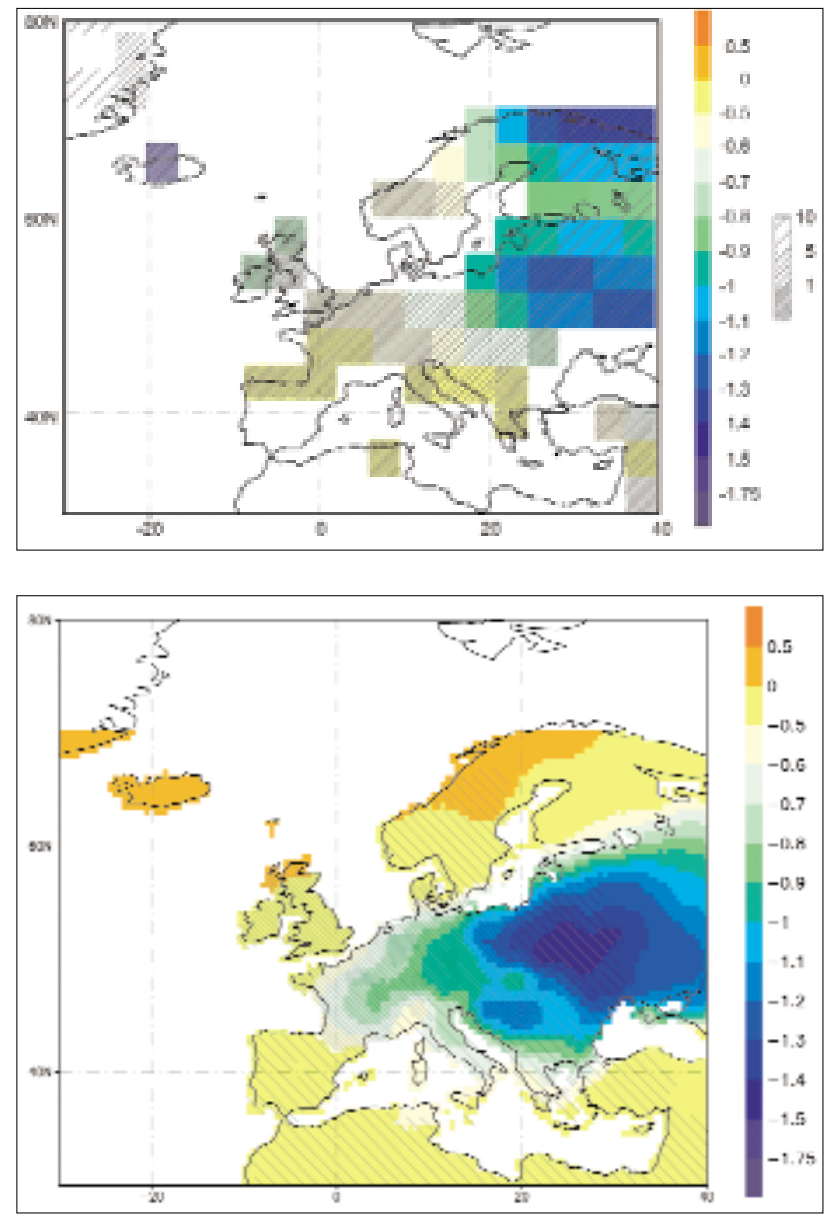

Abbildung 17

Die Temperaturabweichung während des „Späten Maunder Minimums" (1675-1715). Oben: Modellsimulation; unten: rekonstruiert aus historischen Überlieferungen. Die Schraffierung gibt den Grad der Signifikanz wieder. Nach Zorita et al. (2003)

Die Klimamodelle sind für das Klima in diesem Zeitabschnitt jedoch nicht primär gerechnet worden, um das Klima darzustellen. Vielmehr wurden die Modellexperimente in erster Linie dazu benutzt, sie mit den Beobachtungen zu vergleichen, um die Güte der Simulation zu prüfen. In vielen internationalen Modellvergleichen wurde festgestellt, dass die Modelle in der Lage sind, das heutige Klima in seinen wesentlichen Zügen wiederzugeben. Es gibt jedoch nicht „das perfekte Modell"; vielmehr haben alle Modelle ihre eigenen Schwächen und Stärken. Insbesondere sei daraufhingewiesen, dass derzeitige Klimamodelle aufgrund unvollständiger Prozessverständnisse das reale Klima nur unvollkommen abzubilden in der Lage sind. Dies gilt insbesondere auch für die Einbeziehung der Aerosole, deren Wirkung im Klimasystem nur für

\section{Abbildung 18}

Ergebnisse numerischer Klimaexperimente. In Abbildung a) werden nur die natürlichen Antriebe, d.h. die solare Variabilität und der Vulkanismus, berücksichtigt, in Abbildung b) nur die anthropogenen Anteile (Treibhausgase und Sulfat-Aerosole (nur direkter Effekt, siehe Text)).

In Abbildung c) werden sowohl natürliche als auch anthropogene Faktoren in ein Klimamodell eingebracht.

Das blaue Band gibt die Modellhochrechnungen einschließlich einer Abschätzung ihrer Unsicherheiten wieder, die rote Kurve den beobachteten Klimaverlauf. Diese Abbildung zeigt deutlich, dass das Klimamodell in der Lage ist, nicht nur das beobachtete Klima zu reproduzieren, sondern auch die verschiedenen Einflussfaktoren zu separieren. Quelle: IPCC, Third Assessment Report (2001)

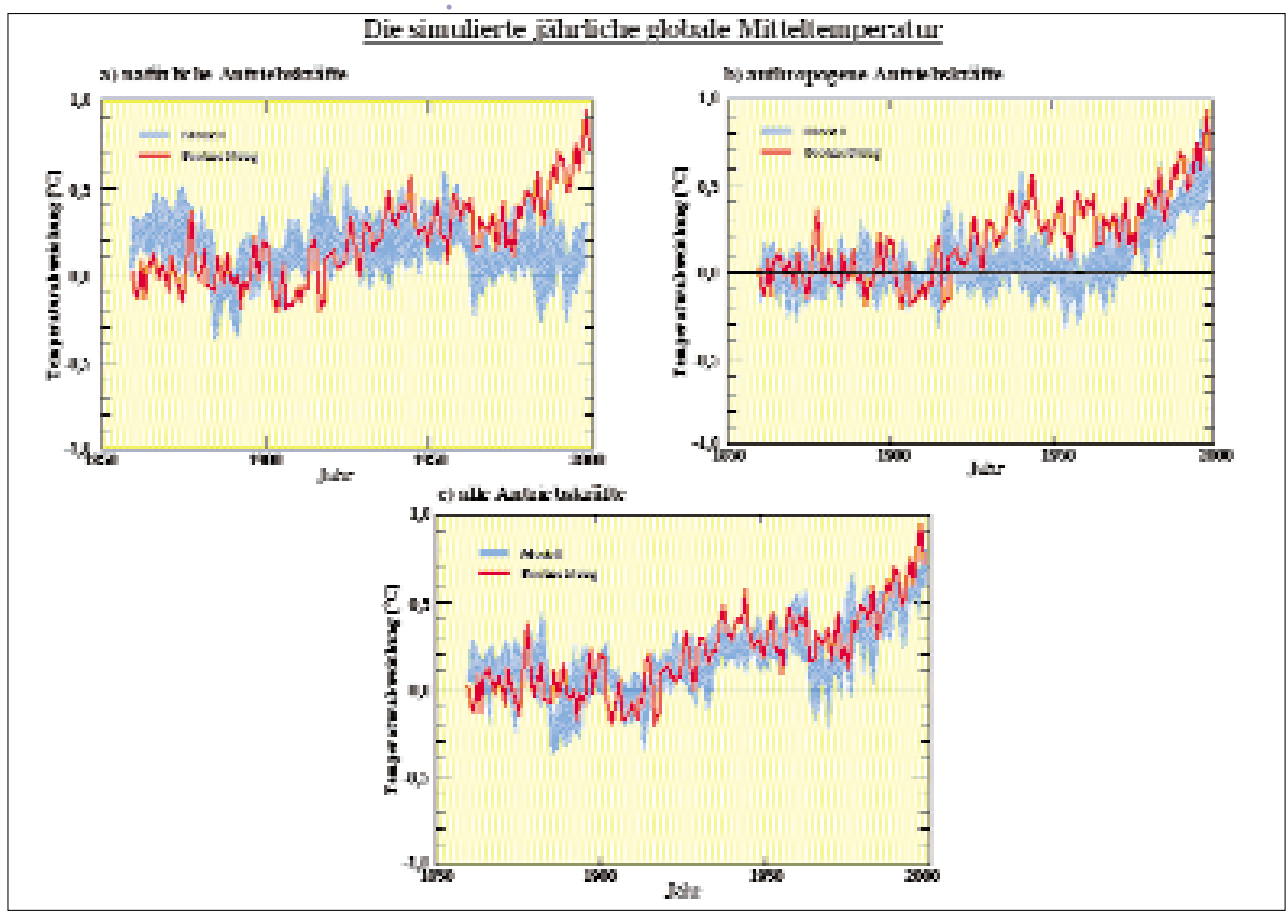


die direkte Rückstreuung des Sonnenlichts (dem so genannten direkten Effekt) hinreichend gut verstanden ist. Der indirekte Effekt, der den Einfluss des Aerosols auf die Wolkenbildung berücksichtigt, ist höchst unsicher.

\subsection{Resumée}

\section{- Warum beschäftigen wir uns mit der Klima- geschichte?}

Die Erforschung der Klimageschichte trägt dazu bei, das Klimasystem und seine natürliche Variabilität zu verstehen. Die Klimageschichte liefert darüber hinaus den Basiszustand, der vor der Einwirkung des Menschen das Klima bestimmt hat. Klimageschichte dient aber auch dazu, die Güte von Klimamodellen über längere Zeiträume zu überprüfen.

\section{- Wie rekonstruieren wir Klima in der Erdgeschichte?}

Bei der Rekonstruktion des Klimas der Erdgeschichte ist man auf indirekte Klimadaten angewiesen, die aus so genannten Klimaarchiven hergeleitet werden. Klimaarchive sind z.B. Eisbohrkerne, Baumringe, Sedimentablagerungen sowie eine Vielfalt von historischen Aufzeichnungen (Ernteerträge, Deichreparaturen, Segelzeiten von Schiffen). Die aus Klimaarchiven gewonnenen so genannten Stellvertreterdaten (Proxies) geben indirekt die Temperatur oder andere Klimaelemente wieder. Validierte und aufbereitete Proxydaten dienen auch als Eingabedaten für Klimamodelle. Seit einigen Jahren werden auch Klimamodelle mit zunehmendem Erfolg zur Rekonstruktion des Klimas der Erdgeschichte eingesetzt, insbesondere was die Zeitspanne seit der letzten Eiszeit und die letzten Jahrhunderte angeht.

\section{- Temperatur und $\mathrm{CO}_{2}$ : Wer hat wen gesteuert?}

Die Rekonstruktion von Änderungen der atmosphärischen $\mathrm{CO}_{2}$-Konzentration im Verlauf der weit zurückliegenden Erdgeschichte ist noch mit erheblichen Unsicherheiten verbunden. Für die letzten 400.000 Jahre wurde aber ein bemerkenswerter Gleichlauf von $\mathrm{CO}_{2}$ und Temperatur im Wechsel von Kalt- und Warmzeiten gefunden. Aus dieser Ähnlichkeit im Verlauf kann aber nicht geschlossen werden, dass $\mathrm{CO}_{2}$ die Temperaturänderungen antreibt oder umgekehrt. Die atmosphärische $\mathrm{CO}_{2}$-Konzentration ergibt sich aus der Wechselwirkung zwischen den Kohlenstoffreservoirs der verschiedenen Komponenten im Klimasystem. Diese Wechselwirkung hängt unter anderem von der Temperatur ab, die wiederum - neben zahlreichen anderen Prozessen im Klimasystem - auch über den Treibhauseffekt durch die $\mathrm{CO}_{2}$-Konzentration bestimmt wird. Als sehr wahrscheinlich gilt, dass die heutige $\mathrm{CO}_{2}$-Konzentration erheblich höher ist als jemals zuvor in den vergangenen $\mathbf{4 0 0 . 0 0 0}$ Jahren.

\section{- Welchen Einfluss hatte die Sonne?}

Die Sonne hatte in der Klimageschichte insgesamt einen dominierenden Einfluss. In manchen Perioden lässt sich die Variabilität des solaren Energieflusses deutlich in den Klimaarchiven ablesen. So kann man z.B. die Klimageschichte der letzten 1000 Jahre vor der Industrialisierung nicht ohne die Schwankungen des solaren Energieflusses erklären. Auch die Temperaturzunahme der letzten 100 Jahre ist trotz eines deutlichen anthropogenen Beitrags ohne den Einfluss der Sonne nicht verständlich. Nach dem gegenwärtigen Kenntnisstand könnte sich der Einfluss der Sonne und des Vulkanismus aber schwächer als der menschliche Beitrag ausgewirkt haben. Es gibt allerdings auch statistische Analysen, die nahe legen, dass es einen Zusammenhang gibt zwischen der von der Sonne beeinflussten kosmischen Strahlung und atmosphärischen Parametern, wie z.B. der Wolkenbildung. Dies würde bedeuten, dass die Sonne auch indirekt auf das Klima Einfluss nimmt. Für eine solche Annahme fehlt aber noch der exakte physikalische Nachweis. 


\section{- Was sagen uns Gletscher und das Polareis über die Klimageschichte?}

Das Eis in den großen Schilden der hohen Breiten der nördlichen und südlichen Hemisphäre sowie in den Gletschern niedriger Breiten bildet sich aus jahreszeitlich wechselndem Schneefall. Dieser hängt von wichtigen physikalischen und chemischen Eigenschaften der Atmosphäre ab und führt in vielen Fällen auch zu einer erhaltenen Jahres-, ja sogar Jahreszeitenschichtung im Schnee, Firn und Eis. Bohrkerne aus den Schichten dieser Eismassive sind daher vorzügliche Klimaarchive. Gletschervorstoß und -rückzug waren in der Vergangenheit natürliche Prozesse, so beispielsweise auch in den Alpen. Rekonstruktionen belegen, dass die Alpen während der letzten zehntausend Jahre wiederholt nahezu frei von Gletschern waren. Wenn die Eisschilde in den hohen Breiten wachsen, fällt der globale Meeresspiegel. Während der Eiszeiten zum Beispiel lag der Meeresspiegel bis zu 140 m niedriger. Würden alle Gletscher der Erde dagegen schmelzen, würde der globale Meeresspiegel um bis zu $80 \mathrm{~m}$ ansteigen.

\section{- Ist das Klima der letzten Jahrzehnte ungewo̊hnlich?}

Die Frage, ob ein Klimazustand ungewöhnlich ist oder nicht, hängt sehr stark vom betrachteten Zeitraum ab. Bezieht man lediglich die letzten 150 Jahre ein, so ist die Häufung hoher Temperaturen (im globalen Mittel) innerhalb des letzten Jahrzehnts durchaus signifikant, insbesondere was die Geschwindigkeit dieser Änderung angeht. Auf noch längeren Zeitskalen werden Aussagen dieser Art unsicherer. Dass es Regionen gibt, in denen die Temperatur in der Vergangenheit deutlich über den heutigen lag, ist nicht auszuschließen. Ob es aber im letzten Jahrzehnt im globalen Mittel wärmer war als jemals zuvor in den letzten 1000 Jahren, ist noch Gegenstand von Untersuchungen.

\section{- Gab es früher bereits schnelle Klimaänderungen?}

Viele, zeitlich hoch auflösende Klimaarchive belegen dramatisch starke und schnelle Klimawechsel. Die Eisschichten, die sich auf Grönland während der letzten Eiszeit und in der nacheiszeitlichen Warmzeit gebildet haben, zeigen, dass der Klimaumschwung von der letzten Eiszeit zur nacheiszeitlichen Warmzeit nur 20 bis 50 Jahre gedauert hat. Jahresschichten in norddeutschen Seen zeigen einen noch schnelleren Temperaturwechsel um mindestens $5 \mathrm{Grad}$ innerhalb von 10 bis 15 Jahren.

\section{- Gibt es Regionen auf der Erde, die besonders empfindlich auf Änderungen im externen Klimaantrieb reagiert haben?}

Geologische Rekonstruktionen und Klimamodelle stimmen dahingehend überein, dass die polaren und subpolaren Klimazonen der Erde besonders anfällige Gebiete für Klimawechsel sind. Dieses betrifft insbesondere Europa, das heute unter dem Einfluss des Colfstroms im Vergleich zu anderen Gebieten gleicher Breitengrade in einer sehr milden Klimazone liegt. Jede signifikante Veränderung des großräumigen ozeanischen und atmosphärischen Zirkulationsmusters im Nordatlantik würde zu einer nachhaltigen Veränderung der Lebensbedingungen in Europa führen. Abrupte Klimaänderungen sind auch für das nördliche Afrika (Ausdehnung der Sahara) und für den östlichen Nordatlantik sowie Grönland bekannt. Obwohl mittlerweile abrupte Klimaänderungen während der letzten Eiszeit in nahezu allen Teilen der Welt nachgewiesen wurden, gelten die genannten Regionen als ,hot spots”. Nach weiteren empfindlichen Regionen wird noch geforscht.

\section{- Können die heutigen Klimamodelle die Klimageschichte abbilden?}

Erst seit wenigen Jahren hat man begonnen, mit Modellen das Klima der Vergangenheit zu unter- 
suchen. Die letzten 100 Jahre sind relativ gut reproduzierbar und auch anhand von Daten zu validieren. Je weiter man in die Erdgeschichte zurückschaut, d.h. je länger die Zeitskalen sind, desto unsicherer werden die Ergebnisse. Dies beruht darauf, dass zum einen nicht genügend Daten verfügbar sind, zum anderen dass die beteiligten Prozesse noch nicht hinreichend verstanden sind. Allerdings ist es bereits gelungen, einige paläoklimatologische Befunde, z.B. den drastischen Rückgang der Sahara vor einigen tausend Jahren, zu erklären.

\section{WIE WIRD DAS KLIMA IN DER ZUKUNFT AUSSEHEN?}

Die Frage, wie das Klima in der Zukunft aussehen könnte, ist sowohl von wissenschaftlichem als auch von großem gesellschaftlichem Interesse. Nicht zuletzt wird bereits durch einfache qualitative Abschätzungen über die Wirkung des Treibhauseffektes eine deutliche Temperaturzunahme bei wachsender $\mathrm{CO}_{2}$-Emission vorausgesagt. Die heutige Klimawissenschaft verwendet komplexe Modelle, in denen alle bekannten physikalischen Prozesse berücksichtigt sind und mit denen so genannte „Klimaszenarien” getestet werden. Solche Szenarien sind keine Prognosen, sondern nur ein Spektrum von Annahmen über zukünftige Entwicklungen und des begleitenden Einflusses auf das globale Klima.

Eine wesentliche Frage, die die Klimawissenschaft zu beantworten hat, ist die der Extremereignisse, da diese gesellschaftlich am stärksten erfahren werden.

Klimamodellierung wird in der Öffentlichkeit oft mit großer Skepsis wahrgenommen. Sind die Ergebnisse unterschiedlich, werden sie verständlicherweise nicht akzeptiert, sind sie dagegen ähnlich, steigt die Akzeptanz dennoch nicht automatisch, weil der Verdacht besteht, das sich die Klimaforscher untereinander „abgestimmt” haben.

\subsection{Klimavorhersage}

In der theoretischen Klimatologie werden zwei verschiedenen Typen von Klimavorhersagen unterschieden. Zum einen die Klimavorhersage erster Art, bei der von einem bestimmten Zeitpunkt ausgehend die weitere Klimaentwicklung berechnet wird. Diese Art der Vorhersage entspricht im Prinzip der Wettervorhersage, nur mit dem Unterschied, dass bei der Klimavorhersage die statistischen Kenngrößen des Klimasystems für einen bestimmten Zeitbereich in der Zukunft berechnet werden und bei der Wettervorhersage der Zustand der Atmosphäre (vgl. 
hierzu auch Kapitel 1). In beiden Fällen werden neben den Erwartungswerten (z.B. Jahressumme des Niederschlages oder Eintrittswahrscheinlichkeit von Starkniederschlägen bei der Klimavorhersage oder Regenwahrscheinlichkeit des nächsten Tages bei der Wettervorhersage) auch die Unsicherheit der Abschätzung angegeben - obwohl dies bei der täglichen Wettervorhersage in den Medien meist nicht erkennbar ist.

Bei der Klimavorhersage erster Art wird davon ausgegangen, dass die Entwicklung der Randbedingungen bekannt ist. Es wird also im Wesentlichen die interne Klimavariabilität prognostiziert (siehe Kapitel 1). Bei der Klimavorhersage der zweiten Art dagegen steht nicht die Klimaentwicklung oder das Klima zu einem bestimmten Zeitpunkt in der Zukunft im Vordergrund, sondern die Reaktion des Klimasystems auf Veränderungen verschiedener hypothetischer Antriebe, z.B. $\mathrm{CO}_{2}$. Es wird auf diese Weise die dynamische Struktur und die Belastbarkeit des Klimasystems erkundet.

Für die Diskussion der Klimaentwicklung in diesem Jahrhundert spielt die Klimavorhersage erster Art eine untergeordnete Rolle. In der Klimaforschung wird daher oft von Projektionen oder Szenarien gesprochen - gemeint ist damit die Klimavorhersage zweiter Art, also die Analyse möglicher Klimaänderungen bei verschiedenen Belastungszuständen. Diese Klimaveränderungen werden mit den in Kapitel 1.6 vorgestellten Modellen berechnet.

\subsection{Sozioökonomische Szenarien oder: Was bringt Kyoto?}

Um realistisch abzuschätzen, wie sich das Klima in der Zukunft entwickeln wird, werden so genannte Szenarien entwickelt. Die Szenarien sind keine Prognosen, sondern ein Spektrum von Annahmen über zukünftige Entwicklungen, so z.B. die Weltbevölkerung, den Lebensstandard, den sie erreichen könnte, wie viel Energie verbraucht werden könnte und welche Energie- träger man dafür nehmen würde. Die von der UN und dem IPCC in Auftrag gegebene Studie über mögliche zukünftige Entwicklungen der Weltbevölkerung und der Weltwirtschaft, die so genannten SRES Szenarien (Special Report on Emission Scenarios), sind die zur Zeit gängigsten Szenarien zur Modellierung einer möglichen zukünftigen Klimaentwicklung. Sie zeigen mögliche Entwicklungspfade auf und sollen keine politischen Maßnahmen empfehlen („non policy prescriptive”). Aus diesem Grunde gibt es auch kein Szenarium, das die Emissionsvorgaben des Kyoto-Protokolls, welches einen politischen Charakter hat, implementiert.

Offiziell sind laut IPCC-Bericht alle Standardszenarien und die individuellen Szenarien gleich wahrscheinlich oder unwahrscheinlich. Jedoch sind auch einige Szenarien entwickelt worden, welche sehr extreme zukünftige Entwicklungen darstellen und deren Eintritt deshalb wenig wahrscheinlich ist. Hierzu gehört z.B. ein Szenarium, in dem ausschließlich fossile Brennstoffe als Energieträger genutzt werden, obwohl die dabei verbrauchte Menge die heute als gewinnbar nachgewiesene Menge an fossilen Energien vermutlich übersteigt.

In internationalen Gremien hat man sich auf ca. 35 Szenarien geeinigt. Diese Szenarien werden in 4 Szenarienfamilien unterteilt, und werden durch 6 Standardszenarien repräsentiert (vgl. fett gedruckten Text im Kasten „Szenarien“).

Da die Klimasimulationen sehr aufwendig sind, hat man sich auf 4 ,Marker”-Szenarien geeinigt, die von jeder Forschergruppe mit den komplexen Klimamodellen hochgerechnet werden. Damit hat man eine direkte Vergleichsmöglichkeit der Ergebnisse.

Das Szenarium, welches dem Kyoto-Protokoll am ehesten entspricht, ist das A2 Szenarium. Im Gegensatz zum Kyoto-Protokoll sieht dieses jedoch keine Stabilisierung der TreibhausgasEmissionen vor. Eine Analyse hat gezeigt, dass bis zum Jahre 2030 die Temperaturentwicklung bei nahezu allen Szenarien in etwa gleich ist, 


\section{Szenarien}

A1: Die A1-Szenarienfamilie beschreibt eine Welt mit sehr schnellem Wirtschaftswachstum, einer Weltbevölkerung, die in der Mitte des nächsten Jahrhunderts ihr Maximum erreicht und danach abnimmt, und die schnelle Einführung neuer und effizienterer Technologien. Regionale Unterschiede im Lebensstandard und Einkommen werden ausgeglichen. Diese A1-Familie kann in drei Gruppen unterteilt werden, welche die technologischen Möglichkeiten der Energiegewinnung berücksichtigen: A1FI (fossil intensive) sieht den Schwerpunkt auf fossilen Brennstoffen (Kohle, Öl, Erdgas), bei der Gruppe A1T geht man von nicht-fossilen Energieträgern aus, und bei A1B von einer Mischung von verschiedenen Energieträgern.

A2: Die A2-Szenarien-Familie beschreibt eine sehr heterogene Welt. Man geht von einer gewissen regionalen Autarkie und dem Erhalt lokaler Unterschiede aus. Die Weltbevölkerung nimmt kontinuierlich zu. Die ökonomische Entwicklung, der Lebensstandard und die Einkommen sind regional sehr unterschiedlich, der technologische Wandel geht nur langsam voran.

B1: Die B1-Szenarien-Familie geht wie A1 von einer Weltbevölkerung aus, die nur bis Mitte des nächsten Jahrhunderts anwächst. Die ökonomische Entwicklung geht aber mehr in eine Dienstleistungs- und Informationsgesellschaft mit weniger Materialverbrauch und der Einführung von sauberen und effizienten Technologien. Das Gewicht liegt auf globalen nachhaltigen Lösungen der ökonomischen, sozialen und Umweltprobleme.

B2: Die B2-Szenarien-Familie nimmt eine Welt an, in der lokale nachhaltige Lösungen zu ökonomischen, sozialen und Umwelt-Problemen gefunden werden. Die Bevölkerung steigt kontinuierlich an, aber langsamer als in A2. Es gibt eine weniger schnelle ökonomische Entwicklung und eine stärker unterschiedliche technologische Entwicklung als in den anderen Szenarien. Der Schwerpunkt liegt auf Umweltschutz und sozialer Gerechtigkeit, aber mehr auf lokaler und regionaler Ebene.

Abbildung 19

Die Marker-Szenarien des Second Report on Emission Scenarios (SRES)

\section{Ein neuer Satz von IPCC Emissions Szenarien (SRES-Szenarien)}

A 1 Eine Welt mit schnellem Wirtschaftswachstum und schneller Einfúhrung neuer und effizienterer Technologien.

A 2 Eine sehr heterogene Welt mit einem Schwerpunkt auf traditionelle Werte (family values and local traditions).

B1 Eine sich vom Materialismus abkehrende Welt und die Einführung sauberer Technologien.

B2 Eine Welt mit dem Schwerpunkt auf lokale Lösungen für ökonomische und ökologische Nachhaltigkeit.

IS 92a " Wir machen so weiter wie bisher " Szenarium okonomisch

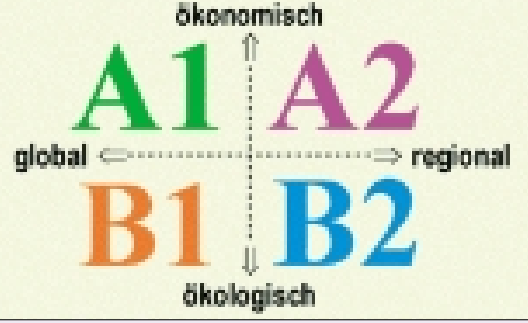

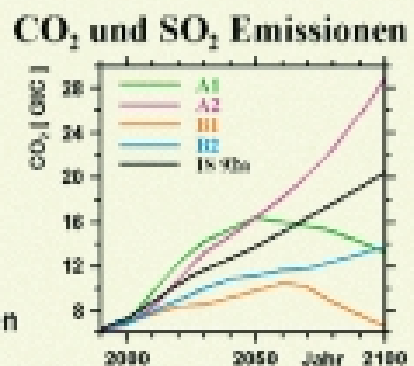

(1992).

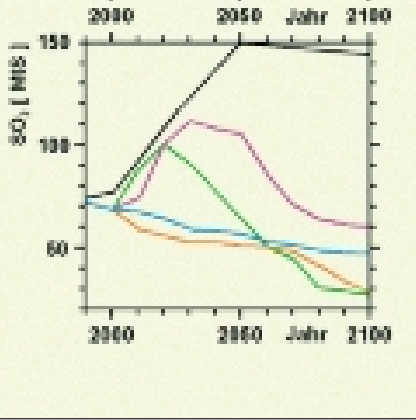


erst danach laufen sie auseinander. Die Stabilisierung durch das Kyoto-Protokoll scheint erst nach 2070 einen Effekt zu haben, der sich dann eher längerfristig auswirkt.

\subsection{Globales Klima}

Die Ergebnisse der Szenarienrechnungen des IPCC sind wie unten folgend zusammengestellt. Die Auswertung ist noch sehr lückenhaft und heterogen, d.h. ein Vergleich der Ergebnisse unterschiedlicher Modelle hat nur bei einigen Grundgrößen wie Temperatur und mittlerem Niederschlag stattgefunden. Andere Analysen, wie die der Sturmhäufigkeit oder von Extremereignissen, sind von einzelnen Forschergruppen nur an einzelnen Modellergebnissen durchgeführt worden, nicht jedoch an den Ergebnissen aller Modelle.

Temperatur: Es wird hochgerechnet, dass die global gemittelte bodennahe Lufttemperatur um 1,4 bis $5,8^{\circ} \mathrm{C}$ über den Zeitraum von 1990 bis 2100 ansteigt. Dieses Resultat umspannt alle 35 SRES Szenarien und basiert auf mehreren Klimamodellen (Abb. 16). Damit wird eine Temperatur erreicht, die höher ist als die, die man im 20. Jahrhundert beobachtet hat und sehr wahrscheinlich die höchste der letzten 10.000 Jahre ist.

Niederschlag: Der globale Wasserdampfgehalt in der Atmosphäre wird ansteigen. In der zweiten Hälfte des 21. Jahrhunderts wird der Niederschlag in den mittleren und hohen Breiten der Nordhemisphäre zunehmen. Dort wird auch die Variabilität (Niederschlagsdauer und -intensität) anwachsen (siehe Abb. 20).

Extremereignisse: Durch eine Zunahme der mittleren Temperatur und des mittleren Niederschlags nimmt schon aus einfachen statistischen Erwägungen die Wahrscheinlichkeit von entsprechenden Extremereignissen zu. Bei vielen anderen Parametern wie der Sturmintensität und -häufigkeit ist die Lage nicht so einfach. Die Ergebnisse werden in Tabelle 4 zusammenge- fasst. Die Definition der Unsicherheitsgrenzen entspricht denen des IPCC und gibt eine Expertenabschätzung wieder, die auf Auswertungen der jeweils relevanten Veröffentlichungen basiert.

Die Ereignisse sind bisher nur für eine beschränkte Anzahl von Regionen analysiert worden, und viele Extreme in anderen Größen sind noch überhaupt nicht erfasst worden. Dies bedeutet, dass derartige Analysen für die Industrieländer vorliegen, aber nicht für die dritte Welt. Für Stürme gibt es nur Studien einzelner Modelle, aber keinen zusammenhängenden Vergleich. Viele sehr kleinräumige Phänomene (z.B. Tornados, Gewitter) können allerdings wegen der groben Auflösung der Modelle nicht berechnet werden.

El Niño: Die meisten Modelle sind noch nicht in der Lage, El Niño-Ereignisse hinreichend genau zu simulieren, so dass sie keine Prognose abgeben können. Das Hamburger Modell sagt eine Zunahme voraus, das Modell des englischen Hadley-Centers dagegen eine gleichbleibende Häufigkeit. Beide Modelle sind von ihrer Qualität her vergleichbar.

Monsun: Es ist wahrscheinlich, dass die Variabilität des Indischen Sommermonsuns zunehmen wird. Veränderungen seiner Stärke und Dauer hängen sehr stark vom jeweiligen Szenarium ab.

Thermohaline Zirkulation: Die meisten Modelle zeigen eine Abschwächung der thermohalinen Zirkulation und damit des Golfstroms (THC, vgl. Kapitel 1.5) im 21. Jahrhundert, wodurch weniger Wärme in den europäischen Raum transportiert würde. Aber selbst in den Berechnungen, in denen die THC stark abnimmt, findet man immer noch eine Erwärmung durch die Zunahme der atmosphärischen Treibhausgaskonzentration. In den folgenden Jahrhunderten besteht die Möglichkeit eines Zusammenbruchs der THC, wenn die Erwärmung stark und lang anhaltend genug ist. 


\begin{tabular}{|c|c|c|}
\hline $\begin{array}{l}\text { Vertrauenswürdigkeit } \\
\text { beobachteter } \\
\text { Änderungen } \\
\text { (zweite Hälfte des 20. Jahrhunderts) }\end{array}$ & $\begin{array}{l}\text { Änderungen } \\
\text { des } \\
\text { Phänomens }\end{array}$ & $\begin{array}{l}\text { Vertrauenswürdigkeit } \\
\text { projizierter } \\
\text { Änderungen } \\
\text { (im 21. Jahrhundert) }\end{array}$ \\
\hline Wahrscheinlich & $\begin{array}{l}\text { Höhere Temperaturmaxima } \\
\text { und mehr Hitzetage über } \\
\text { nahezu allen Landmassen }\end{array}$ & Sehr wahrscheinlich \\
\hline Sehr wahrscheinlich & $\begin{array}{l}\text { Höhere Temperaturminima, } \\
\text { weniger Kälte- und Frosttage } \\
\text { über nahezu allen Landmassen }\end{array}$ & Sehr wahrscheinlich \\
\hline Sehr wahrscheinlich & $\begin{array}{l}\text { Geringerer täglicher } \\
\text { Schwankungsbereich der } \\
\text { Temperatur über den } \\
\text { meisten Landmassen }\end{array}$ & Sehr wahrscheinlich \\
\hline $\begin{array}{l}\text { Wahrscheinlich, } \\
\text { über vielen Gebieten }\end{array}$ & $\begin{array}{l}\text { Ansteigen des Hitzeindexes } \\
\text { über Landmassen }\end{array}$ & $\begin{array}{l}\text { Sehr wahrscheinlich, } \\
\text { über vielen Gebieten }\end{array}$ \\
\hline $\begin{array}{l}\text { Wahrscheinlich, über vielen } \\
\text { Landmassen mittlerer bis hoher } \\
\text { Breiten der Nordhemisphäre }\end{array}$ & $\begin{array}{l}\text { Häufigere intensive } \\
\text { Niederschlagsereignisse }\end{array}$ & $\begin{array}{l}\text { Sehr wahrscheinlich, } \\
\text { über vielen Gebieten }\end{array}$ \\
\hline $\begin{array}{l}\text { Wahrscheinlich, } \\
\text { in wenigen Gebieten }\end{array}$ & $\begin{array}{l}\text { Ansteigen der kontinentalen } \\
\text { Sommertrockenheit und der } \\
\text { damit verbundenen Dürregefahr }\end{array}$ & $\begin{array}{l}\text { Wahrscheinlich, über } \\
\text { den meisten } \\
\text { innerkontinentalen } \\
\text { Landmassen mittlerer } \\
\text { Breiten (anderswo feh- } \\
\text { len übereinstimmende } \\
\text { Hochrechnungen) }\end{array}$ \\
\hline $\begin{array}{l}\text { Wurde in den wenigen } \\
\text { vorliegenden Analysen nicht } \\
\text { beobachtet }\end{array}$ & $\begin{array}{l}\text { Zunahme der Spitzen- } \\
\text { windgeschwindigkeiten in } \\
\text { tropischen Zyklonen }\end{array}$ & $\begin{array}{l}\text { Wahrscheinlich, über } \\
\text { einigen Gebieten }\end{array}$ \\
\hline $\begin{array}{l}\text { Datenlage für Beurteilung } \\
\text { nicht ausreichend }\end{array}$ & $\begin{array}{l}\text { Zunahme der mittleren } \\
\text { und maximalen Niederschlags- } \\
\text { intensitäten in tropischen } \\
\text { Zyklonen }\end{array}$ & $\begin{array}{l}\text { Wahrscheinlich, über } \\
\text { einigen Gebieten }\end{array}$ \\
\hline
\end{tabular}

\section{Tabelle 4}

Wahrscheinlichkeiten beobachteter und prognostizierter Veränderungen extremer Wetterund Klimaereignisse. Quelle: IPCC, Third Assessment Report (2001). Nach IPCC bedeutet hier „wahrscheinlich“ eine Wahrscheinlichkeit von 66-90\%, „sehr wahrscheinlich“ eine Wahrscheinlichkeit von 90-99\% nach einer Expertenabschätzung der Literaturergebnisse. 
Schnee und Eisbedeckung: Die Schnee- und Eisbedeckung auf der Nordhalbkugel wird weiter abnehmen. Auch die Gletscher und Eiskappen werden sich weiter zurückziehen. Die südpolare Eiskappe wird wegen des größeren Niederschlags leicht an Masse gewinnen, während das Grönlandeis an Masse verlieren wird, weil die Zunahme durch die Niederschläge durch das vermehrte Abschmelzen überkompensiert wird.

Meeresspiegel: In den Szenarienrechnungen geht man davon aus, dass der Meeresspiegel in den nächsten 100 Jahren um 0,09 bis $0,88 \mathrm{~m}$ ansteigen wird. Diese Bandbreite erklärt sich dadurch, dass der Anstieg in erster Linie auf Wärmeausdehnung und das Abschmelzen der Gletscher zurückzuführen ist, die beide von der Unsicherheit in der Temperaturprojektion abhängen (siehe oben). Zur Veranschaulichung: Sollte Grönland vollständig abschmelzen, was dann möglich wäre, wenn die Temperaturänderung auf $7^{\circ} \mathrm{C}$ anstiege und für 1000 Jahre erhöht bliebe, so höbe sich der Meeresspiegel um sieben Meter, das Westantarktische Eisschild würde dann noch einmal drei Meter beitragen, so dass man auf etwa zehn Meter käme.

\subsection{Regionales Klima}

„Klima“ wird regional bzw. lokal erlebt. Deshalb geschieht auch die Anpassung an realisierte Klimaänderungen lokal und regional.

Die Beschreibung des regionalen Klimas gelingt mit globalen Modellen nur eingeschränkt, weil die horizontale Auflösung dieser Modelle nur Strukturen ab einer gewissen Größe darstellt. Nach dem dritten IPCC Sachstandsbericht kann man bisher nur konsistente Aussagen über Regionen einer Größe von 1000 × $1000 \mathrm{~km}^{2}$ und mehr machen. Allerdings gibt es auf dem japanischen „Earth Simulator”-Computer erste Hochrechnungen, die auf globalem Maßstab Auflösungen von $10 \times 10 \mathrm{~km}^{2}$ erreichen.

Um das regionale Klima und seine Änderungen auf feineren Skalen zu beschreiben, bedient man sich dynamischer oder empirischer Methoden. In beiden Fällen kommt das so genannte „downscaling“-Konzept zum Einsatz, wonach das regionale Klima Ausdruck eines Wechselspiels großskaligen Klimas (kontinentale bis subkontinentale Skala) und regionaler physiographischer Details ist.

Dynamische Methoden verwenden prozessbasierte numerische Modelle; sie liefern dynamisch konsistente vollständige regionale Darstellungen von atmosphärischen Zustandsgrößen. Empirische Methoden verwenden statistische Modelle, die zumeist lokale, nicht notwendigerweise physikalische Größen, wie z.B. phänomenologische oder biogeochemische Daten, in Beziehung zu großräumigen analysierten Zuständen stellen.

Obwohl sich die Anwendungen verändern können und werden, wird es für beide Methoden auf Dauer Bedarf geben. Veränderungen ergeben sich aus der stetig verbesserten Auflösung der globalen Klimamodelle; neue Möglichkeiten werden sich für empirische Methoden aufgrund neuer regionaler und lokaler Datensätze ergeben.

Die Modellergebnisse des englischen HADCMund des deutschen ECHAM-Modells für die Regionalisierung von „ $\mathrm{CO}_{2}$-Verdopplungsszenarien“ sind in Abbildung 20 gezeigt. Beide Modelle zeigen eine winterliche Temperaturerhöhung in Mittel- und Nordeuropa, wobei die Erwärmung im ECHAM-Modell stärker ausfällt als im HADCM-Modell. Auch sind sich beide Szenarien einig in einer winterlichen Erhöhung des Niederschlags über Skandinavien, aber im Hinblick auf Mitteleuropa gibt es widersprüchliche Einschätzungen.

Systematisch vergleichbare Szenarien werden derzeit erst im Rahmen des europäischen Projektes PRUDENCE zusammengestellt. Bisherige Ergebnisse deuten an, dass der von den globalen Modellen angebotene großskalige Antrieb noch von Modell zu Modell zu unterschiedlich ist, um robuste, konsistente Szenarien auf der 
regionalen Skala mit Gitterzellen im Bereich von 10 bis $40 \mathrm{~km}$ zu erlauben.

\subsection{Resumée}

\section{- Kann man Klima vorhersagen?}

Klimavorhersage ist nicht Wettervorhersage, da nicht einzelne Zustände des Systems, sondern nur Mittelwerte und Varianzen berechnet werden können. Eine exakte Klimavorhersage setzt voraus, dass man die Entwicklung aller Klimaantriebe (solare Aktivitätsänderung, Vulkanaktivität, menschliche Einflüsse) kennt. Klimavorhersage für einzelne Regionen oder einzelne Klimasystemkomponenten wird darüber hinaus
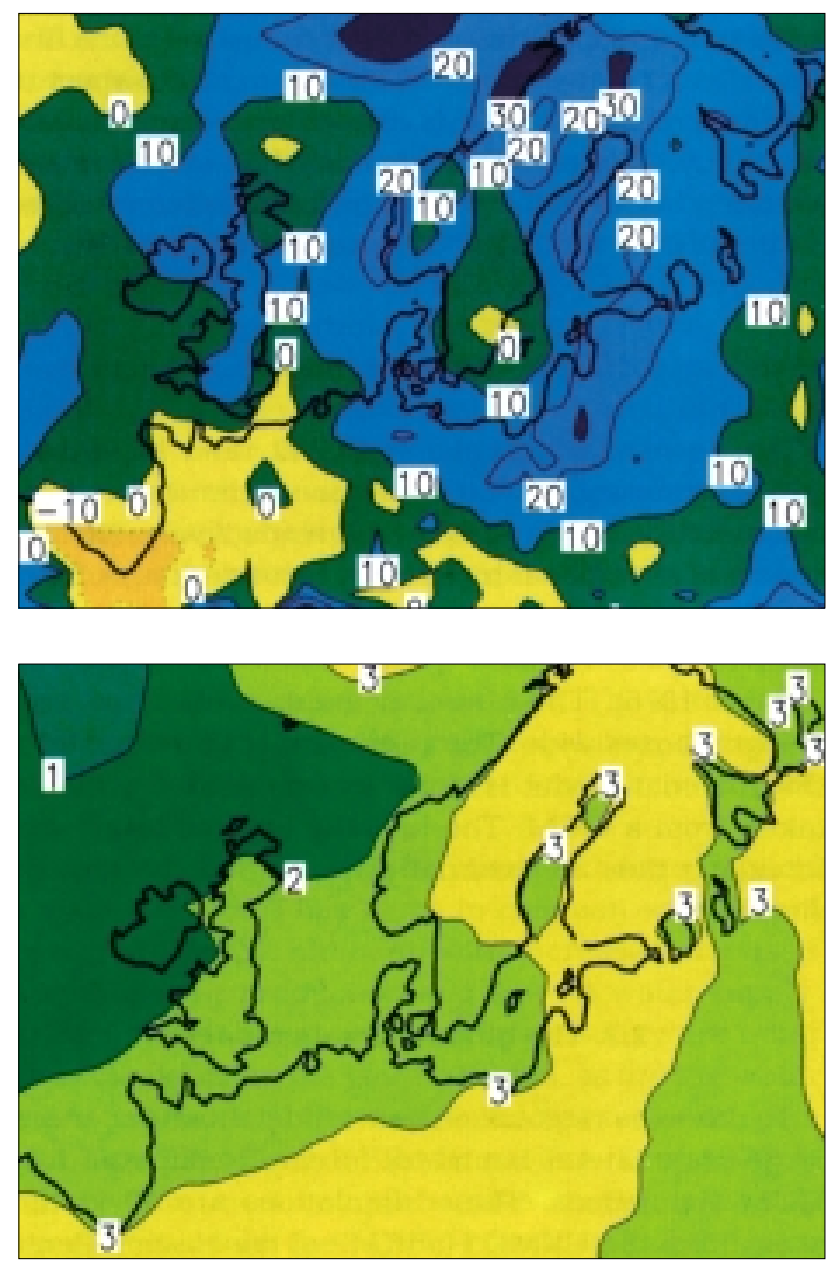

dadurch begrenzt, dass Klimamodellgleichungen einen nichtlinearen Charakter besitzen und daher eine chaotische Dynamik aufweisen. Nach dem gegenwärtigen Kenntnisstand verhält sich das global gemittelte Klima in der Nähe des gegenwärtigen Klimazustands nahezu linear und erscheint daher prinzipiell und im Rahmen der oben erwähnten Unsicherheiten vorhersagbar.

\section{- Sind die Ergebnisse von Klimamodellen „robust”?}

Klimamodelle sind nach gegenwärtigem Kenntnisstand hinsichtlich globaler Mittelwerte und ausgedehnter Strukturen (d.h. Kontinente und
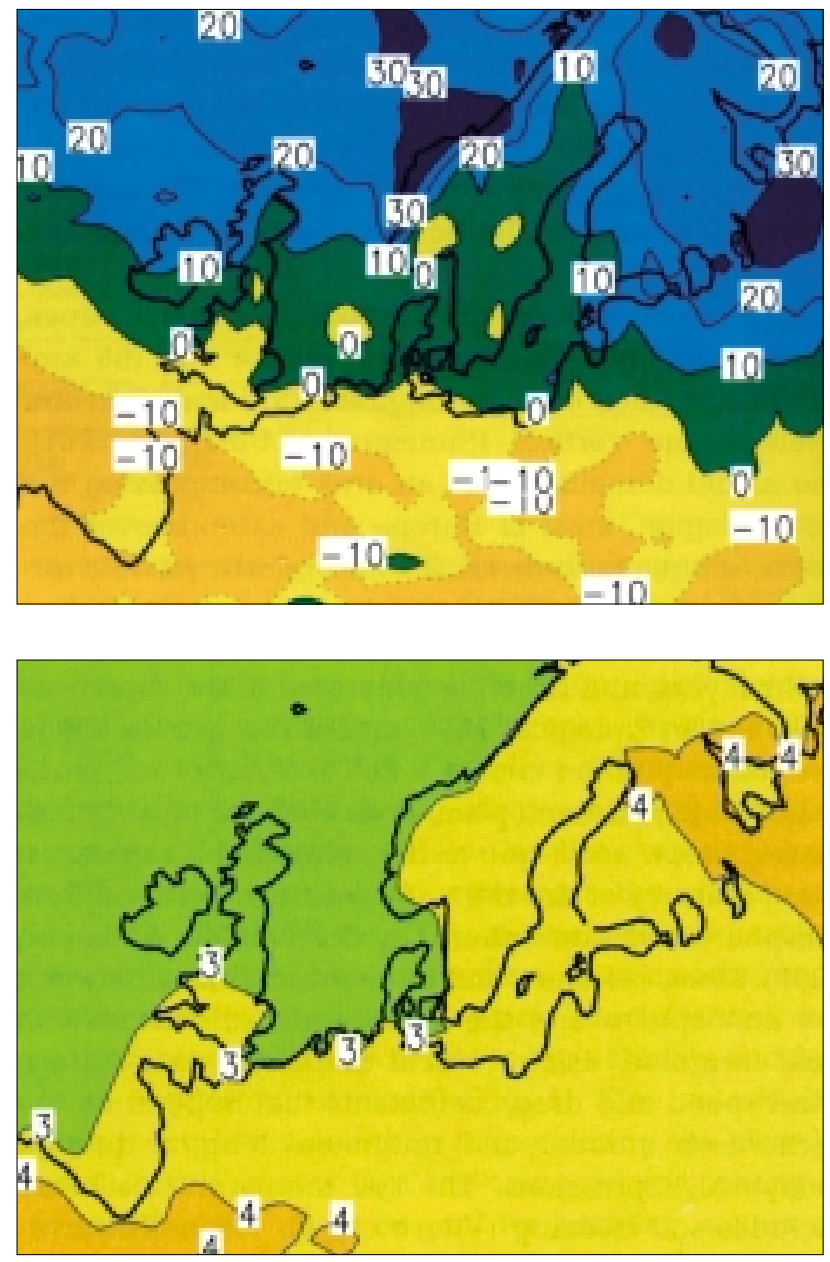

Abbildung 20

Änderung von Niederschlag (oben, in \%) und Temperatur (unten, in K) in Nordeuropa aufgrund des Szenarios einer $\mathrm{CO}_{2}$-Verdopplung. Simulationen mit dem Regionalmodell des Rossby-Centers.

Links: Antrieb des Modells mit Daten des HADCM3-Modells, rechts: Antrieb des Modells mit Daten des ECHAM3/OPYC-Modells. 
größer) von Temperatur und Niederschlag aussagekräftig („robust”). Dies gilt nicht für die regionale Ausprägung von Temperatur und Niederschlag: Im kleinräumigen Maßstab sind robuste Aussagen aufgrund des nichtlinearen Charakters der mathematischen Struktur und des zu groben großskaligen Antriebs zur Zeit nicht möglich.

\section{- Nehmen die Extremereignisse zu?}

Nach Aussagen der Klimamodellierung werden Extremereignisse von Temperatur, Niederschlag (Starkregen, Dürren) und Windgeschwindigkeiten in Zukunft häufiger auftreten. Die Ergebnisse sind jedoch umstritten, da in vielen Fällen die Statistik noch nicht ausreicht, um allgemeingültige Aussagen zu machen.

\section{- Wann kommt die nächste Eiszeit und/oder gibt es in absehbarer Zeit andere „Überraschungen”?}

Wir leben heute in einer Warmzeit, die vor etwa 11.600 Jahren begann und etwa 15.000 bis 20.000 Jahre dauern sollte, wenn man die Längen der letzten vier Warmzeiten statistisch bewertet. Neue physikalische Überlegungen, basierend auf der astronomischen Theorie der Eiszeiten, zeigen allerdings, dass die heutige Warmzeit durchaus auch 50.000 Jahre andauern könnte. Die meisten Klimamodelle zeigen eine Abschwächung der thermohalinen Zirkulation (THC) und damit des Colfstroms im 21. Jahrhundert; infolgedessen würde weniger Wärme in den europäischen Raum transportiert. Aber selbst unter diesen Bedingungen ist es möglich, dass sich diese Region in Folge einer Zunahme der atmosphärischen Treibhausgaskonzentration erwärmt. In den folgenden Jahrhunderten besteht aber auch durchaus die Möglichkeit eines Zusammenbruchs der THC. Dies bedeutet, dass man in den nächsten 100 Jahren in Europa nicht mit einer Eiszeit rechnen muss, sehr langfristig jedoch auch eine regionale Abkühlung trotz Zunahme der Treibhausgase erfolgen könnte.

\section{- Was bringt Kyoto?}

Die Auswirkungen des Kyoto-Protokolls sind nur vereinzelt hochgerechnet worden. Danach scheint die im Kyoto-Protokoll vorgesehene Reduktion der Treibhausgas-Emissionen der Industrieländer nur einen geringen Effekt auf die Temperaturentwicklung zu haben. Auf der Zeitskala bis etwa 2050 ist sogar durch das KyotoProtokoll keinerlei Veränderung gegenüber dem „business-as-usual”-Szenarium zu erkennen. 


\section{WIE GEHEN WIR MIT DEM BEVORSTEHENDEN KLIMAWANDEL UM?}

Dass die Diskussion des Klimawandels auch unsere Gesellschaft erreicht hat, ist unumstritten. In der öffentlichen Diskussion dominiert die Frage, ob es überhaupt einen Einfluss des Menschen auf das Klimageschehen gibt oder nicht. In relativ undifferenzierter Weise wird der anthropogene Klimawandel als schlecht bis katastrophal wahrgenommen oder als irreal abgetan. Die öffentliche Aufmerksamkeit und Anstrengung gilt vor allem der Vermeidung der „Klimakatastrophe”. Insofern spielen das KyotoProtokoll und sein ausbleibender Erfolg eine wichtige Rolle in der öffentlichen Diskussion. Genauso wichtig ist die Frage nach den Kosten und der volkswirtschaftlichen Verträglichkeit.

\subsection{Vermeidung und Anpassung}

Nach den Erfahrungen der vergangenen Jahre ist es sehr wahrscheinlich, dass die Emissionen von Treibhausgasen in den nächsten Jahrzehnten weiter zunehmen werden. Eine Stabilisierung in näherer Zukunft auf gegenwärtigem Niveau oder gar auf einem Niveau etwa des Jahres 1990 ist unwahrscheinlich. Die bisher diskutierten und politisch durchsetzbaren Formen der moderaten Mäßigung von Treibhausgasemissionen beeinflussen den Klimawandel nur in einem geringen Maße. Ein weiterer anthropogener Klimawandel kann nur vermieden werden, wenn der Ausstoß von Treibhausgasen kurzfristig um etwa siebzig Prozent reduziert wird.

Es ist daher wahrscheinlich, dass sich das Klima in den kommenden Jahrzehnten als Folge der weiter ansteigenden Emissionen von Treibhausgasen und anderen klimarelevanten Substanzen ändern wird. Ebenso wahrscheinlich ist, dass als Folge eines Klimawandels auch Veränderungen in den Gesellschaften stattfinden werden.

Gesellschaft und Wirtschaft werden sich an die Klimaänderungen anpassen müssen und zwar auf Zeitskalen von wenigen Jahrzehnten.
Demnach sehen sich die Gesellschaft und die Politik vor zwei wesentlichen Aufgaben:

- Die Vermeidung der Nutzung der Atmosphäre und anderer Umweltkompartimente zur Entsorgung von ungewollten Nebenprodukten des modernen Lebens im Rahmen des wirtschaftlich Vertretbaren, politisch Machbaren und gesellschaftlich Akzeptablen. Dies betrifft insbesondere das Kyoto-Protokoll zur Verminderung der Emission von Treibhausgasen in die Atmosphäre.

- Die Vorbereitung und Vorsorge von Gesellschaft und Wirtschaft auf Veränderungen im Klima. Diese Veränderungen erfordern Anpassungen nicht nur in der Nutzung und dem Management der Umwelt (einschließlich der bewirtschafteten Ökosysteme), sondern auch der Lebensverhältnisse sowie das frühzeitige Erkennen veränderter Möglichkeiten.

Bisher wurde die Debatte über Klimawandel auf die Verminderung von Emissionen fokussiert, während der Aspekt der Anpassung kaum thematisiert wurde. Die bisherige pauschale Annahme, dass Klimaänderungen „negativ” zu sehen seien, sollte durch eine vorurteilsfreie Sicht ersetzt werden, da es nicht um "gut" und „schlecht” geht, sondern darum, wie mit dem, was da kommt, rational umgegangen wird.

Beide Aspekte, Vermeidung und Anpassung, sind vor dem Hintergrund einer sich ohnehin dramatisch verändernden Gesellschaft und ihrer Umweltnutzung zu sehen. Diese gesellschaftlichen und wirtschaftlichen Veränderungen werden für die Zukunft der Menschen vermutlich von zumindest ähnlich großer Bedeutung sein wie klimatische Veränderungen. Aufgabe der Politik wird es sein, einen Entwicklungsrahmen für die gesellschaftlichen und wirtschaftlichen Veränderungen und ihre Akzeptanz zu schaffen, so dass gleichzeitig die Emissionen von Treibhausgasen und anderer umweltrelevanter Substanzen in Atmosphäre und Ozean eingeschränkt werden und Gesellschaft und Wirtschaft zukünftig weniger empfindlich gegen- 
über gegenwärtigen Klimaextremen und zukünftigen Klimaveränderungen sind. Dabei ist zu bedenken, dass in den kommenden Jahren und Jahrzehnten auch noch andere Umweltgefahren entdeckt werden könnten, die gleichermaßen die gesellschaftliche und politische Aufmerksamkeit erfordern werden.

Die Entwicklung nicht nur von emissionsmindernden und -vermeidenden Maßnahmen, sondern auch von Technologien und Methoden zum Umgang mit einer sich verändernden Umwelt ist nicht nur eine Herausforderung, sondern gleichzeitig eine Chance für ein Hochtechnologieland wie Deutschland, das durch die Bereitstellung entsprechender Technologien eine internationale Führungsrolle übernehmen kann. Darüber hinaus sollte die bisherige Perspektive des „Klimaschutzes” komplettiert werden durch die Perspektive des „Gesellschaftsschutzes”. Hier geht es insbesondere um den Schutz vor bzw. den Umgang mit Wetterextremen. Letzteres ist insbesondere sinnvoll, da signifikante Risiken und Schäden schon von gegenwärtigen Extremen ausgehen.

Aus Extremen werden nur dann Katastrophen mit großen Schäden, wenn die Gesellschaft auf diese nicht hinreichend vorbereitet ist und entsprechende Vorsorge einleitet. Die Entwicklung von Strategien und Techniken zum Umgang mit Extremen ist also auf jeden Fall angesagt, ganz unabhängig davon, ob sich die Extreme in Zukunft verschärfen oder nicht. Mit anderen Worten:

- Die Anpassung an herrschende Risiken ist konsistent mit Anpassungsnotwendigkeiten an zukünftige Risiken.

- Anpassung vermindert die Verletzbarkeit.

- Anpassung ist politisch durchsetzbar.

- Anpassungs- und Vermeidungsprozesse können zum Motor nachhaltigen Wirtschaftens werden.

\subsection{Klimaforschung als sozialer/kultureller Prozess}

Eine andere für die öffentliche Debatte und den politischen Entscheidungsprozeß relevante Tatsache ist die Einbettung der Klimadebatte und -forschung in einen kulturellen und sozialen Rahmen. „Klima“ ist sowohl ein naturwissenschaftliches Konzept als auch ein zumindest in der westlichen Kultur fest verankertes soziales und kulturelles Konstrukt. Beide Konzepte konkurrieren in der politischen Arena miteinander.

Bemerkenswerterweise herrscht in der öffentlichen Debatte ein Widerspruch. Die wissenschaftliche Einsicht, dass sich die Statistik globaler Größen, also insbesondere die „global gemittelte Temperatur”, ändert, erhält einen zentralen symbolischen Wert für die öffentliche Debatte. Da Klimawandel per se als „schlecht” angesehen wird, reicht der Nachweis, dass es inn irgendwo gibt. Andererseits ist die „global gemittelte Temperatur" eine für Ökosysteme, Gesellschaft und Wirtschaft irrelevante Größe, weil Klimaimpakt regional bzw. lokal stattfindet. Die Verbindung zwischen Klimawandel und Umweltwandel auf der lokalen Skala ist kaum untersucht. Die Politik und die Klimaforschung sollten hier eine andere Sichtweise fördern. Die Untersuchung der Veränderungen der Regional- und Lokalklimate und die Unterscheidung großklimatischer und lokaler Ursachen sind erforderlich, um diese Versachlichung zu fördern.

Klimaforschung ist „postnormal science”, d.h. große Unsicherheit und hohe Risiken sind miteinander gekoppelt. Die Unsicherheit kann nur in einem beschränkten Maße durch weitere Forschung vermindert werden; oftmals erhöht die Forschung die Unsicherheit im Umgang mit dem Problem als Ganzes. Die Wissenschaftstheorie sagt für diesen Fall die Konkurrenz von verschiedenen Wissensformen voraus, und dies lässt sich im Falle der Klimaproblematik auch gut beobachten. Wissenschaft ist nicht mehr der wichtigste gesellschaftliche Ratgeber, und wissen- 
schaftliche Argumente sind nicht die einzigen, die in den Köpfen der Wissenschaftler wirken. Klimaforschung wird damit zu einem sozialen Prozess, und in einem demokratischen System ist es angezeigt, den Beratungsprozess und seine Dynamik im Hinblick auf vorgefasste Meinungen und sozio-kulturell geprägtes Wissen zu analysieren.

Bisher wurde die Klimaforschung weitgehend disziplinär von physikalisch ausgebildeten Meteorologen und Ozeanographen betrieben. Es ist an der Zeit, die Forschung programmatisch neu zu gestalten, d.h. in einem genuinen transdisziplinären Verbund, um Öffentlichkeit und Politik über die Problematik der Klimaänderung „holistisch” beraten zu können.

\subsection{Resumée}

\section{- Welche gesellschaftlichen Implikationen} gab es in der Vergangenheit durch Klima?

Es erscheint durchaus plausibel, und es ist sogar in einigen Fällen dokumentiert, dass die Klimaentwicklung - zumindest regional begrenzt und kurzfristig - einen Einfluss auf die menschliche Gesellschaft genommen hat. Ein dokumentiertes Beispiel ist die Aufgabe der Besiedlung Grönlands im späten Mittelalter. Die langfristige Entwicklung der sozialökonomischen und technischen Struktur der menschlichen Gesellschaft in der Neuzeit ist aber durch Klimaänderungen praktisch nicht aufgehalten worden.

\section{• Können wir den Klimawandel vermeiden?}

Wenn man voraussetzt, dass die derzeit beobachteten Temperaturänderungen tatsächlich Anzeichen für einen anthropogenen Klimawandel sind, dann ist ein weiterer Klimawandel nicht zu vermeiden. Dies gilt zumindest dann, wenn man sich auf Vermeidungsmaßnahmen beschränken will, die sozialverträglich sind und nicht regional oder global zu Verzerrungen der derzeitigen sozialökonomischen Struktur führen. Für eine Begrenzung zukünftiger Klima- änderungen auf ein noch tolerierbares Niveau gibt es eine Vielzahl von Möglichkeiten.

\section{- Ist der Klimawandel "schlimm"?}

Klimawandel ist ein ernstzunehmendes Problem, insbesondere in Ländern mit hoher Bedrohung und geringem Anpassungspotential. Es ist aber dringend erforderlich, das Phänomen Klimawandel auf regionaler Skala weiter zu konkretisieren, selbst auf die Gefahr hin, dass sich daraus folgend Gewinner- und Verliererlager bilden. Der Dissens zwischen solchen Lagern könnte allerdings eine weltweit einheitliche Strategie verhindern oder zumindest verzögern.

\section{- Können wir uns dem Klimawandel anpassen?}

Grundsätzlich muss davon ausgegangen werden, dass die Bevölkerung anpassungsfähig, unter Umständen sogar verzichtbereit ist. Anpassung kann auch bedeuten, dass die Menschen willens sind, ihre Lebensgewohnheiten zu verändern. Eine solche Anpassung ist aber am ehesten über Generationen hinweg, also über einen Zeitraum von mehreren Jahrzehnten zu erreichen. Erfolgreich und wirksam ist dies aber nur dann, wenn Klimawandel und Anpassung sich in vergleichbarem Tempo vollziehen. Soweit Verzicht erforderlich ist, muss er aber sozial verträglich umgesetzt werden.

\section{- Wird Klimawandel im Nord-/Südgefälle verschärft?}

In den Entwicklungsländern sind extreme Ereignisse des Klimas schon heute mit größeren Folgen verbunden als in den Industrieländern, weil deren Gesellschaften schlechter geschützt sind und daher eine höhere Verletzlichkeit aufweisen. Auch ohne weiteren Klimawandel sind manche Entwicklungsländer durch Wetterextrema schon jetzt regelmäßig und hochgradig bedroht. Jeder weitere Klimawandel wird diese Probleme zusätzlich verschärfen. 


\section{-Welchen Einfluss haben Unsicherheiten in den Emissionsszenarien?}

Alle Klimaszenarien beinhalten hohe Unsicherheiten hinsichtlich der zukünftigen Emission von klimawirksamen Substanzen, da die technologische, demographische und sozioökonomische Entwicklung nur schwer vorhersagbar ist. Ergebnisse von Klimaszenarienrechnungen sind deshalb keine Prognosen, sondern nur Bandbreiten, in denen sich die Klimaentwicklung ver- mutlich bewegen wird, sofern man die Extremszenarien ausklammert. Da alle derzeit diskutierten Szenarien eine globale Temperaturerhöhung prognostizieren, können die Unsicherheiten in den Szenarien nicht als Argument dienen, die Diskussion über den bevorstehenden Klimawandel zu beenden. Sie müssen eher Motivation für weiterführende Forschung sein, um die Gesellschaft auf bevorstehende Klimaänderungen besser vorzubereiten. 


\section{REFERENZEN}

Albritton, D.L., Barker, T., Bashmakov, I.A., Canziani, O., Christ, R., Cubasch, U., Davidson, O., Gitay, H., Griggs, D., Houghton, J., House, J., Kundzewicz, Z., Lal, M., Leary, N., Magadza, C., McCarthy, J.J., Mitchell, J.F.B., Moreira, J.R., Munasinghe, M., Noble, I., Pachuri, R., Pittock, B., Prather, M., Richels, R.G., Robinson, R.B., Sathaye, J., Schneider, S., Scholes, R., Stocker, T., Sundararaman, N., Swart, R., Taniguchi, T., Zhou, D., 2001: Climate Change 2001: Synthesis Report. Watson, R.T. (Ed.), Cambridge University Press, $200 \mathrm{~S}$.

Bergström, S., Carlsson, B., Gardelin, M., Lindström, G., Pettersson, A., Rummukainen, M., 2001: Climate change impacts on runoff in Sweden - assessments by global climate models, dynamical downscaling and hydrological modelling. Climate Research 16, 101-112.

Bond, G., Kromer, B., Beer, J., Muscheler, R., Evans, M.N., Showers, W., Hoffmann, S., LottiBond, R., Hajdas, I., Bonani, G., 2001: Persistent Solar Influence on North Atlantic Climate During the Holocene. Science, 294, 2130-2136.

Claussen, M., 2003: Klimaänderungen:

Mögliche Ursachen in Vergangenheit und Zukunft. Umweltchem Ökotox, 15 (1), 21-30.

Climate Change 2001: The Scientific Basis. Contribution of Working Group I to the Third Assessment Report of the Intergovernmental Panel on Climate Change. Houghton, J.T., Ding, Y., Griggs, D.J., Noguer, M., van der Linden, P., Dai, X., Maskell, K., Johnson, C.I., (Eds.). Cambridge University Press, ISBN 0521014956. Crowley, T.J., North, G., 1992: Paleoclimatology. Oxford Monographs on Geology and Geophysics, 18. Oxford University Press, New York, 339 S.

Frakes, L.A., Francis, J.E., Syktus, J.I., 1992:

Climate modes of the Phanerozoic. The history of the Earth's climate over the past 600 million years. Cambridge University Press, Cambridge.
Ganopolski, A., Rahmstorf, S., 2001:

Simulation of rapid glacial climate changes in a coupled climate model. Nature, 409, 153-158.

Grootes, P.M., Stuiver, M., White, J.W.C., Johnsen, S., Jouzel, J., 1993: Comparison of oxygen isotope records from the GISP2 and GRIP Greenland ice cores. Nature, 366, 552-554.

Kondratyev, K.Y., Moskalenko, N.I., 1984: The role of carbon dioxide and other minor gaseous components and aerosols in the radiation budget. In: J.T. Houghton (Ed.) „The Global Climate“, Cambridge University Press, 225-233.

Mann, M., 2002: The Value of Multiple Proxies. Science, 297, 1481-1482.

Petit, J.R., Jouzel, J., Raynaud, D., Barkov, N.I., Barnola, J.-M., Basile, I., Bender, M., Chappellaz, J., Davis, M., Delaygue, G., Delmotte, M., Kotlyakov, V.M., Legrand, M., Lipenkov, V.Y., Lorius, C., Pépin, L., Ritz, C., Saltzman, B., Stievenard, M., 1999: Climate and atmospheric history of the past 420,000 years from the Vostok ice core, Antarctica. Nature, 399, 429-436.

Pfister, C., 1999: Wetternachhersage. 500 Jahre Klimavariationen und Naturkatastrophen 1496-1995. Haupt, Bern Stuttgart Wien.

Zorita, E., von Storch, H., González-Rouco, F., Cubasch, U., Luterbacher, J., Legutke, S., FischerBruns I., Schlese, U., 2003: Simulation of the climate of the last five centuries, GKSS Report 2003/12, 43 S. 

Diese Druckschrift wird im Rahmen der Öffentlichkeitsarbeit vom Bundesministerium für Bildung und Forschung unentgeltlich abgegeben. Sie ist nicht zum gewerblichen Vertrieb bestimmt. Sie darf weder von Parteien noch von Wahlwerberinnen/Wahlwerbern oder Wahlhelferinnen/Wahlhelfern während eines Wahlkampfes zum Zwecke der Wahlwerbung verwendet werden. Dies gilt für Bundestags-, Landtags- und Kommunalwahlen sowie für Wahlen zum Europäischen Parlament. Missbräuchlich ist insbesondere die Verteilung auf Wahlveranstaltungen und an Informationsständen der Parteien sowie das Einlegen, Aufdrucken oder Aufkleben parteipolitischer Informationen oder Werbemittel. Untersagt ist gleichfalls die Weitergabe an Dritte zum Zwecke der Wahlwerbung.

Unabhängig davon, wann, auf welchem Weg und in welcher Anzahl diese Schrift der Empfängerin/dem Empfänger zugegangen ist, darf sie auch ohne zeitlichen Bezug zu einer bevorstehenden Wahl nicht in einer Weise verwendet werden, die als Parteinahme der Bundesregierung zugunsten einzelner politischer Gruppen verstanden werden könnte. 